\title{
Computational Fatigue Analysis of Welded Structures
}

by

\section{Mark Coulombe}

\author{
A Thesis submitted to \\ the Faculty of Graduate Studies and Research \\ in partial fulfilment of \\ the requirements for the degree of \\ Master of Applied Science \\ Ottawa-Carleton Institute for \\ Mechanical and Aerospace Engineering \\ Department of Mechanical and Aerospace Engineering \\ Carleton University \\ Ottawa, Ontario, Canada \\ May 21, 2008 \\ Copyright (c) \\ 2008 - Mark Coulombe
}




$\begin{array}{ll}\begin{array}{l}\text { Library and } \\ \text { Archives Canada }\end{array} & \begin{array}{l}\text { Bibliothèque et } \\ \text { Archives Canada }\end{array} \\ \begin{array}{l}\text { Published Heritage } \\ \text { Branch }\end{array} & \begin{array}{l}\text { Direction du } \\ \text { Patrimoine de l'édition }\end{array} \\ \begin{array}{l}\text { 395 Wellington Street } \\ \text { Ottawa ON K1A 0N4 } \\ \text { Canada }\end{array} & \begin{array}{l}\text { 395, rue Wellington } \\ \text { Ottawa ON K1A 0N4 } \\ \text { Canada }\end{array}\end{array}$

Your file Votre référence ISBN: 978-0-494-44034-6

Our file Notre référence

ISBN: 978-0-494-44034-6

NOTICE:

The author has granted a nonexclusive license allowing Library and Archives Canada to reproduce, publish, archive, preserve, conserve, communicate to the public by telecommunication or on the Internet, loan, distribute and sell theses worldwide, for commercial or noncommercial purposes, in microform, paper, electronic and/or any other formats.

The author retains copyright ownership and moral rights in this thesis. Neither the thesis nor substantial extracts from it may be printed or otherwise reproduced without the author's permission.
AVIS:

L'auteur a accordé une licence non exclusive permettant à la Bibliothèque et Archives Canada de reproduire, publier, archiver, sauvegarder, conserver, transmettre au public par télécommunication ou par l'Internet, prêter, distribuer et vendre des thèses partout dans le monde, à des fins commerciales ou autres, sur support microforme, papier, électronique et/ou autres formats.

L'auteur conserve la propriété du droit d'auteur et des droits moraux qui protège cette thèse. $\mathrm{Ni}$ la thèse ni des extraits substantiels de celle-ci ne doivent être imprimés ou autrement reproduits sans son autorisation.
In compliance with the Canadian Privacy Act some supporting forms may have been removed from this thesis.

While these forms may be included in the document page count, their removal does not represent any loss of content from the thesis.
Conformément à la loi canadienne sur la protection de la vie privée, quelques formulaires secondaires ont été enlevés de cette thèse.

Bien que ces formulaires aient inclus dans la pagination, il n'y aura aucun contenu manquant.

\section{Canada}




\section{Abstract}

Welding is one of the most common methods of joining engineering structures. Under cyclic loading, welds, particularly weld toes, are prone to fatigue cracking. This is because of their geometry, which act a stress concentrator, along with the often high residual stresses due to the welding process. Computational weld and fatigue analyses present great advantages for design engineers. An accurate analysis can help the designer predict and account for the fatigue lives of welded structures before beginning experimental testing, which can be costly and time consuming. Crack initiation is predicted using the strain-life method with the Ramberg-Osgood stressstrain constitutive model and crack growth is predicted using linear elastic fracture mechanics. Finite element models of a hole and a double-fillet weld joint are used to predict the stress concentrations at blunt notches and sharp notches and agree very well with analytic results. A single-edge crack specimen is cyclically loaded to predict stress intensity factors and fatigue crack propagation. These results also agree very well with analytic solutions. Finally, a welded gusset joint is analyzed, incorporating both welding residual stresses and in-service loading. 
I would like to dedicate this thesis to my parents, Pierre and Patricia Coulombe, for their support and encouragement. 


\section{Acknowledgments}

I would like to thank Dr. John Goldak for the opportunity to continue my education and advance my knowledge in the field of fatigue and fracture mechanics. I am very grateful for the guidance and financial support I have received. I would like to thank Daniel Downey, Stanislav Tchernov and Jianguo Zhou for their assistance and support. I would like to thank Dr. Gregory Glinka for the opportunity to attend his fatigue and fracture mechanics workshop in the summer of 2007. Finally, I would like to thank Dr. Mohamad El-Zein from John Deere for the opportunity to see the industrial applications of weld fatigue analysis. 


\section{Preface}

The purpose of this thesis is to lay the foundation for computational fatigue analysis of welded joints using VrSuite. VrSuite a finite element analysis package, developed by Goldak Technologies Inc., used to model welding, heat treatment and structural tests. Previous works using VrSuite have explored in great detail thermal, microstructural and residual stress analyses during welding and heat treating. This thesis aims to build on the computational analysis of welded joints by examining the prediction of local peak stresses at weld toes due to in-service cyclic loading and subsequent crack initiation and crack propagation. 


\section{Table of Contents}

Abstract $\quad$ iii

Acknowledgments $\quad$ v

Preface vi vi vis

Table of Contents vii

List of Tables $\quad$ x

List of Figures $\quad$ xi

Nomenclature $\quad$ xiv

1 Introduction $\quad 1$

1.1 Factors Affecting Fatigue Life of Welded Joints . . . . . . . . . 1

1.2 Computational Welding Analysis . . . . . . . . . . . . 2

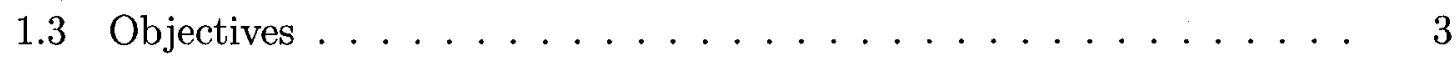

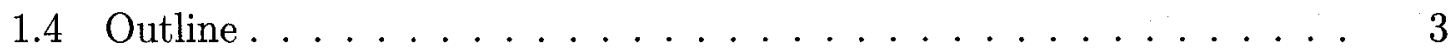

2 Fatigue Theory 5

2.1 Weld Toe Stress Concentration . . . . . . . . . . . 5

2.1 Hot Spot Stress Method . . . . . . . . . . . 5

2.1.2 Direct Method .................. 8 
2.2 Crack Initiation $\ldots \ldots \ldots \ldots \ldots \ldots \ldots$

2.2 .1 Stress-Strain Relationship . . . . . . . . . . . . 9

2.2 .2 Neuber's Rule . . . . . . . . . . . . . . . . . . . . . 11

2.2 .3 Equivalent Strain Energy Density . . . . . . . . . . . 13

2.2.4 Strain-Life $(\varepsilon-N)$ Equation . . . . . . . . . . . 15

2.3 Crack Propagation . . . . . . . . . . . . . . . 16

2.3.1 Paris-Erdogan Equation . . . . . . . . . . . . . . 17

2.4 Stress Intensity Factor $\ldots \ldots \ldots \ldots$

2.4 .1 Analytic Method . . . . . . . . . . . . . 20

2.4.2 Material Forces Method . . . . . . . . . . . . . 21

3 Test Problems $\quad 25$

3.1 Stress Concentration at the Hole in a Finite Plate . . . . . . . 25

3.1.1 Problem Geometry and Setup . . . . . . . . . . . 25

3.1 .2 Results . . . . . . . . . . . . . . . . . 27

3.2 Stress Concentration at the Toe of a Double-Fillet T-Joint Weld . . 29

3.2 .1 Problem Geometry and Setup . . . . . . . . . . . . 30

3.2 .2 Results . . . . . . . . . . . . . . . . . . 32

3.3 Single-Edge Crack Test for Stress Intensity Factor . . . . . . . . 33

3.3.1 Problem Geometry and Setup . . . . . . . . . . . . . 33

3.3 .2 Results . . . . . . . . . . . . . . . 36

4 Fatigue Life Prediction of a Welded Gusset Joint 40

4.1 Problem Geometry and Setup . . . . . . . . . . . . . . . 40

4.2 Results . . . . . . . . . . . . . . . . . . . 43

$\begin{array}{lll}5 & \text { Conclusions } & 57\end{array}$

5.1 Stress Concentrations . . . . . . . . . . . . . . . . 57 
5.2 Local Non-Linear Stress and Strain . . . . . . . . . . . . . 58

5.3 Crack Initiation . . . . . . . . . . . . . . . . . . . . 59

5.4 Stress Intensity Factors . . . . . . . . . . . . . . . . . . 59

5.5 Crack Propagation $\ldots \ldots \ldots \ldots \ldots \ldots \ldots$

List of References $\quad 62$

Appendix A Crack Initiation Calculation $\quad 67$

A.1 Part 1: Cyclic Ramberg-Osgood Curve . . . . . . . . . . . 67

A.2 Part 2: Ramberg-Osgood Hysteresis Curve . . . . . . . . . . . . 69

A.2.1 Building the Hysteresis: From $\sigma_{r o_{1}}, \varepsilon_{r o_{1}} \rightarrow \sigma_{r o_{2}}, \varepsilon_{r o_{2}} \ldots \ldots 70$

A.2.2 Building the Hysteresis: From $\sigma_{r o_{2}}, \varepsilon_{r o_{2}} \rightarrow \sigma_{r o_{1}}, \varepsilon_{r o_{1}} \ldots \ldots 71$

A.3 Strain-Life Equation for Crack Initiation _ . . . . . . . . . . 72

A.4 MATLAB code . . . . . . . . . . . . . . . . 73 


\section{List of Tables}

3.1 Double-fillet stress concentration factors for weld toe radii of $0.5 \mathrm{~mm}$, $1 \mathrm{~mm}$ and $1.5 \mathrm{~mm} . \ldots \ldots . \ldots . \ldots . \ldots . \ldots 32$

3.2 Double-fillet weld toe stresses. . . . . . . . . . . . . . . . 33

3.3 SEC test stress intensity factors at different crack lengths. . . . . . . 39

4.1 Fatigue life properties . . . . . . . . . . . . . . . 42

4.2 Gusset joint peak stresses. . . . . . . . . . . . . . . . . 45

4.3 Gusset joint non-linear stresses and strains. . . . . . . . . . . . . 46 


\section{List of Figures}

2.1 (a) Weld macrograph and (b) FEM mesh around the weld toe. . . 6

2.2 Stress distribution and stress components at the weld toe [1] . . . . . 6

2.3 Construction of the cyclic stress strain curve [2] . . . . . . . . . . 10

2.4 Idealized three crack growth stages $[3] . \ldots \ldots \ldots$

3.1 Hole test problem geometry. . . . . . . . . . . . . 26

3.2 Hole test submodel stress distribution. . . . . . . . . . . . . . . 27

3.3 Hole test stress distribution plot from edge of hole to edge of plate. The computed peak and nominal stresses are 11.11 MPa and 4.11 MPa respectively. The computed minimum stress at the edge of the plate is 3.76 MPa. The analytic peak and nominal stresses are 11.35 $\mathrm{MPa}$ and $4.00 \mathrm{MPa}$ respectively. . . . . . . . . . . . . . . . . 28

3.4 (a) Material force vectors from hole test problem in VrDesigner and (b) material force vectors in a hole from [4]. . . . . . . . . . . 29

3.5 Double-fillet weld geometry. . . . . . . . . . . . . 30

3.6 Double-fillet submodel stress distribution at the $1.5 \mathrm{~mm}$ weld toe. . . 34

3.7 Double-fillet weld stress distribution through the thickness from the $1.5 \mathrm{~mm}$ weld toe. . . . . . . . . . . . . . . 35

3.8 SEC specimen geometry. . . . . . . . . . . . . . 36

3.9 SEC test $\log \frac{\mathrm{d} a}{\mathrm{~d} N}$ vs. $\log \Delta K$ for remote stresses of $138 \mathrm{MPa}, 69 \mathrm{MPa}$ and $34.5 \mathrm{MPa} . \ldots \ldots \ldots 37$ 
3.10 SEC test $a$ vs. $N$ for remote stresses $138 \mathrm{MPa}, 69 \mathrm{MPa}$ and $34.5 \mathrm{MPa} . \quad 38$

3.11 SEC test submodel crack displacement at $a / b=0.5 \ldots 38$

3.12 SEC test stress distribution and graded mesh perpendicular to the

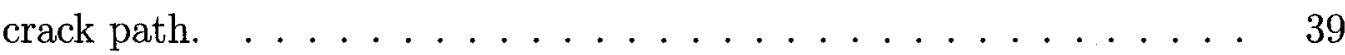

4.1 Gusset joint geometry and constraints. . . . . . . . . . . . . . 41

4.2 (a) Gusset joint three-dimensional total weld model and (b) threedimensional slice submodel. . . . . . . . . . . . . . . 44

4.3 Gusset joint 2D submodel mesh and in-service stress. . . . . . . . . 46

4.4 Gusset joint 2D submodel mesh and in-service stress (close). . . . . . 46

4.5 Gusset joint stress-strain curve and hysteresis loop with welding residual stress and in-service stress. . . . . . . . . . . . . . . . . 47

4.6 Gusset joint crack path and displacement. . . . . . . . . . . . . . 48

4.7 Gusset joint through-thickness (zz-) stress distributions ahead of the weld toe for in-service loading only. . . . . . . . . . . . . . 50

4.8 Gusset joint through-thickness stress distributions ahead of the weld toe for in-service loading and initial stress. . . . . . . . . . . 51

4.9 Gusset joint 3D slice submodel first principal stress. . . . . . . . . . . 52

4.10 Gusset joint 3D slice submodel second principal stress. . . . . . . . 53

4.11 Gusset joint 3D slice submodel third principal stress. . . . . . . . . 53

4.12 Gusset joint through thickness (zz-) stress distributions at different crack lengths. ......................... 54

4.13 Gusset joint initial through-thickness stress. . . . . . . . . . . 54

4.14 Gusset joint through-thickness stress at $a=2.5 \mathrm{~mm} . \ldots . \ldots 5$

4.15 Gusset joint through-thickness stress at $a=4.0 \mathrm{~mm} . \ldots . . . . .55$

4.16 Gusset joint crack length, $a$, vs. number of cycles, N. . . . . . . 56

5.1 The Paris exponent, $\mathrm{m}$, vs. the dimensionless parameter, $\mathrm{Z}$, for 4340

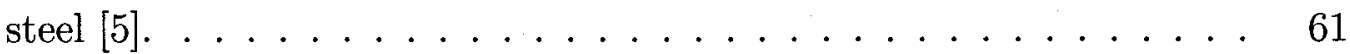


A.1 Cyclic Ramberg-Osgood stress-strain curve . . . . . . . . . . 68

A.2 Ramberg-Osgood constant amplitude hysteresis curve . . . . . . . 71

A.3 Number of cycles to failure according to the strain-life crack initiation

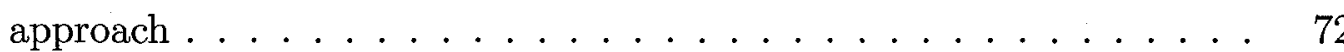




\section{Nomenclature}

$\boldsymbol{b}:$ Body force vector

$b:$ Fatigue strength exponent

$c$ : Fatigue ductility exponent

$\frac{\mathrm{d} a}{\mathrm{~d} N}$ : Increment of crack length ' $a$ ' per load cycle

$k:$ Monotonic Ramberg-Osgood strength coefficient

$k^{\prime}$ : Cyclic Ramberg-Osgood strength coefficient

$m$ : Paris-Erdogan exponent

$n$ : Monotonic Ramberg-Osgood hardening exponent

$n^{\prime}$ : Cyclic Ramberg-Osgood hardening exponent

$\boldsymbol{t}:$ Vector tangent to crack tip

$\boldsymbol{u}$ : Displacement vector

$A$ : Area

$\mathcal{A}:$ Crack area

$C$ : Paris-Erdogan coefficient

$E$ : Modulus of elasticity 
$\boldsymbol{F}_{\text {mat }}$ : Material force vector

$G$ : Energy release rate

$I$ : Identity matrix

$J:$ J-integral

$K_{t}$ : Linear elastic stress concentration factor

$K_{t, h s}^{m}$ : Hot spot membrane stress concentration factor

$K_{t, h s}^{b}$ : Hot spot bending stress concentration factor

$K_{\sigma}:$ Local stress concentration factor

$K_{\varepsilon}:$ Local strain concentration factor

$\Delta K:$ Stress intensity range

$\Delta K_{t h}:$ Threshold stress intensity factor range

$K_{c}$ : Critical stress intensity factor

$N_{i}:$ Number of cycles to crack initiation

$N_{p}$ : Number of crack propagation cycles

$R$ : Loading ratio, stress intensity ratio

$V$ : Spatial volume

$V_{0}$ : Material volume

$W:$ Strain energy density

$\delta:$ Virtual operator 
$\varepsilon_{a}:$ Local non-linear strain

$\varepsilon_{e}:$ Elastic strain

$\varepsilon_{h s}:$ Linear hot spot strain

$\varepsilon_{p}:$ Plastic strain

$\varepsilon_{\text {peak }}:$ Local peak linear elastic strain

$\varepsilon_{t}:$ Total strain

$\frac{\Delta \varepsilon}{2}:$ Cyclic strain amplitude

$\varepsilon_{f}^{\prime}:$ Fatigue ductility coefficient

$\boldsymbol{\sigma}:$ Cauchy stress tensor

$\sigma_{a}:$ Local non-linear stress

$\sigma_{h s}^{m}:$ Linear hot spot membrane stress

$\sigma_{h s}^{b}$ : Linear hot spot bending stress

$\sigma_{\text {nom }}:$ Nominal linear elastic stress

$\sigma_{\text {peak }}:$ Local peak linear elastic stress

$\frac{\Delta \sigma}{2}:$ Cyclic stress amplitude

$\sigma_{f}^{\prime}:$ Fatigue strength coefficient

$v$ : Poisson ratio

$\boldsymbol{\Sigma}$ : Eshelby stress or energy momentum tensor 


\section{Chapter 1}

\section{Introduction}

\subsection{Factors Affecting Fatigue Life of Welded Joints}

Welding is one of the most important and commonly-used industrial joining methods. Because of the nature of the welding process itself, welds are frequently the site of fatigue crack initiation and propagation under cyclic loading. The welding process can leave crack-like imperfections [6] and can generate high tensile residual stresses at the weld toe. The residual stresses are caused by localized thermally-induced expansion and microstructural changes. These stresses can approach the material's yield limit [7] or cause cracking [8] even before in-service loading. In addition to the unfavourable high tensile residual stresses, the geometries of the weld toes themselves can act as sharp notches and are therefore stress concentrators. The use of highstrength materials, thick sections and highly-constrained parts further increases these effects. The advance of computational welding and fatigue models obviously has many benefits. These tools can help the designer predict the stresses caused by welding and in-service loading and estimate the fatigue lives of welded joints. 


\subsection{Computational Welding Analysis}

Welding simulations are complex and weld models must properly account for many variables. Most fundamentally important are the thermal, microstructure and stress models used in the simulation. The analysis should account for transient effects because of the localized, non-uniform and dynamic nature of the heat input. The heat distribution and heating and cooling rates will affect the microstructure of the weld and the heat affected zone. The thermal and microstructure history will, in turn, affect the stress distribution in the model. For a weld analysis, the user must also account for many variables. These include accurately defining the material properties, welding parameters, welding sequence and boundary conditions that include tack welds and constraints. The user must also create a mesh and define time stepping in a way that can accurately capture the thermal, microstructure and stress history of the welding process. For a subsequent fatigue analysis, the in-service loading history, in-service constraints, weld toe geometry and material fatigue coefficients must also be accounted for.

VrSuite [9], a simulation package developed by Goldak Technologies Inc., is used for finite element analyses. VrWeld, which is used for welding simulations, uses Goldak's double-ellipsoid model and performs the transient 3-D thermal, microstructure and residual stress analyses of the welding process. VrDesigner imports the residual stress field from the weld analysis and computes the additional stresses and fatigue crack propagation due to in-service loading.

The scope of this thesis is restricted to fatigue predictions - that is crack initiation and propagation - as much work has already been performed on the thermal and microstructural models used in the weld analysis. For more information, the reader is 
directed to [10] for thermal and microstructural considerations, [11] for the analysis of microstructure evolution from a 3D thermal analysis, and [12] for complete 3D thermal, microstructural and residual stress analyses. In the context of this thesis residual stresses are taken as an input variable. For more information regarding the computation of welding residual stresses the reader is directed to [13], [14], [15] and $[16]$.

\subsection{Objectives}

The objective of this thesis is to assess the capability to computationally predict the fatigue lives of welded structures, incorporating stresses due to both the welding process and constant-amplitude in-service loading. Simple test problems are simulated to establish the mesh sensitivity to stress concentrations and stress intensity factors by comparing computed FEM results to known analytic solutions. The prediction of local non-linear peak stresses and fatigue initiation lives of welded structures from the VrSuite are compared to calculations using Glinka's FALIN crack initiation software [17].

\subsection{Outline}

This thesis is divided into five chapters. Chapter 1 gives an overview of the factors affecting fatigue of welded joints, describes some considerations when performing computational weld analyses and outlines the objectives of this thesis. Chapter 2 presents the relevant fatigue theory used for fatigue life predictions in subsequent chapters. These include strain-life methods to predict crack initiation and linear-elastic fracture mechanics to predict crack propagation. Chapter 3 consists of test problems, which compare results from finite element analyses to known analytic solutions from the 
literature to verify the FEA results. The test problems include the analyses of the stress concentrations at a blunt notch, such as a hole and at a sharp notch, such as the weld toe of a double-fillet T-joint. Also included is the analysis of the stress intensity factor for a single-edge crack (SEC) specimen. Chapter 4 consists of a total life predictions of a welded gusset joint, incorporating both welding residual stresses and in-service loading. Several total model and submodel analyses, predicting welding stresses and in-service stresses are examined and discussed. Finally, Chapter 5 includes conclusions and recommendations for future work. Appendix A details the transformation of local linear-elastic stresses and strains to non-linear elastic stresses and strains, the generation of a hysteresis loop under constant amplitude loading with a load ratio, $\mathrm{R}$, of zero and the calculation of crack initiation life. 


\section{Chapter 2}

\section{Fatigue Theory}

\subsection{Weld Toe Stress Concentration}

In cyclically-loaded welded structures fatigue cracking will often initiate at weld toes. Because of their geometry, the weld toes act as stress concentrators. Therefore, in addition to the tensile residual stresses induced by welding, weld toes exhibit high local stresses during cyclic loading. The stress concentration at the weld toe depends on the weld geometry, including the angle and the toe radius. To accurately predict local stresses near a weld toe one must account for these features. Figure 2.1(a) shows a macrograph of the cross section of an actual weld while Figure 2.1(b) shows a computer model of the toe geometry and the FEM mesh around the toe.

\subsubsection{Hot Spot Stress Method}

A convenient method for accounting for the weld geometry is the hot spot stress method, where the total non-linear stress at the weld toe is broken down into linear membrane (tensile/compressive), linear bending and non-linear components [1] as shown in Figure 2.2. The hot spot stress is defined as the structural stress that "includes all stress raising effects of a structural detail excluding all stress concentrations due to the local weld profile itself" [18]. The non-linear component is discarded 


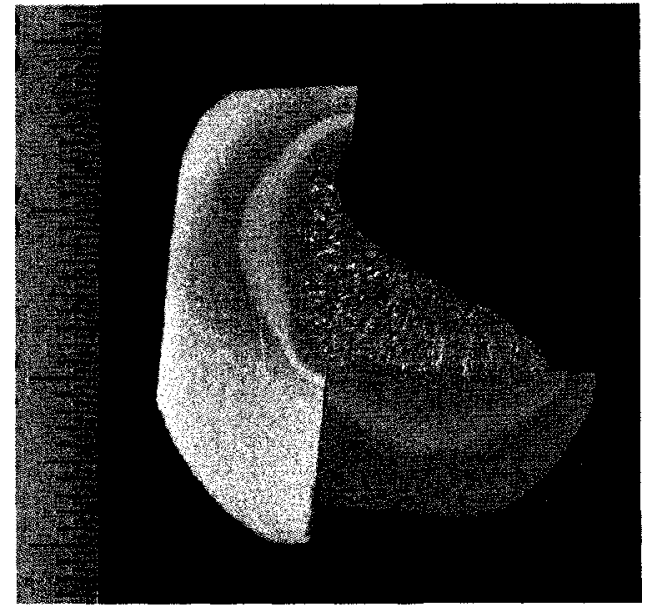

(a)

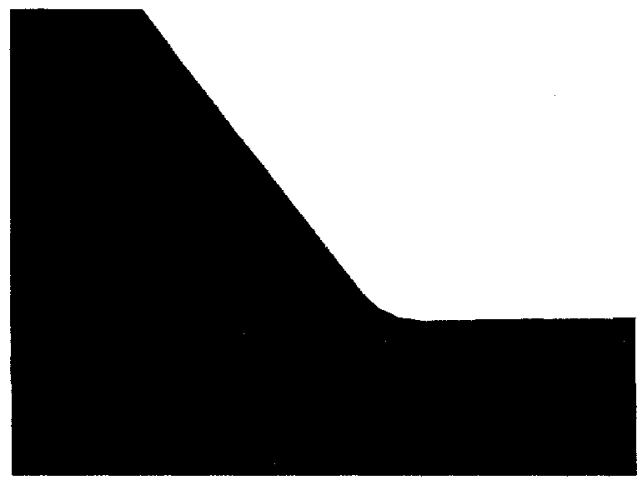

(b)

Figure 2.1: (a) Weld macrograph and (b) FEM mesh around the weld toe.

weld Toe

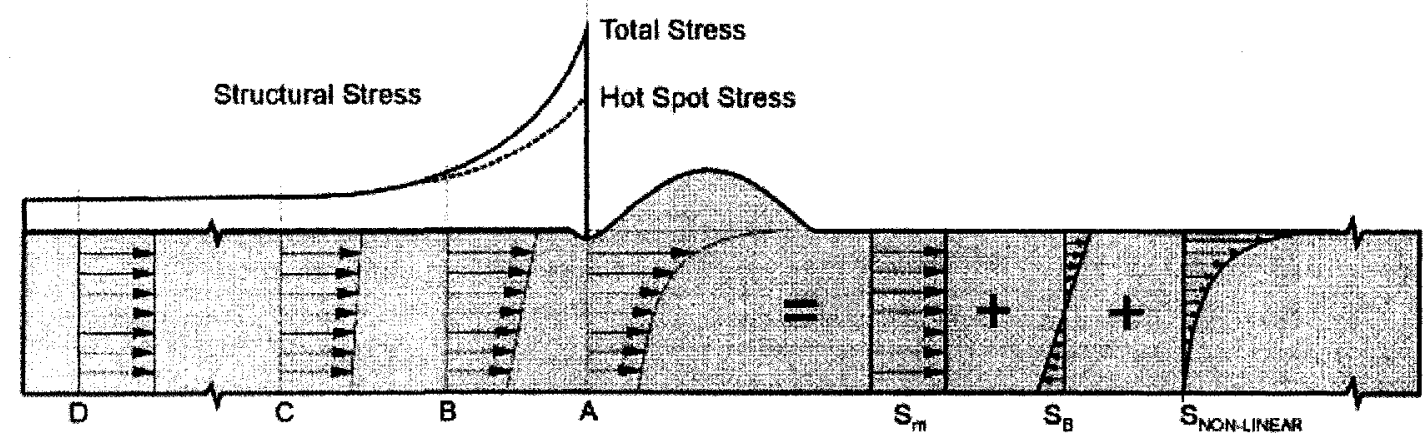

Figure 2.2: Stress distribution and stress components at the weld toe [1].

and a peak weld toe stress is obtained by combining the membrane and bending components with stress concentration factors that are functions of the weld geometry. This method is especially useful when the non-linear component of the stress is difficult to accurately predict, such as when solving a problem analytically or when using a relatively coarse mesh for a finite element analysis. The hot spot stress is oftened determined by extrapolation from reference points ahead of the weld toe. The extrapolation method is preferred when plate or shell elements are used. However, "a multi-layer arrangement of solid elements allows to linearise the stresses over the 
plate thickness directly at the weld toe". Since the analyses performed in this thesis use multiple solid elements through the plate thickness, this is the method used here. The hot spot membrane stress, $\sigma_{h s}^{m}$, and bending stress, $\sigma_{h s}^{b}$, are computed according to $[19]$

$$
\begin{aligned}
\sigma_{h s}^{m} & =\frac{\int_{-t / 2}^{t / 2} \sigma(y) d y}{t} \\
\sigma_{h s}^{b} & =\frac{6 \int_{-t / 2}^{t / 2} \sigma(y) \cdot y \cdot d y}{t^{2}}
\end{aligned}
$$

where $y$ is the through-thickness direction and $t$ is the thickness. The discretized finite element form of equations (2.1) and (2.2) are

$$
\begin{aligned}
\sigma_{h s}^{m} & =\frac{\sum_{i=1}^{N} \sigma\left(y_{i}\right) \Delta y_{i}}{t} \\
\sigma_{h s}^{b} & =\frac{6 \sum_{i=1}^{N} \sigma\left(y_{i}\right) y_{i} \Delta y_{i}}{t^{2}} .
\end{aligned}
$$

The hot spot stress, $\sigma_{h s}$, is the sum of the hot spot membrane and bending stresses and the peak stress, $\sigma_{p e a k}$, is the product of the hot spot stress and hot spot stress concentration factor, $K_{t, h s}$.

$$
\begin{aligned}
\sigma_{h s} & =\sigma_{h s}^{m}+\sigma_{h s}^{b} \\
\sigma_{p e a k} & =K_{t, h s} \cdot \sigma_{h s}
\end{aligned}
$$

Since the stress concentration at the weld toe depends on the ratio of membrane and bending stresses a universal stress concentration formulation cannot be obtained for the total hot spot stress. Instead, analytic formulae are used to calculate separate membrane and bending stress concentration factors, which are purely a function of 
the weld geometry. The peak stress at a point on the weld toe line is then

$$
\sigma_{p e a k}=K_{t, h s}^{m} \sigma_{h s}^{m}+K_{t, h s}^{b} \sigma_{h s}^{b}
$$

\subsubsection{Direct Method}

If the weld geometry detail is accurately modelled and a fine enough mesh is used, the peak stress can be obtained directly from a finite element analysis. In [20] finite element analyses are performed in order to examine the effects of various weld toe radii on stress concentration factors. The smaller the weld toe radius, the greater the stress concentration. In this thesis, three-dimensional simulations are run on a relatively coarse mesh. Three-dimensional slice submodels or two-dimensional plain strain submodels are then created at areas of interest, in this case weld toes, with a much finer mesh. An example of a three-dimensional slice submodel is shown in Figure 4.2(b) while an example of a two-dimensional submodel is shown in Figures 4.3 and 4.4. In [18] it is recommended that the element size be at most $1 / 6$ the radius of curvature of the weld toe for linear elements and $1 / 4$ the radius for higher-order elements. Then the peak stress at the toe can be directly resolved without the use of stress concentration factors.

\subsection{Crack Initiation}

Even under nominally elastic loading there exists the possibility of localized plastic yielding. This can occur at microscopic material discontinuities such as inclusions and dislocations and at macroscopic discontinuities such as holes, sharp notches or weld toes. These areas can be damaged during cyclic loading, which can lead to macroscopic cracks. A popular method to predict crack initiation, which is used here, is to perform a linear elastic stress analysis of the structure under in-service 
loading to obtain the peak linear elastic strains at or near the weld toe. The peak elastic strains are then related to the local total (elastic and plastic) strains and strain amplitudes at the weld toe using either the Neuber Rule [21] or the Equivalent Strain Energy Density (ESED) method [22]. The constitutive stress-strain relationship used to approximate localized plasticity is the Ramberg-Osgood equation. Once the local non-linear strain amplitudes are determined, they can be related to the material's strain-life curve to estimate the number of loading cycles to crack initiation. Crack nucleation is another term for crack initiation frequently used in the literature.

\subsubsection{Stress-Strain Relationship}

The total strain at a point is the sum of the elastic and plastic components:

$$
\varepsilon=\varepsilon_{e}+\varepsilon_{p} .
$$

The stress-strain behaviour of ductile solids can be described by the Ramberg-Ogood relationship [23], a non-linear elastic constitutive equation [24], which is given by

$$
\varepsilon=\frac{\sigma}{E}+\left(\frac{\sigma}{k}\right)^{\frac{1}{n}}
$$

where $k$ and $n$ are the strength coefficient and hardening exponent, respectively. The Ramberg-Osgood relationship is useful for approximating the local elastic-plastic strain at the stress concentration. It does not account for actual plasticity however; if the load is removed, the stress and strain will return along the same path. The stabilized cyclic material stress-strain response can be approximated with the cyclic Ramberg-Osgood relationship, which takes the same form as equation (2.9). Under cyclic loading, engineering materials may cyclically harden or soften until equililibrium, or cyclic stability, is reached. The cyclic stress-strain curve can be obtained 
through various test procedures, all of which cycle the material at various strain amplitudes, generating several hysteresis loops. A curve is fitted to the peaks of each hysteresis loop to give the cyclic stress-strain response [25] as seen in Figure 2.3. The cyclic Ramberg-Osgood equation is

$$
\varepsilon=\frac{\sigma}{E}+\left(\frac{\sigma}{k^{\prime}}\right)^{\frac{1}{n^{\prime}}}
$$

where $k^{\prime}$ and $n^{\prime}$ are the cyclic strength coefficient and hardening exponent, respectively. If the cyclic strain amplitude is:

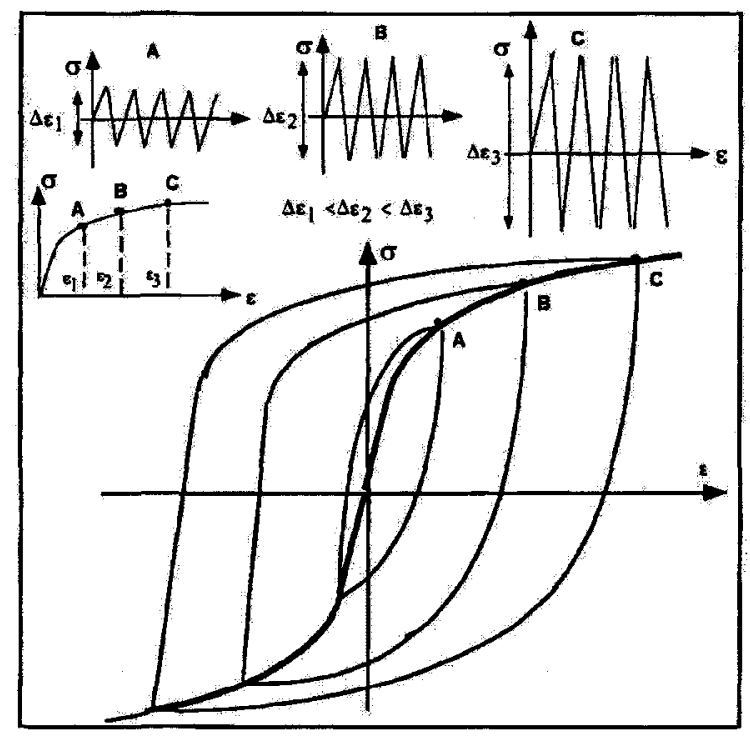

Figure 2.3: Construction of the cyclic stress strain curve [2].

$$
\frac{\Delta \varepsilon}{2}=\frac{\Delta \varepsilon_{e}}{2}+\frac{\Delta \varepsilon_{p}}{2}
$$

then, according to Massing's hypothesis the material's stabilized hysteresis behaviour can be described by doubling the cyclic stress-strain curve to give

$$
\frac{\Delta \varepsilon}{2}=\frac{\Delta \sigma}{2 E}+\left(\frac{\Delta \sigma}{2 k^{\prime}}\right)^{\frac{1}{n^{\prime}}}
$$


Since the Ramberg-Osgood equation describes non-linear elasticity, not plasticity, equation (2.12) will not alone generate the stress-strain hysteresis loop for cyclic loading. Several variations of the equation, using different stress and strain increments, must be assembled to approximate the hysteresis loop for cyclic plasticity. See Appendix A for a more detailed discussion. If experimental data needed to define the hysteresis loop is unavailable, the cyclic hardening exponent, $n^{\prime}$, and the cyclic strength coefficient, $k^{\prime}$, can be approximated from the strain-life coefficients as [26]

$$
\begin{aligned}
n^{\prime} & =\frac{b}{c} \\
k^{\prime} & =\frac{\sigma_{f}^{\prime}}{\left(\varepsilon_{f}^{\prime}\right)^{n^{\prime}}} .
\end{aligned}
$$

\subsubsection{Neuber's Rule}

Neuber's rule is used to relate the nominal linear elastic stress to the actual nonlinear stress and strain at the weld toe, approximated by equation (2.9). Neuber's rule states that the linear elastic stress concentration factor, $K_{t}$, is the geometrical mean of the stress and strain concentration factors, $K_{\sigma}$ and $K_{\varepsilon}$, for any constitutive law [21] and is given by

$$
K_{t}=\sqrt{K_{\sigma} K_{\varepsilon}}
$$

For nominal linear elastic loads the stress and strain concentration factors are functions of the local non-linear stress and strain at the weld toe, $\sigma_{a}$ and $\varepsilon_{a}$, and the nominal linear elastic stress and strain, $\sigma_{\text {nom }}$ and $\varepsilon_{\text {nom }}$.

$$
\begin{aligned}
K_{\sigma} & =\frac{\sigma_{a}}{\sigma_{\text {nom }}} \\
K_{\varepsilon} & =\frac{\varepsilon_{a}}{\varepsilon_{n o m}}
\end{aligned}
$$


Since the nominal linear-elastic strain is

$$
\varepsilon_{n o m}=\frac{\sigma_{n o m}}{E}
$$

Neuber's rule can be rewritten as

$$
\frac{\left(K_{t} \sigma_{n o m}\right)^{2}}{E}=\sigma_{a} \varepsilon_{a}
$$

In this method, the welding residual stress is accounted for by considering it to be a prestress. The initial strain energy density due to the weld residual stress is added to the left-hand side of equation (2.19) and the residual stress is added to the linear elastic stress to give

$$
\frac{\left(K_{t} \sigma_{n o m}+\sigma_{r}\right)^{2}}{E}+\sigma_{r} \varepsilon_{r}=\sigma_{a} \varepsilon_{a}
$$

When applied to the Ramberg-Osgood stress-strain model, where $\sigma_{a}$ and $\varepsilon_{a}$ represent the non-linear Ramberg-Osgood stress and strain, Neuber's rule gives

$$
\frac{\left(K_{t} \sigma_{n o m}+\sigma_{r}\right)^{2}}{E}+\sigma_{r} \varepsilon_{r}=\frac{\sigma_{a}^{2}}{E}+\sigma_{a}\left(\frac{\sigma_{a}}{k^{\prime}}\right)^{\frac{1}{n^{\prime}}}
$$

and the residual strain, $\varepsilon_{r}$, is computed from the cyclic Ramberg-Osgood equation with the residual stress as the input. The residual stress does not change the stress amplitude, but it does change the mean stress value. Neuber's rule was extended to cyclic loading in [27] to give

$$
\frac{\left(K_{t} \Delta \sigma_{n o m}\right)^{2}}{E}=\Delta \sigma_{a} \Delta \varepsilon_{a}
$$


When applied to the Ramberg-Osgood hysteresis equation, equation (2.12), the relationship becomes

$$
\frac{\left(K_{t} \Delta \sigma_{n o m}\right)^{2}}{E}=\frac{\left(\Delta \sigma_{a}\right)^{2}}{2 E}+\Delta \sigma_{a}\left(\frac{\Delta \sigma_{a}}{2 k^{\prime}}\right)^{\frac{1}{n^{\prime}}}
$$

When using the hot spot method, the nominal elastic stress and strain are equivalent to the hot spot stress and strain.

\subsubsection{Equivalent Strain Energy Density}

Since the local peak linear elastic stress and strain for a uniaxial case are

$$
\begin{aligned}
\sigma_{p e a k} & =K_{t} \sigma_{n o m} \\
\varepsilon_{p e a k} & =\frac{K_{t} \sigma_{n o m}}{E}
\end{aligned}
$$

the Neuber rule gives

$$
\sigma_{p e a k} \varepsilon_{p e a k}=\sigma_{a} \varepsilon_{a}
$$

This relationship tends to overestimate the non-linear weld toe stress and strains, however. The linear-elastic strain energy according to Hook's Law is $\frac{1}{2} \sigma_{e} \varepsilon_{e}$ but this is not true for non-linear models such as the Ramberg-Osgood formulation. Glinka proposed the equivalent strain-energy density (ESED) method to correctly model the strain energy relationship for any constitutive equation based on observations that for localized plasticity the strain energy distribution in the plastic and elastic zones were nearly equal [22].

Remark: For elastic stress models it is appropriate to integrate $\int_{0}^{\varepsilon} \sigma d \varepsilon$ where $d \varepsilon$ 
is the elastic strain increment to compute the strain energy density. However, if plastic strain occurs, then it would be more precise to write $\int \sigma d \varepsilon_{\text {total }}=\int \sigma d \varepsilon_{\text {elastic }}+$ $\int \sigma d \varepsilon_{\text {plastic }}$. The first integral on the right hand side is the strain energy density. The second integral is the plastic work density. Since the literature on this topic ignores this distinction, this thesis adheres to the notation as generally described in the literature and ignores the separation into strain energy density and plastic work density.

The strain energy density, $W$, is

$$
W=\int_{0}^{\varepsilon} \sigma d \varepsilon
$$

Integrating, the linear-elastic strain energy density is

$$
\frac{1}{2} \sigma_{\text {peak }} \varepsilon_{\text {peak }}=\frac{\sigma_{\text {peak }}^{2}}{2 E} .
$$

Integrating the strain energy density according to the Ramberg-Osgood cyclic stressstrain relationship gives

$$
\int_{0}^{\varepsilon_{a}} \sigma_{a} d \varepsilon_{a}=\frac{\sigma_{a}^{2}}{2 E}+\frac{\sigma_{a}}{n+1}\left(\frac{\sigma_{a}}{k}\right)^{\frac{1}{n^{\prime}}}
$$

Equating the linear and non-linear strain energy densities gives

$$
\frac{\sigma_{p e a k}^{2}}{2 E}=\frac{\sigma_{a}^{2}}{2 E}+\frac{\sigma_{a}}{n^{\prime}+1}\left(\frac{\sigma_{a}}{k^{\prime}}\right)^{\frac{1}{n^{\prime}}}
$$

Integrating the Ramberg-Osgood hysteresis equation gives

$$
\int_{0}^{\varepsilon_{a}} \Delta \sigma_{a} d\left(\Delta \varepsilon_{a}\right)=\frac{\Delta \sigma_{a}^{2}}{2 E}+2 \frac{\Delta \sigma_{a}}{n^{\prime}+1}\left(\frac{\Delta \sigma_{a}}{2 k^{\prime}}\right)^{\frac{1}{n^{\prime}}}
$$




\subsubsection{Strain-Life $(\varepsilon-N)$ Equation}

The strain-life approach to fatigue crack initiation is based on the works of Basquin [23], Coffin and Manson [23]. Basquin found that for constant amplitude loading, a linear relationship exists between the logarithm of the stress amplitude and the number of load reversals, $2 N_{I}$, to failure. The Basquin relationship is given by

$$
\frac{\Delta \sigma_{e}}{2}=\sigma_{f}^{\prime}\left(2 N_{I}\right)^{b}
$$

where $\sigma_{f}^{\prime}$ is the fatigue strength coefficient, $b$ is the fatigue strength (Basquin) exponent. Since the elastic strain amplitude is

$$
\frac{\Delta \varepsilon_{e}}{2}=\frac{\Delta \sigma}{2 E}
$$

the relationship between elastic strain amplitude and number of load reversals to failure is

$$
\frac{\Delta \varepsilon_{e}}{2}=\frac{\sigma_{f}^{\prime}}{E}\left(2 N_{I}\right)^{b}
$$

Similarly, Coffin and Manson found that a linear relationship exists between the logarithm of the plastic strain amplitude and the number of load reversals to failure. The Coffin-Manson equation is given by

$$
\frac{\Delta \varepsilon_{p}}{2}=\varepsilon_{f}^{\prime}\left(2 N_{I}\right)^{c}
$$

where $\varepsilon_{f}^{\prime}$ is the fatigue ductility coefficient and $c$ is the fatigue ductility exponent. The total strain amplitude, $\Delta \varepsilon$, is the linear superposition of the elastic and plastic components. This gives the strain-life equation, which relates the total strain 
amplitude to the number of reversals to failure.

$$
\frac{\Delta \varepsilon}{2}=\frac{\sigma_{f}^{\prime}}{E}\left(2 N_{I}\right)^{b}+\varepsilon_{f}^{\prime}\left(2 N_{I}\right)^{c}
$$

The strain-life curve given by equation (2.36) is constant for a given material and is determined by smooth-specimen experimental tests. The local weld toe strains obtained from the cyclic Ramberg-Osgood equation are related to the strain-life curve to obtain an estimate of the component's crack initiation life. Several variations of the strain-life equation exist to account for mean stress effects. These include the Morrow equation and the Smith-Watson-Topper equation, presented in equations (2.37) and (2.38), respectively [28].

$$
\begin{gathered}
\frac{\Delta \varepsilon}{2}=\frac{\sigma_{f}^{\prime}-\sigma_{\text {mean }}}{E}\left(2 N_{I}\right)^{b}+\varepsilon_{f}^{\prime}\left(2 N_{I}\right)^{c} \\
\sigma_{\max } \frac{\Delta \varepsilon}{2}=\frac{\left(\sigma_{f}^{\prime}\right)^{2}}{E}\left(2 N_{I}\right)^{2 b}+\sigma_{f}^{\prime} \varepsilon_{f}^{\prime}\left(2 N_{I}\right)^{b+c}
\end{gathered}
$$

where $\sigma_{\text {mean }}=\sigma_{\max }+\sigma_{\min }$ and $\sigma_{\max }=\frac{\Delta \sigma}{2}+\sigma_{\text {mean }}$. For a compressive maximum stress, however, the Smith-Watson-Topper equation becomes undefined [29].

\subsection{Crack Propagation}

When a macroscopic crack has formed in a structure, the crack can be viewed as an infinitely sharp notch. Because of the stress singularity that exists at the crack tip, stress-based criteria cannot be used to predict failure and instead the stress intensity factor is used. The stress intensity factor is a function of the structure's geometry, loading and crack length [23]. If the structure is sufficiently loaded so that the stress intensity factor reaches the material's critical value, or fracture toughness, 
the crack will grow unstably and this will lead to fracture. Cyclic loading, even at stress intensities well below the material's fracture toughness, can still lead to crack growth. Fatigue crack growth is often slow and predictable and in many cases the use of fracture mechanics allows the crack propagation life to be accurately and safely predicted. The most widely-used approach for predicting crack growth is linear elastic fracture mechanics (LEFM). LEFM assumes quasi-static crack growth and that plasticity is confined to a small area around the crack tip in an otherwise linear elastic surrounding.

\subsubsection{Paris-Erdogan Equation}

The most commonly-used method of predicting fatigue crack growth is the ParisErdogan equation, which was developed empirically. However, Barenblatt has shown that it can be derived by the method of intermediate asymptotes [5]. This equation relates the increment in crack length per loading cycle to the stress intensity factor range. The Paris-Erdogan equation is given by

$$
\frac{\mathrm{d} a}{\mathrm{~d} N}=C(\Delta K)^{m}
$$

where $a$ is the crack length, $N$ is the number of cycles and $C$ and $m$ are usually viewed as material constants. $\Delta K$ is the stress intensity factor range, defined as

$$
\Delta K=K_{\max }-K_{\min }
$$

In the crack growth algorithm used in this thesis, the crack is incremented by one element in each time step and the stress intensity factor is re-computed for each increment in crack tip position. Rearranging equation (2.39) and integrating from $a$ 


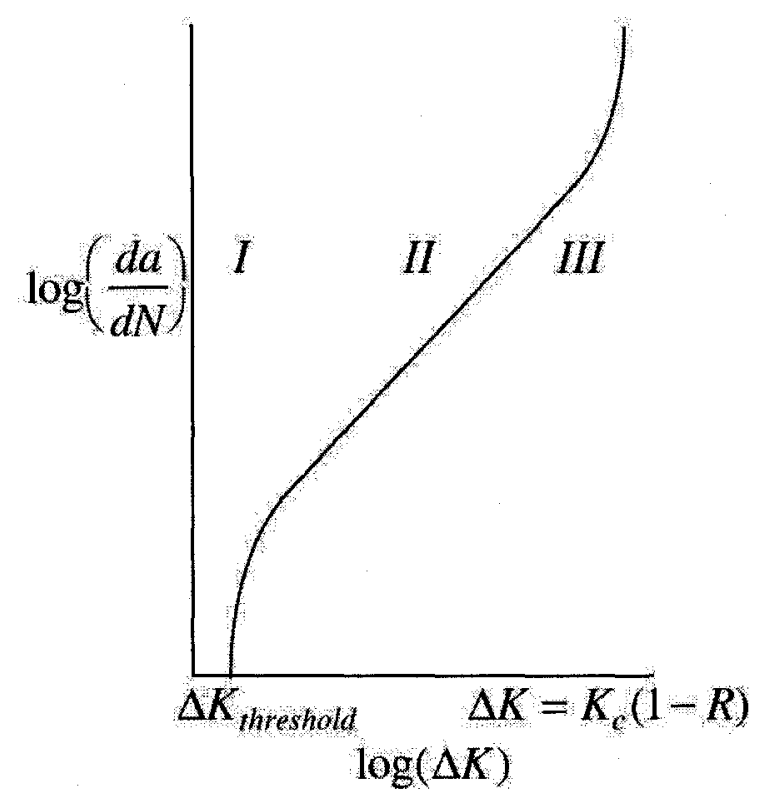

Figure 2.4: Idealized three crack growth stages [3].

to $\Delta a$, the number of cycles required for each increment of crack length, $\Delta N$, is then

$$
\Delta N=\int_{a-\Delta a}^{a} C^{-1}(\Delta K)^{-m} d a .
$$

In [30], it is proposed that integrating the Paris-Erodogan equation be evaluated using the following equation:

$$
\Delta N=\frac{\Delta a\left(\left(\Delta K_{a-\Delta a}\right)^{1-m}-\left(\Delta K_{a}\right)^{1-m}\right)}{C\left(\Delta K_{a}-\Delta K_{a-\Delta a}\right)(m-1)}
$$

Many variations of the Paris equation exist to account for mean stress and other effects. But, as mentioned in [31], the usefulness of such empirical relations is not great, owing to the large scatter of empirical data and limited applicability. Since different methods are used to determine crack initiation according to the strain-life equation and crack propagation according to the Paris-Erdogan equation, an initial macroscopic crack size, $a_{o}$, must be estimated to begin crack propagation. The applied stress intensity factor range, $\Delta K$, must be greater than the minimum stress intensity 
factor range for a crack to propagate. This minimum value is known as the threshold stress intensity factor range, $\Delta K_{t h}$. The propagation life is determined by either specifying a critical crack size, $a_{c}$, or a critical stress intensity factor, $K_{c}$, at which the component is considered to have failed. Then the number of propagation cycles until failure, $N=N_{P}$. The threshold and critical stress intensity factors represent

the lower and upper bounds on the Paris-Erdogan equation, where $\frac{\mathrm{d} a}{\mathrm{~d} N}$ tends to zero as $\Delta K$ approaches $\Delta K_{t h}$ and tends to infinity as $\Delta K$ approaches $(1-R) K_{c}$ and unstable growth occurs [32]. It has been observed that in the threshold regime the stress intensity factor range is much more dependent on the loading ratio than the Paris regime. For austenitic, ferrite-pearlite, martensitic and bainitic steels, [33] gives conservative estimates for $\Delta K_{t h}$ as

$$
\begin{array}{lll}
\Delta K_{t h}=7(1-0.85 R) & \mathrm{MPa} \sqrt{\mathrm{m}} & (R>0.1) \\
\Delta K_{t h}=6 & \mathrm{MPa} \sqrt{\mathrm{m}} &
\end{array}
$$

where

$$
R=\frac{K_{\min }}{K_{\max }}
$$

\subsection{Stress Intensity Factor}

The stress intensity factor, which characterizes the state of stress at the crack tip due to remote loading and/or residual stresses, can be determined through various methods. Analytic solutions have been formulated for many geometries, most are relatively simple, and assembled in compositions such as Rooke and Cartwright's Compendium of Stress Intensity Factors [34]. Energy methods, such as Rice's Jintegral, are often used computationally. The material forces method, from which the 
$\mathrm{J}$-integral can be determined as a special case, is a more recent advance in determining the 'driving force' for crack propagation. It does not require the assumptions inherent to the J-integral. Its use, however, is still mostly confined to the academic field.

Linear elastic fracture mechanics is based on Griffith's strain energy release rate, which states that the decrease in potential energy of a system due to crack extension is equal to the energy required to extend the crack surface [23]. The total energy change of the system, $d E$, which is conserved during a unit crack extension is [35]

$$
d E=d \Pi+d S=0
$$

where $d \Pi$ and $d S$ are the potential energy change and the surface energy change, respectively. If the potential energy change of the cracked body is defined in terms of the elastic strain energy density, $W$, and the work done per unit volume by external forces, $W_{F}$, as

$$
\Pi=W-W_{F}
$$

then the strain energy density released per unit crack extension, $d a$, is

$$
G=-\frac{d \Pi}{d \mathcal{A}}
$$

where $\mathcal{A}$ is the crack surface area.

\subsubsection{Analytic Method}

The linear elastic analytic solution for the stress intensity factor takes the form

$$
K=\sigma \sqrt{\pi a} \cdot Y
$$


where $Y$ is a geometry correction factor. For example, the mode-I (tensile opening mode) stress intensity factor for an edge crack in a finite width sheet, from p. 84 of $[34]$ is

$$
K_{I}=\sigma \sqrt{\pi a} \cdot\left[1.12-0.23\left(\frac{a}{b}\right)+10.6\left(\frac{a}{b}\right)^{2}-21.7\left(\frac{a}{b}\right)^{3}+30.4\left(\frac{a}{b}\right)^{4}\right]
$$

This example is used in Section 3.3 to varify the stress intensity factor computed using the material forces method. Under more complex loading conditions, such as a combination of membrane and bending loads, the stress intensity factor is a linear superposition of the stress intensity factors due to each condition.

$$
K=K^{m}+K^{b}
$$

Another, more advanced method of computing stress intensity factors for more complex geometries, such as a crack in a weld toe, is the weight function method. The weight function method determines the stress intensity factor by determining the stress distribution, $\sigma(x)$, normal to the potential crack plane of the un-cracked specimen [36]. The stress distribution is then applied as tractions to the crack surface and is integrated according to

$$
K=\int_{0}^{a} \sigma(x) m(x, a) d x
$$

where $m(x, a)$ is a weight function for a one-dimensional stress field that is dependent on geometry but not the stress distribution [37].

\subsubsection{Material Forces Method}

The material force method for determining the crack driving force was advanced by Maugin [38,39] and Steinmann [24,40] among others and is based on the works of 
Eshelby [41]. Eshelby derived a momentum balance in the material, as opposed to the spatial, configuration to describe the forces acting on defects and inhomogeneities. The more popular J-integral, developed by Rice, was also based on the works of Eshelby but is more restrictive. In [42] it was shown that material forces can be formulated for magnetic, thermal, dissipative and dynamic effects. Here, both the material force and the J-integral are restricted to the elastic, quasi-static assumptions of LEFM. The pointwise quasi-static spatial balance of momentum is given by

$$
\nabla \cdot \boldsymbol{\sigma}+\boldsymbol{b}=\mathbf{0}
$$

where $\boldsymbol{\sigma}$ is the stress tensor $\boldsymbol{b}$ is the body force vector. By applying a virtual displacement, $\delta \boldsymbol{u}$, the weak form of the spatial momentum balance is

$$
\int_{V} \nabla \delta \boldsymbol{u}^{T} \boldsymbol{\sigma} d V-\int_{V} \delta \boldsymbol{u}^{T} \boldsymbol{b} d V-\int_{\partial V} \delta \boldsymbol{u}^{T} \boldsymbol{\sigma} \boldsymbol{n} d A=0
$$

where $V$ is a spatial volume and $\partial V$ is a spatial surface. Through deformation and hyperelasticity concepts [43] the momentum balance can be mapped from the spatial configuration to the material, or reference, configuration to give

$$
\nabla \cdot \Sigma+g=0
$$

where $\boldsymbol{\Sigma}$ is the energy-momentum, or Eshelby stress tensor, and $\boldsymbol{g}$ is the configurational body force vector. The energy-momentum tensor is defined as [41]

$$
\boldsymbol{\Sigma}=W \boldsymbol{I}-\nabla \boldsymbol{u}^{T} \boldsymbol{\sigma}
$$

where $W$ is the strain energy density, $\boldsymbol{I}$ is the identity matrix and $\boldsymbol{u}$ is the spatial displacement vector. The material force, $\boldsymbol{F}_{\boldsymbol{m a t}}$, acting on the singular part of the 
material surface, $\partial V_{0}^{s}$, is approximated in terms of the regular part of the material surface, $\partial V_{0}^{r}$ as

$$
\boldsymbol{F}_{\boldsymbol{m a t}} \approx-\lim _{\partial V_{0}^{r} \rightarrow 0} \int_{\partial V_{0}^{r}} \Sigma \cdot \boldsymbol{N} d A
$$

The material force vector represents a generalized version of the scalar J-integral. Material forces will appear at geometric discontinuities such as holes and cracks and at material inhomogeneities such as a boundary between dissimilar materials. In finite element analyses, material forces will also appear at nodes which are constrained, such as interior nodes in a coarse mesh or boundary nodes with prescribed displacements. The J-integral is restricted to a two-dimensional plane normal to the crack, an infinite domain length and steady-state growth. The crack driving force is restricted to the direction tangent $(\mathrm{t})$ to the crack plane and normal to the crack tip curve and is represented as

$$
J=\lim _{\Gamma \rightarrow 0} \int_{\Gamma}\left[W n_{t}-\boldsymbol{u}, t(\boldsymbol{\sigma} \cdot \boldsymbol{n})\right] d s
$$

Integration is performed along an arbitrary contour path, $\Gamma$, counterclockwise from an arbitrary point on the lower crack surface to one on the upper surface. The Jintegral can be derived from Griffith's energy balance [35], equations (2.46)-(2.48). It can also be obtained by simply projecting the negative material force onto the two-dimensional crack plane in the direction tangent to the straight crack path [24].

$$
J=-\boldsymbol{F}_{\text {mat }} \cdot \boldsymbol{t}
$$

Under LEFM assumptions, the scalar material force and J-integral are equal to Griffith's strain energy release rate. The energy release rate is related to the stress 
intensity factor according to

$$
\begin{aligned}
K & =\sqrt{E G} \quad \text { (plane stress) } \\
K & =\sqrt{\frac{E G}{1-\nu^{2}}} \quad \text { (plane strain) }
\end{aligned}
$$

where $E$ is the modulus of elasticity, $G$ is the energy release rate and $v$ is the Poisson ratio. Computationally, several contour integrals, with increasing distances from the crack tip, are usually evaluated using the J-integral or the material force until the value converges to a desired tolerance. 


\section{Chapter 3}

\section{Test Problems}

\subsection{Stress Concentration at the Hole in a Finite Plate}

The first test problem examines the accuracy of a two-dimensional finite element submodel stress analysis of a blunt notch by analyzing a plate with a central hole in tension. The objectives of the analysis are to:

1. Compare the submodel stress concentration at the edge of the hole to a known analytic solution.

2. Compare the magnitudes and directions of the material force vectors at the hole to a model from literature.

\subsubsection{Problem Geometry and Setup}

The analytic solution for the stress concentration at the edge of the hole is taken from [44] who claim that the formula predicts a maximum stress within $2 \%$ of photoelastic measurements. The problem geometry is shown in Figure 3.1. The analysis uses plate dimensions $D=0.1143 \mathrm{~m}$ and $2 r=0.00635 \mathrm{~m}$ and an applied tensile stress, $\sigma_{0}$, of 
3.78 MPa. The nominal stress, $\sigma_{n o m}$, is the average tensile stress across section B-

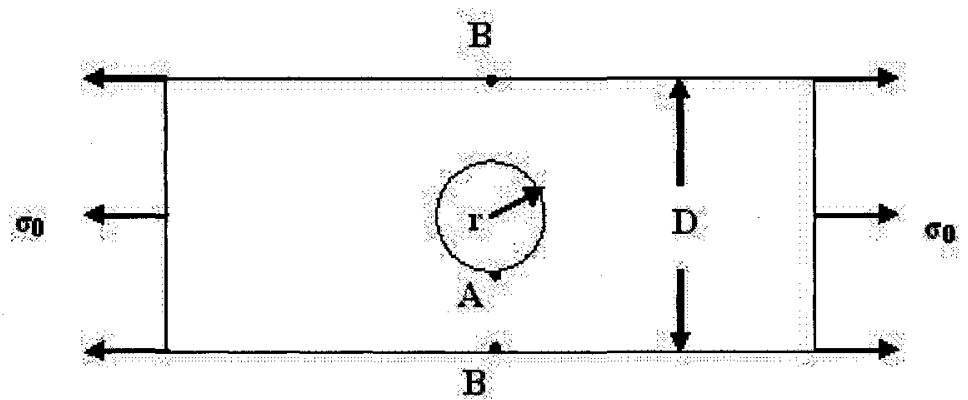

Figure 3.1: Hole test problem geometry.

$\mathrm{B}$ in Figure 3.1 due to the reduction in area from the hole. The nominal stress is determined according to

$$
\sigma_{n o m}=\frac{D}{D-2 r} \sigma_{0}
$$

The stress concentration factor, $K_{t}$, for a plate with a hole in tension is 3.0 when the plate has an infinite width $(D=\infty)$. For a plate with a finite width, the stress concentration will be lower and the analytic solution is determined according to

$$
K_{t}=3.00-3.13\left(\frac{2 r}{D}\right)+3.66\left(\frac{2 r}{D}\right)^{2}-1.53\left(\frac{2 r}{D}\right)^{3}
$$

As the plate width goes to infinity, the stress concentration factor from equation 3.2 goes to 3.0 . The maximum stress, $\sigma_{\max }$, at the boundary of the hole, point A, is

$$
\sigma_{\max }=K_{t} \sigma_{n o m}
$$

The finite element analysis consisted of a coarse 3D stress analysis using 8-node bricks and a fine 2D stress analysis using 4-node quads in a circular region around the hole and assumed plain strain conditions. The minimum submodel element size in the 
vicinity of the hole was $0.15 \mathrm{~mm}$.

\subsubsection{Results}

The uniaxial stress in the direction of the applied load is shown in Figure 3.2. The tensile load stretches the hole vertically, resulting in compressive stresses on the top and bottom of the hole and large tensile maximum stresses at the sides. The stress distribution from the maximum stress at the hole to the minimum stress at the plate edge is plotted in Figure 3.3. The computed nominal stress and analytic maximum and nominal stresses are also shown. There is good agreement between the finite element results and the analytic solution. The analytic nominal stress is $4.00 \mathrm{MPa}$ and the analytic stress concentration factor is 2.837 , which gives a maximum stress of 11.35 $\mathrm{MPa}$ at the hole. The computed nominal stress is 4.11 MPa and the computed maximum stress is $11.11 \mathrm{MPa}$ at the hole. The slightly lower maximum stress and slightly higher nominal stress give a computed stress concentration factor of 2.703 , slightly lower than the analytic value. The computed minimum stress at the edge of the plate is $3.76 \mathrm{MPa}$.

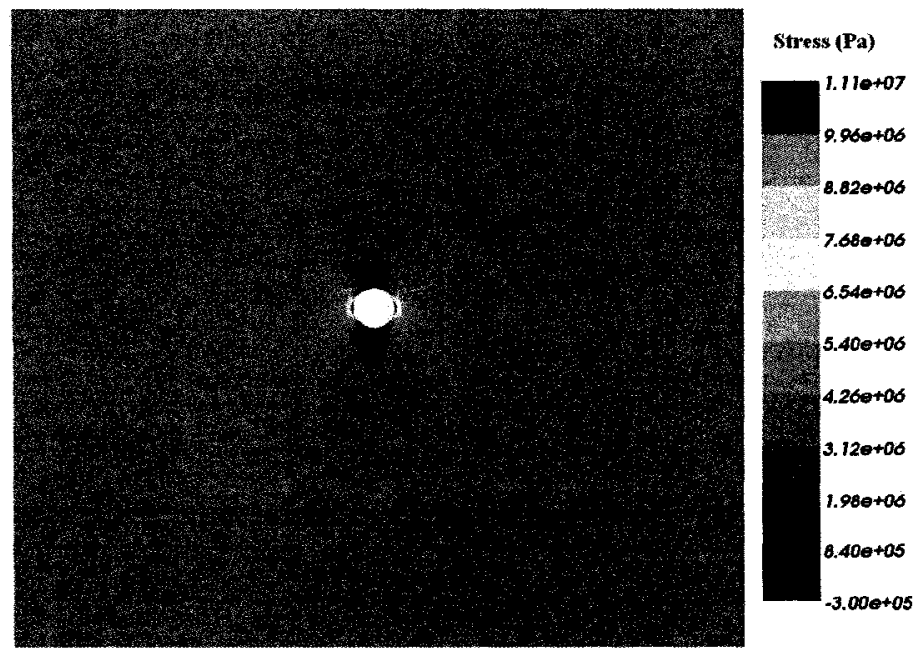

Figure 3.2: Hole test submodel stress distribution. 


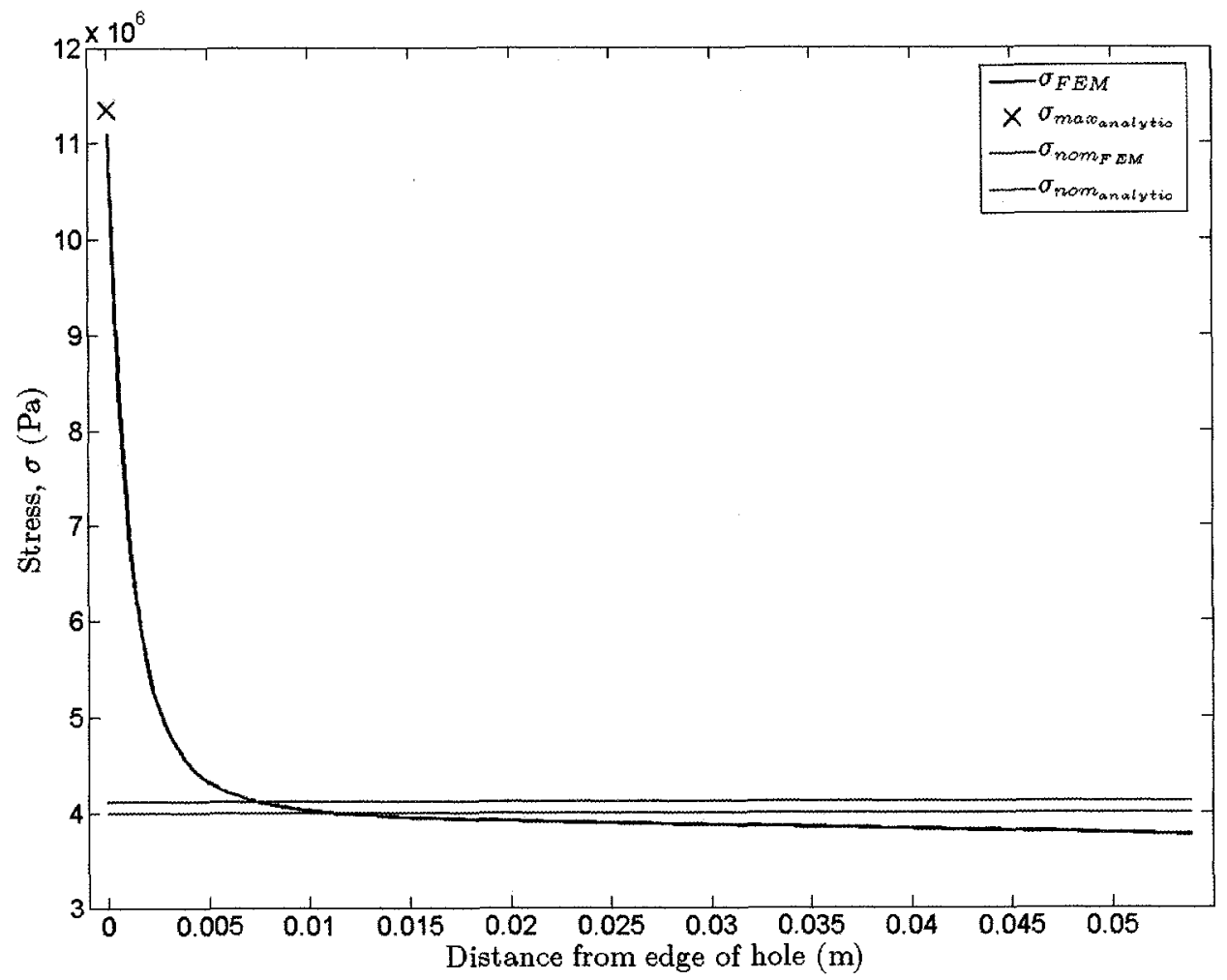

Figure 3.3: Hole test stress distribution plot from edge of hole to edge of plate. The computed peak and nominal stresses are 11.11 MPa and 4.11 MPa respectively. The computed minimum stress at the edge of the plate is $3.76 \mathrm{MPa}$. The analytic peak and nominal stresses are $11.35 \mathrm{MPa}$ and $4.00 \mathrm{MPa}$ respectively.

The material force vectors are shown in Figure 3.4 and compared to results from [4]. From Eshelby's viewpoint the hole can be viewed as an inclusion of zero stiffness. The material forces at the interior nodes would zero if the FEM solution was exact because the plate is homogeneous. The material forces at the interior nodes tend to zero because the error in the FEM solution is small because of the fine mesh. At the boundary of the hole the material force vectors are large and point in the direction of the large strain energy gradients at the discontinuity (the hole). In Figure 3.4(b) displacements are prescribed to the top and bottom plate edges which results in material forces as reactions because the edge nodes are constrained. If the circular 
hole was perturbed to an elliptical hole, then the change in strain energy would be the dot product of the material nodal force and the displacement of the nodes on the hole boundary from the circle to the ellipse. In other words, if a stress analysis was done with the circular hole and a second stress analysis done with an elliptical hole, the difference in the total strain energy would exactly equal the energy computed using the material nodal force.

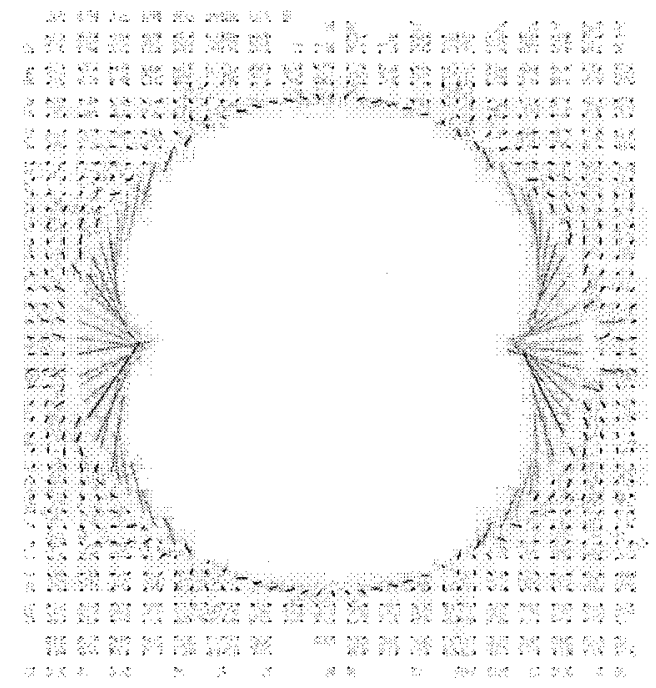

(a)

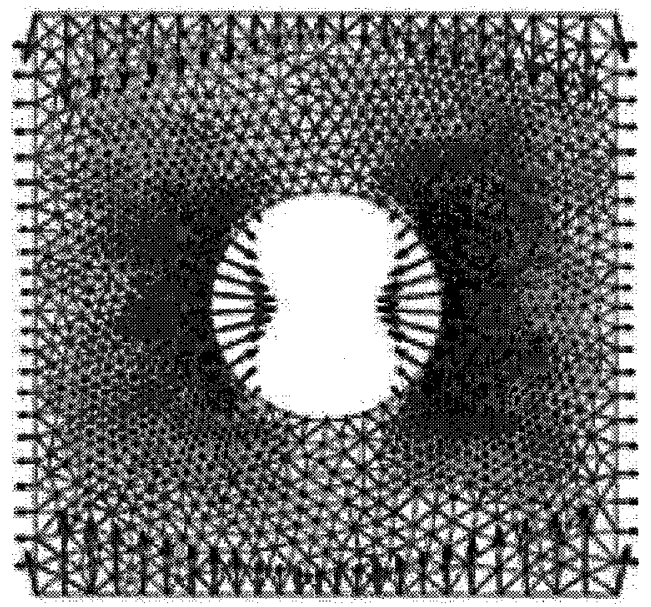

(b)

Figure 3.4: (a) Material force vectors from hole test problem in VrDesigner and (b) material force vectors in a hole from [4].

\subsection{Stress Concentration at the Toe of a Double- Fillet T-Joint Weld}

The second test problem examines the accuracy of a two-dimensional finite element submodel stress analysis of a sharp notch by analyzing a double-fillet t-joint weld loaded in tension. The objective is to compare the submodel peak stress, using a fine mesh to accurately model the weld toe radius, to the hot spot peak stress using 
theoretical stress concentration factors with membrane and bending stresses obtained from a coarse three-dimensional finite element stress analysis.

\subsubsection{Problem Geometry and Setup}

The hot spot and direct methods for determining the stress at the weld toe are detailed in Sections 2.1.1 and 2.1.2 respectively. Three analyses are performed using weld toe radii of $\rho=0.5 \mathrm{~mm}, 1.0 \mathrm{~mm}$ and $1.5 \mathrm{~mm}$ while keeping the loading and other geometry the same. The geometry of the t-joint is shown in Figure 3.5 with dimensions $W=15 \mathrm{~mm}, h=h_{p}=5 \mathrm{~mm}, t=t_{p}=10 \mathrm{~mm}, S=20 \mathrm{~mm}$ and $\theta=45^{\circ}$. Although the loading is purely tensile, the nature of the geometry causes some bending, which cannot be ignored. In the coarse three-dimensional analysis

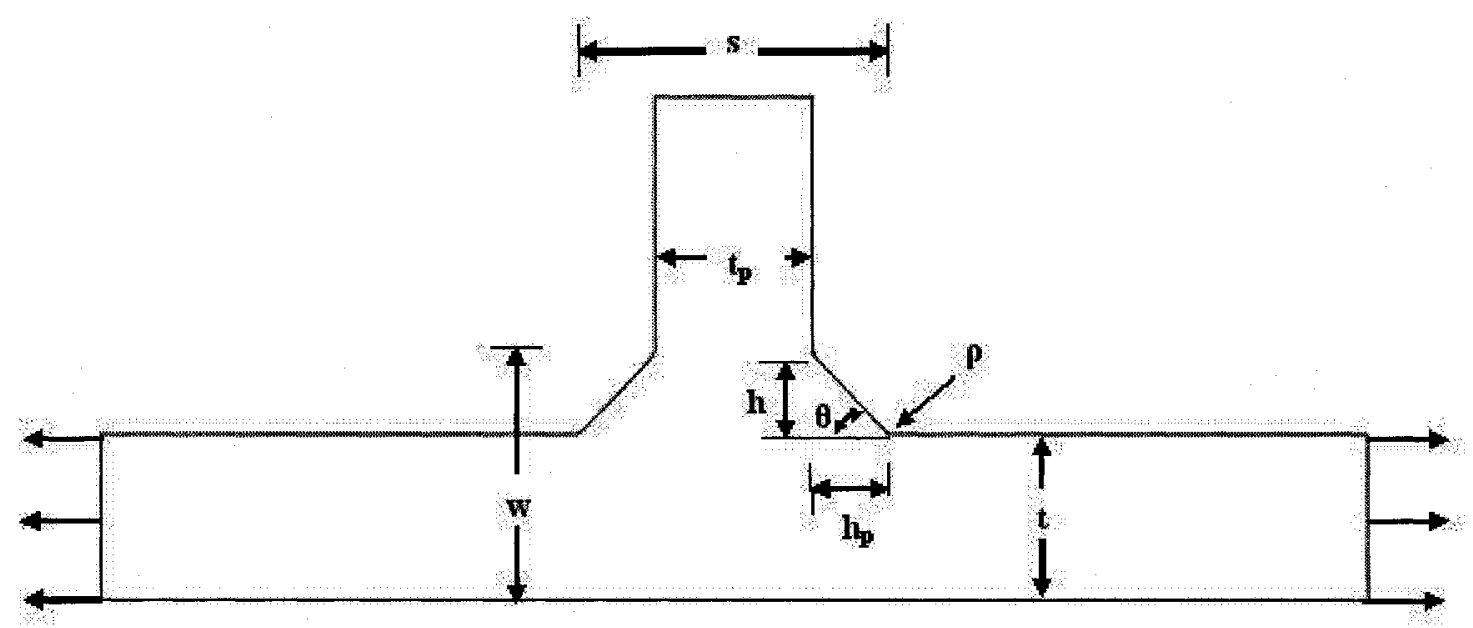

Figure 3.5: Double-fillet weld geometry.

rigid body modes are removed, one end of the plate is prescribed to zero horizontal displacement and a tensile stress of $100 \mathrm{MPa}$ is applied at the opposite end of the plate. The hot spot membrane and bending stresses at the weld toe are determined from the through-thickness stress distribution in the coarse 3D finite element stress analysis and 
multiplied by theoretical membrane and bending stress concentration factors to obtain the peak stress. The stress concentration factors are obtained using Tsuji's equations, developed from boundary element method calculations and presented in [45] and Monahan's equations, presented in [46]. Tsuji's equations for the membrane and bending stress concentration factors for a t-joint are

$$
\begin{aligned}
K_{m} & =1+1.015 Q^{0.446} f(\theta) \\
K_{b} & =1+\left\{0.629+0.058 \ln \left(\frac{S}{t}\right)\right\}\left(\frac{\rho}{t}\right)^{-0.431} \tanh \left(\frac{6 h}{t}\right) f(\theta)
\end{aligned}
$$

where $Q$ and $f(\theta)$ are

$$
\begin{aligned}
Q & =\frac{1}{2.8\left(\frac{W}{2 t}\right)-2}\left(\frac{h}{\rho}\right) \\
f(\theta) & =\frac{1-\exp \{-0.90 \theta \sqrt{W / 2 h}\}}{1-\exp \{-0.90(\pi / 2) \sqrt{W / 2 h}\}}
\end{aligned}
$$

Monahan's equations for a fillet weld are much simpler and are given by

$$
\begin{aligned}
& K_{t, h s}^{m}=1+0.388 \theta^{0.37}\left(\frac{t}{\rho}\right)^{0.454} \\
& K_{t, h s}^{b}=1+0.512 \theta^{0.572}\left(\frac{t}{\rho}\right)^{0.469}
\end{aligned}
$$

The direct method for determining the weld toe peak stress uses a 2D submodel plane strain stress analysis with a $0.1 \mathrm{~mm}$ element size around the weld toe. The displacements prescribed to the boundaries are obtained from the coarser three-dimensional analysis. 


\subsubsection{Results}

The stress concentration factors caculated for each weld toe radius are given in Table 3.1. There is very little difference in the stress concentration factors obtained using the Tsuji method and the relatively simpler Monahan method. Table 3.2 shows the hot spot membrane and bending stresses for each of the three radii and the peak stresses calculated from the different approaches. The hot spot membrane stresses are roughly the same for each radius and very close to the $100 \mathrm{MPa}$ applied traction. Bending causes compressive stress components at the weld toes, which are much smaller than the tensile membrane stresses but still contribute to a decrease in the peak stresses. The finite element submodel peak stresses agree slightly more with the peak stresses obtained using the Monahan stress concentration factors, but even the largest error compared to the Tsuji model is below $5 \%$. Figure 3.6 shows the submodel mesh and stress distribution around the $1.5 \mathrm{~mm}$ weld toe. Figure 3.7 plots the submodel stress distribution from the weld toe through the thickness for the 1.5 $\mathrm{mm}$ weld toe. While it is small compared to the membrane stress, the influence of the negative bending stress near the weld toe is clearly visible.

\begin{tabular}{|c|c|c|c|}
\hline Stress Concentration Factor & $\boldsymbol{\rho}=\mathbf{0 . 5} \mathbf{~ m m}$ & $\boldsymbol{\rho}=\mathbf{1 . 0} \mathbf{~ m m}$ & $\boldsymbol{\rho}=\mathbf{1 . 5} \mathbf{~ m m}$ \\
\hline$K_{t, h s}^{m}$, Tsuji & 2.4022 & 2.0293 & 1.8590 \\
$K_{t, h s}^{b}$, Tsuji & 2.7046 & 2.2644 & 2.0617 \\
$K_{t, h s}^{m}$, Monahan & 2.3826 & 2.0093 & 1.8396 \\
$K_{t, h s}^{b}$, Monahan & 2.8174 & 2.3130 & 2.0856 \\
\hline
\end{tabular}

Table 3.1: Double-fillet stress concentration factors for weld toe radii of $0.5 \mathrm{~mm}, 1 \mathrm{~mm}$ and $1.5 \mathrm{~mm}$. 


\begin{tabular}{|c|c|c|c|}
\hline Stress (Mpa) & $\boldsymbol{\rho}=\mathbf{0 . 5} \mathbf{~ m m}$ & $\boldsymbol{\rho}=\mathbf{1 . 0} \mathbf{~ m m}$ & $\boldsymbol{\rho}=\mathbf{1 . 5} \mathbf{~ m m}$ \\
\hline$\sigma_{h s}^{m}$ & 96.151 & 98.026 & 97.265 \\
$\sigma_{h s}^{b}$ & -6.190 & -3.797 & -3.429 \\
$\sigma_{\text {peak }}$, Tsuji & 214.231 & 190.316 & 173.746 \\
$\sigma_{\text {peak }}$, Monahan & 211.649 & 188.171 & 171.777 \\
$\sigma_{\text {peak }}$, FEM & 205.120 & 184.180 & 168.970 \\
\hline \hline \% Error , FEM vs. Tsuji & 4.25 & 3.22 & 2.75 \\
$\%$ Error , FEM vs. Monahan & 3.08 & 2.12 & 1.64 \\
\hline
\end{tabular}

Table 3.2: Double-fillet weld toe stresses.

\subsection{Single-Edge Crack Test for Stress Intensity}

\section{Factor}

The single edge crack test examines the accuracy of a fine two-dimensional fracture mesh used for fatigue crack propagation. The objectives of the analysis are to:

1. Predict fatigue crack growth along a projected crack path using the ParisErdogan equation for three different maximum loads with a minimum stress of 0 .

2. Compare the stress intensity factors from re-computed J-integral values during crack growth, obtained from the material force, to stress intensity factors from a known analytic solution.

\subsubsection{Problem Geometry and Setup}

The mode-I analytic solution for the SEC under tensile loading is given in [34] and in equation 2.50 and is valid for a crack length-to-plate length ratio of $a / b \leq 0.6$. The SEC geometry is shown in Figure 3.8. The plate dimensions used in the analysis are $h=0.1 \mathrm{~m}$ and $b=0.1 \mathrm{~m}$. The plate thickness is $0.05 \mathrm{~m}$. In the coarse 


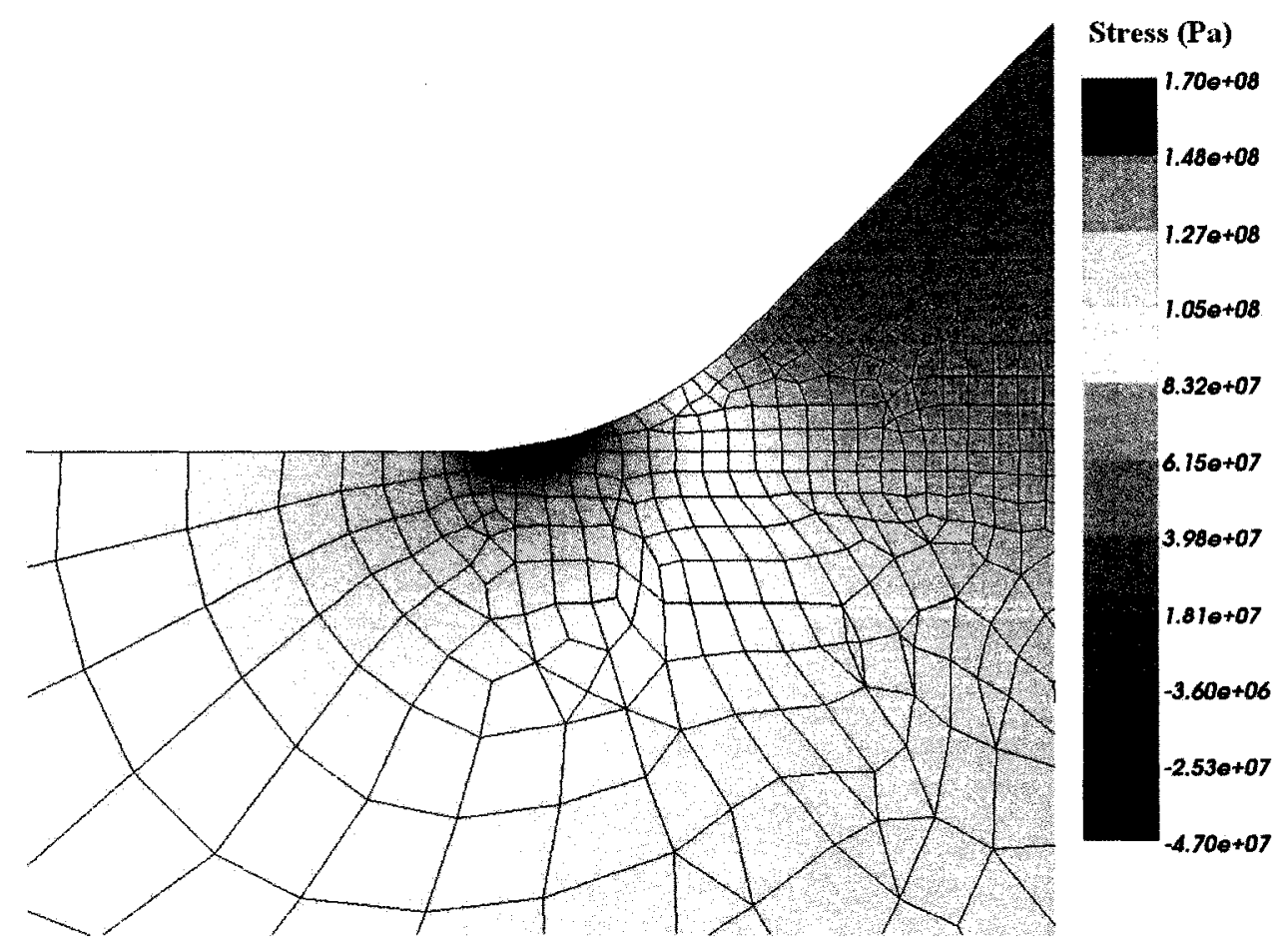

Figure 3.6: Double-fillet submodel stress distribution at the $1.5 \mathrm{~mm}$ weld toe.

three-dimensional finite element stress analysis, the bottom edge of the plate was constrained in the vertical direction, rigid body motion was removed, and tractions of $138 \mathrm{MPa}, 69 \mathrm{MPa}$ and $34.5 \mathrm{MPa}$ were applied to the top surface in three successive tests. In the two-dimensional plane strain submodel fracture analysis, the displacement at one edge of the submodel was prescribed to zero while the traction, obtained from the three-dimensional analysis, was applied to the other edge. The crack was grown from $a / b=0.25$ to $a / b=0.5(a=0.025 \mathrm{~m}$ to $a=0.05 \mathrm{~m})$ in increments of one element, or $0.2 \mathrm{~mm}$, and did not incorporate a threshold or a critical stress intensity factor. A Paris-Erdogan coefficient of $C=6.9 \times 10^{-12}(\mathrm{~m} / \mathrm{cycles})(\mathrm{MPa} \sqrt{\mathrm{m}})^{-\mathrm{m}}$ and exponent of $m=3.0$ were used. 


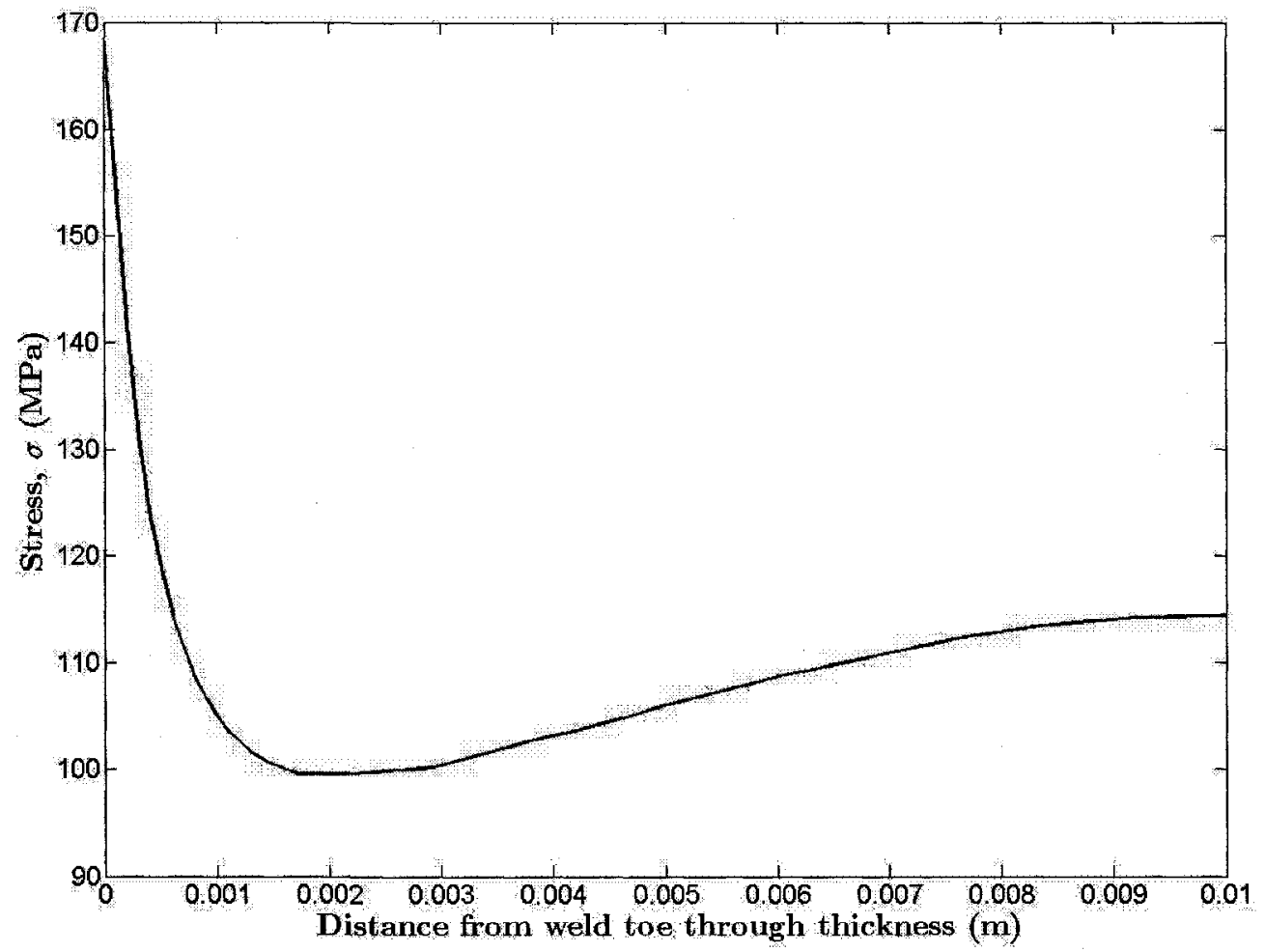

Figure 3.7: Double-fillet weld stress distribution through the thickness from the $1.5 \mathrm{~mm}$ weld toe. 


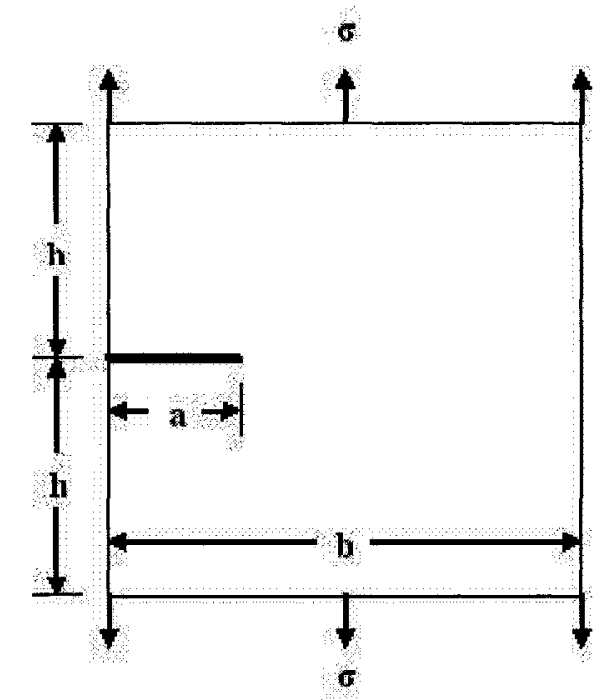

Figure 3.8: SEC specimen geometry.

\subsubsection{Results}

The number of cycles to grow the crack from $0.025 \mathrm{~m}$ to $0.05 \mathrm{~m}$ for the same material at remote stresses of $138 \mathrm{MPa}, 69 \mathrm{MPa}$ and $34.5 \mathrm{Mpa}$ were determined, using the Paris-Erdogan equation, as 4869, 38956 and 311644 cycles, respectively. Figure 3.9 shows a plot of $\log \frac{\mathrm{d} a}{\mathrm{~d} N}$ against $\log \Delta K$ while Figure 3.10 shows a plot of the crack length against the number of cycles. The three load levels plotted in Figure 3.9 are all extensions of the same line because they are the same material and have the same Paris coefficients while the curves in Figure 3.10 demonstrate the much greater rate of crack growth at higher load levels.

Figure 3.11 shows the crack opening displacement at the final crack length of 0.05 $\mathrm{m}$ and Figure 3.12 shows the the stress distribution and mesh perpendicular to the crack path. The analytic and computed stress intensity factors for crack-to-width increments of 0.05 are given in Table 3.3. The error between the computed solution and the analytic solution ranges between $3.25 \%$ and $9.03 \%$ which gives good agreement between results. While the mesh is graded away from the crack perpendicular to the 


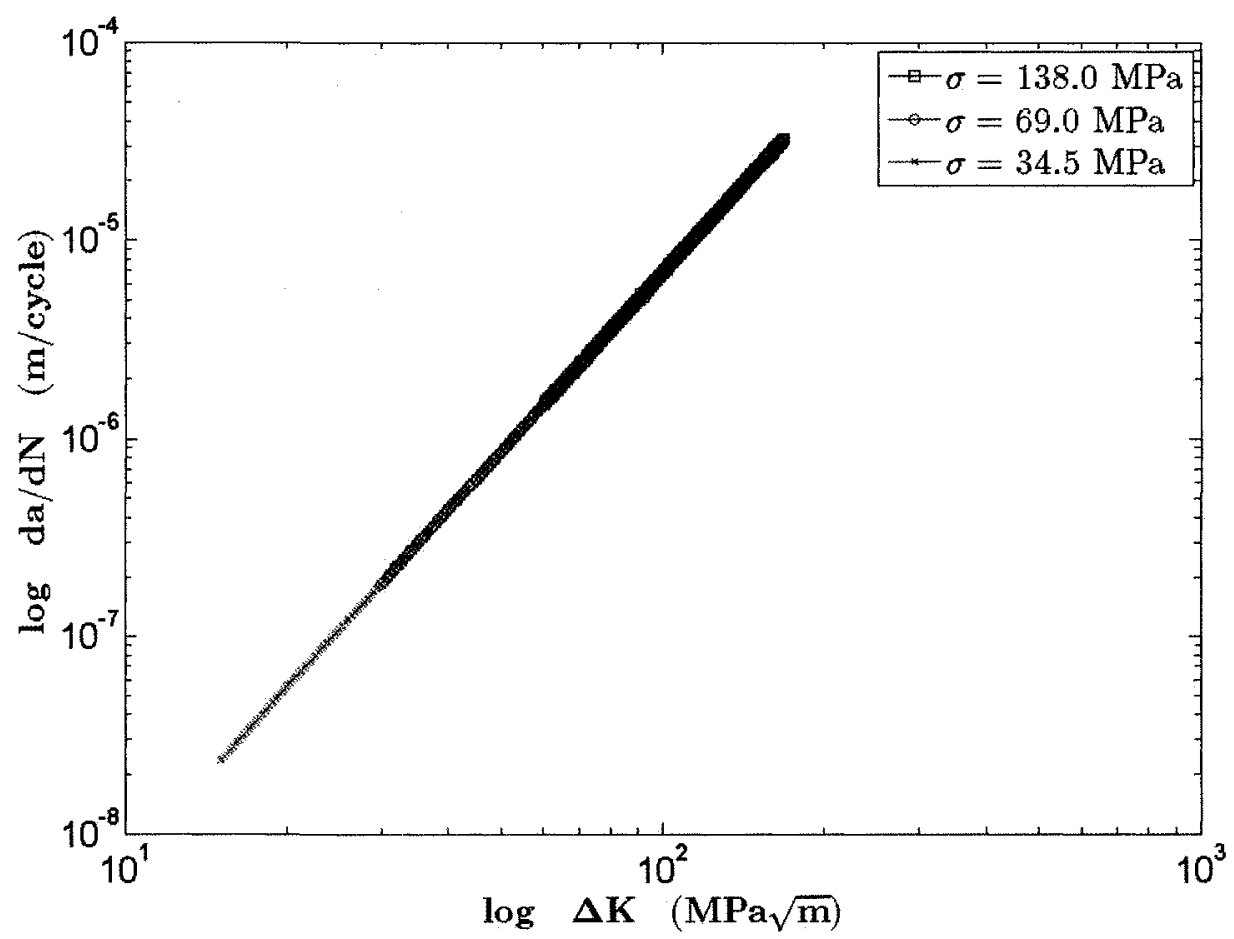

Figure 3.9: SEC test $\log \frac{\mathrm{d} a}{\mathrm{~d} N}$ vs. $\log \Delta K$ for remote stresses of $138 \mathrm{MPa}, 69 \mathrm{MPa}$ and $34.5 \mathrm{MPa}$.

crack path, as shown in Figure 3.12, a closer agreement could possibly be obtained by creating a rounded mesh around the crack tip graded exponentially in the radial direction. The disadvantage would be the need to remesh for every increment in crack length. The analysis also used 4-node quadratic elements. The use of 8-node quadratic elements would better approximate bending and a further step would be to create special crack-tip elements by shifting the mid-edge nodes of the 8-node quads to the quarter-points to capture the stress singularity at the crack tip. This approach was suggested in [47] and demonstrated in [40]. 


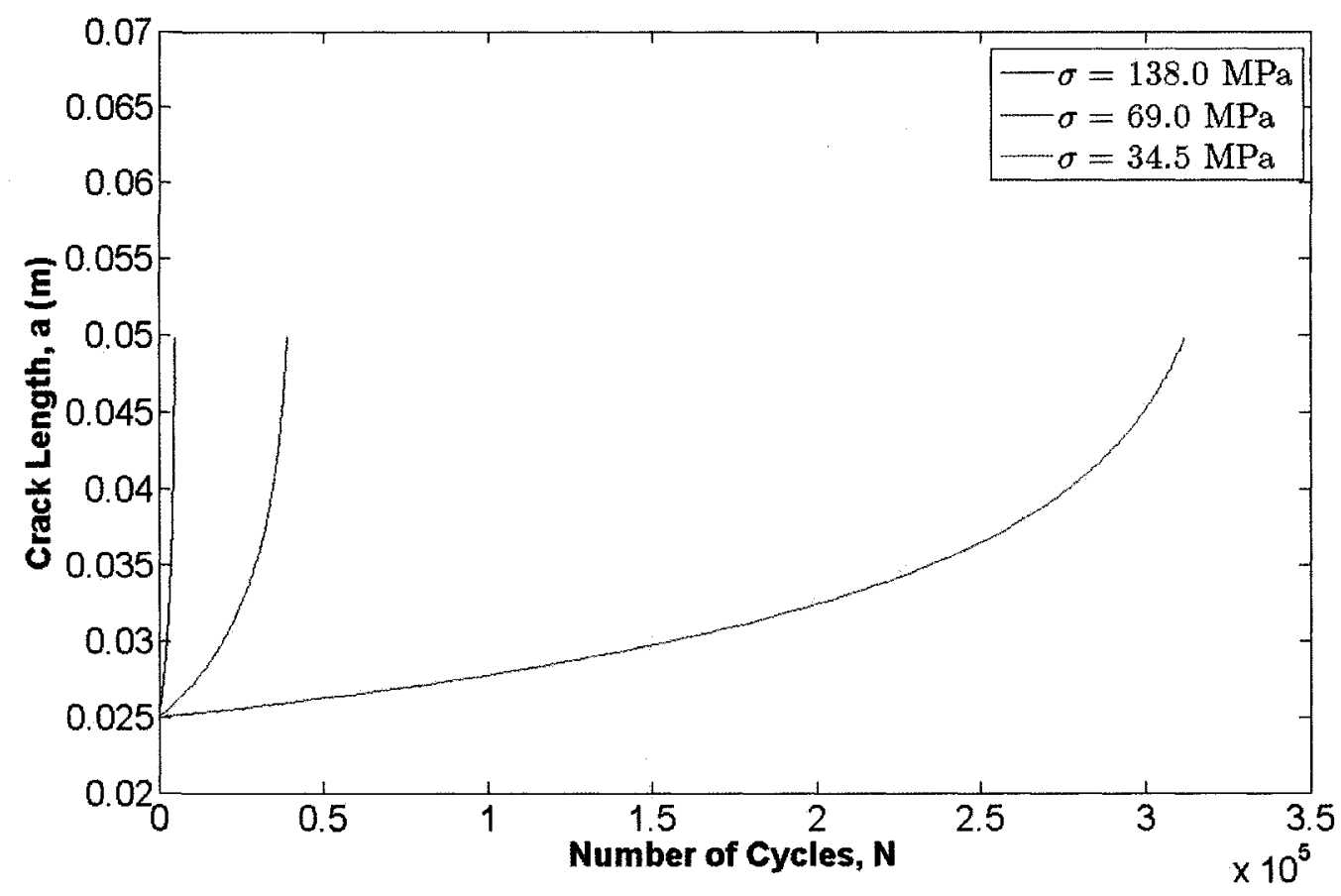

Figure 3.10: SEC test $a$ vs. $N$ for remote stresses $138 \mathrm{MPa}, 69 \mathrm{MPa}$ and $34.5 \mathrm{MPa}$.
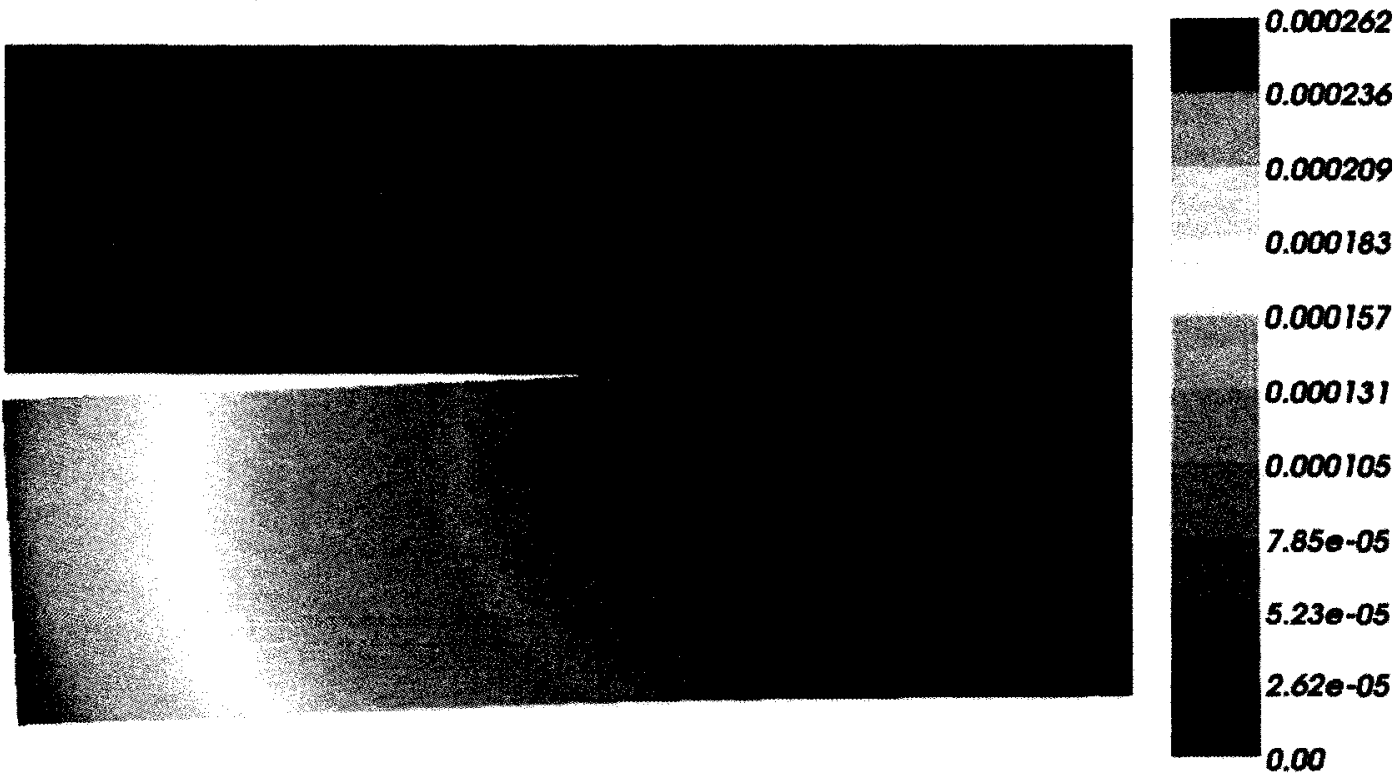

Figure 3.11: SEC test submodel crack displacement at $a / b=0.5$ 


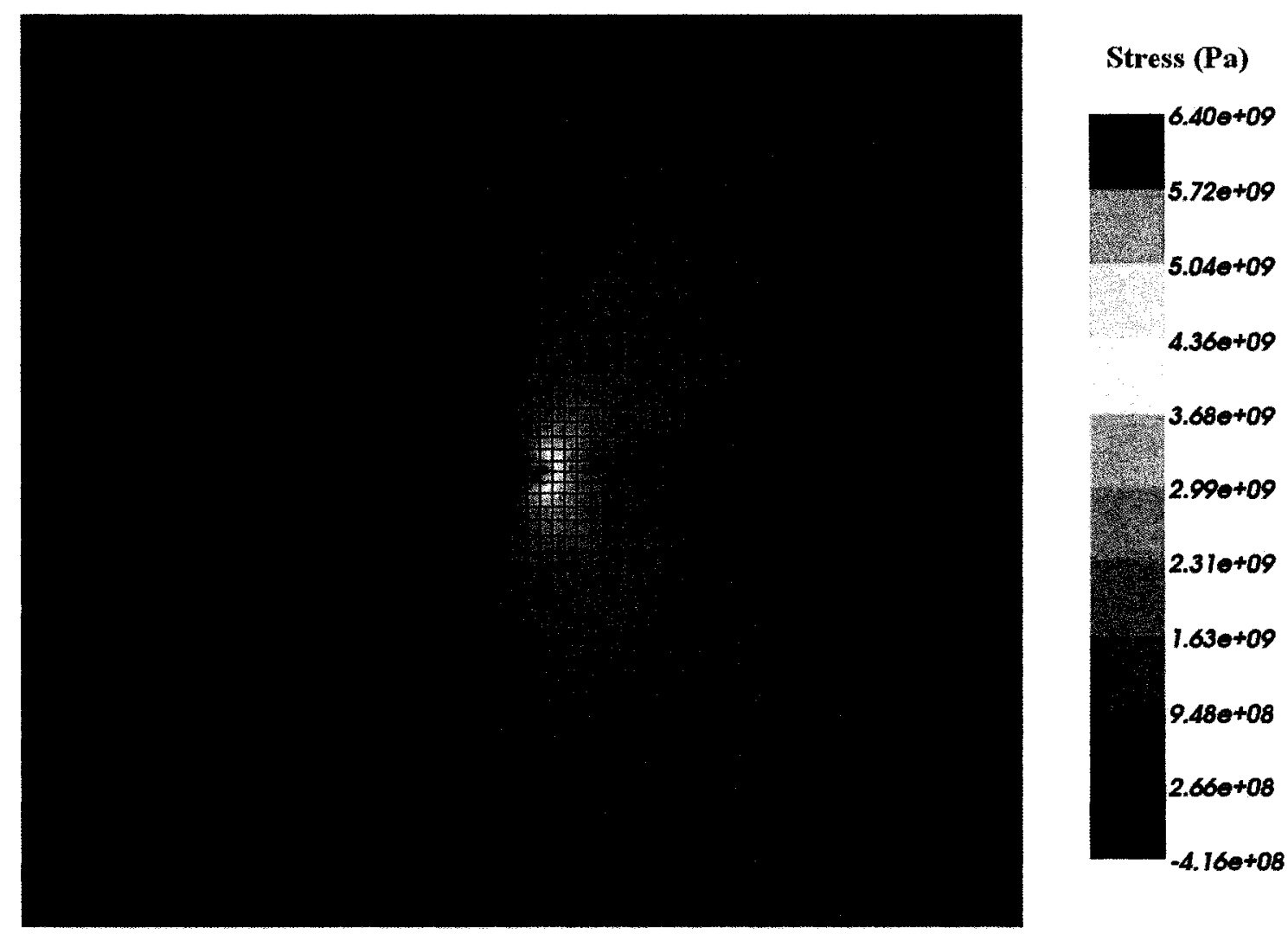

Figure 3.12: SEC test stress distribution and graded mesh perpendicular to the crack path.

\begin{tabular}{|c|c|c|c|}
\hline $\mathbf{a} / \mathbf{b}$ & $\mathbf{K}_{\mathbf{I}_{\text {analytic }}}(\mathbf{M p a} \sqrt{\mathbf{m}})$ & $\mathbf{K}_{\mathbf{I}_{\text {computed }}}(\mathbf{M p a} \sqrt{\mathbf{m}})$ & Error $\mathbf{( \% )}$ \\
\hline 0.25 & 58.19 & 60.15 & 3.25 \\
0.30 & 70.55 & 74.46 & 5.24 \\
0.35 & 85.29 & 92.54 & 7.84 \\
0.40 & 103.39 & 113.65 & 9.03 \\
0.45 & 126.20 & 138.48 & 8.87 \\
0.50 & 155.47 & 168.17 & 7.55 \\
\hline
\end{tabular}

Table 3.3: SEC test stress intensity factors at different crack lengths. 


\section{Chapter 4}

\section{Fatigue Life Prediction of a Welded}

\section{Gusset Joint}

The gusset joint test examines the total life prediction of a weld specimen with a relatively simple geometry, incorporating both residual stresses and in-service loading with an in-service load ratio, $R$, of zero. The residual stress, however, raises the mean stress amplitude, so the Smith-Watson-Topper version of the strain-life equation is used to account for mean stress effects.

\subsection{Problem Geometry and Setup}

The Gusset joint model consists of a $0.1 \mathrm{~m} \times 0.05 \mathrm{~m} \times 0.004 \mathrm{~m}$ vertical rectangular plate with a $0.0125 \mathrm{~m}$ diameter hole welded to a second $0.5 \mathrm{~m} \times 0.5 \mathrm{~m} \times 0.004$ $\mathrm{m}$ horizontal rectangular baseplate, as shown in Figure 4.1. The fillet weld is 5 $\mathrm{mm}$ in height with an angle of $51.34^{\circ}$ and a toe radius of $0.8 \mathrm{~mm}$. The membrane and bending stress concentration factors for this geometry, according to Monahan's equations, are 1.7736 and 2.0228 respectively. A single-pass wrap-around weld is performed at the interface between plates. For fatigue testing, each corner of the baseplate is constrained over an area of $0.08 \mathrm{~m} \times 0.04 \mathrm{~m}$ and the vertical plate is 
loaded by applying a distributed in-plane load of $1000 \mathrm{~N}$ through the hole. The fatigue coefficients are given in Table 4.1. The Ramberg-Osgood and strain-life coefficients are taken from [48]. The Paris-Erdogan coefficients are taken from [29].

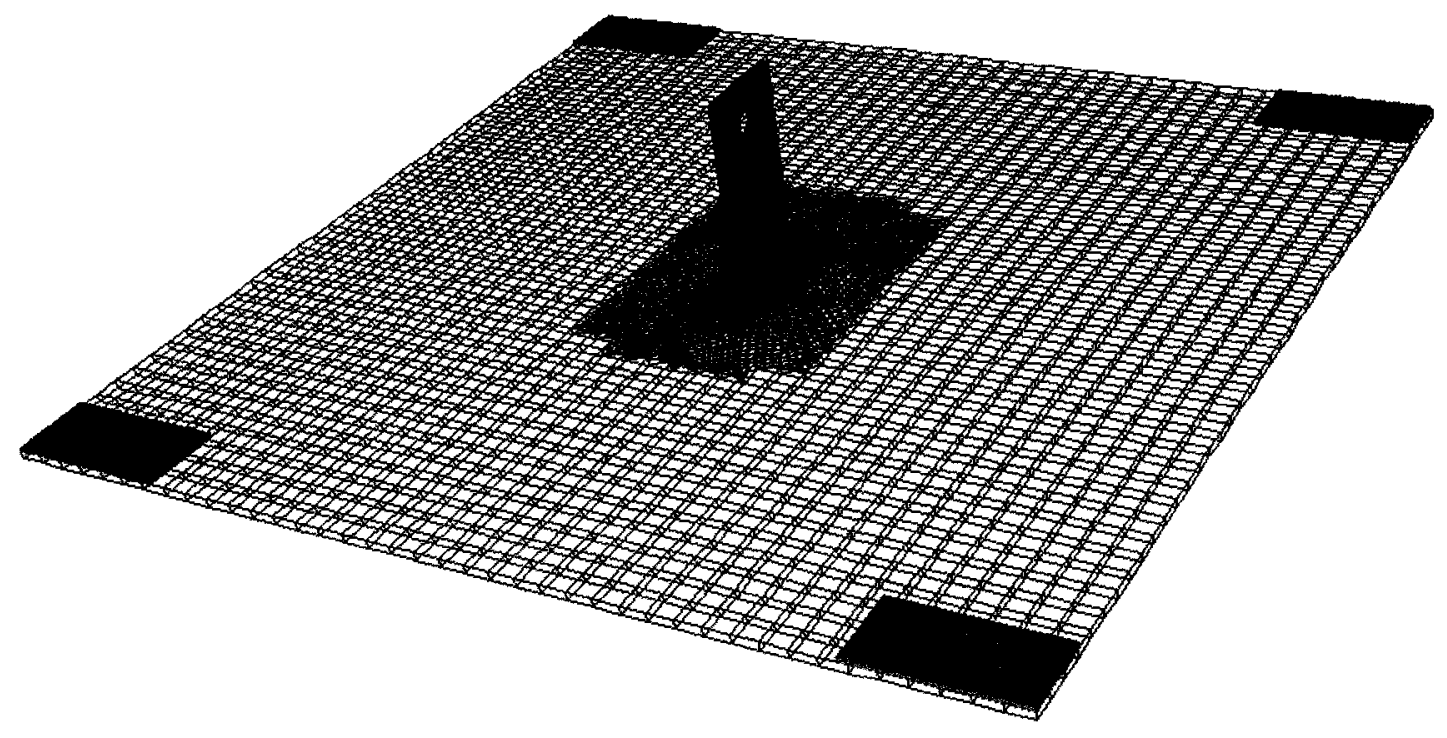

Figure 4.1: Gusset joint geometry and constraints.

Four separate sets of simulations are performed:

1. A three-dimensional thermal, microstructure and stress weld analysis of the total model to determine the residual stress. A submodel analysis maps the final stress and displacement from the total project to a three-dimensional slice with a fine mesh around the weld toe as an initial state. The submodel analysis 


\begin{tabular}{|l||c|}
\hline Yield strength, $\sigma_{y}$ & $440 \mathrm{MPa}$ \\
Modulus of Elasticity, $E$ & $208200 \mathrm{MPa}$ \\
Cyclic Ramberg-Osgood strength coefficient, $k^{\prime}$ & $1270 \mathrm{MPa}$ \\
Cyclic Ramberg-Osgood hardening exponent, $n^{\prime}$ & 0.192 \\
Fatigue strength exponent, $b$ & -0.101 \\
Fatigue ductility exponent, $c$ & -0.524 \\
Fatigue strength coefficient, $\sigma_{f}^{\prime}$ & $1000 \mathrm{MPa}$ \\
Fatigue ductility coefficient, $\varepsilon_{f}^{\prime}$ & 0.422 \\
Paris-Erdogan exponent, $m$ & 3 \\
Paris-Erdogan coefficient, $C$ & $6.9 \times 10^{-12}(\mathrm{~m} / \mathrm{cycles})(\mathrm{MPa} \sqrt{\mathrm{m}})^{-\mathrm{m}}$ \\
Initial crack length, $a_{i}$ & $1 \mathrm{~mm}$ \\
Final crack length, $a_{f}$ & $4 \mathrm{~mm}$ \\
\hline
\end{tabular}

Table 4.1: Fatigue life properties

then recomputes the stress on the finer mesh using linear elasticity. A threedimensional submodel slice is used instead of a two-dimensional submodel to facilitate the residual stress mapping from the 8-node brick elements of the total model.

2. A stress analysis of the total model using only in-service loading. The hot spot method with analytic stress concentration factors computes the weld toe stress from the total analysis. The displacements from the total analysis are mapped to the 3D submodel slice, the stress is re-solved on the finer mesh and the toe stress is obtained directly. A two-dimensional submodel is also analyzed in the same way to examine any differences between the use of $3 \mathrm{D}$ and $2 \mathrm{D}$ submodels.

3. A three-dimensional submodel slice analysis incorporating both residual and inservice stresses. The final stress state from the total weld analysis is imported to the submodel slice as an initial state and the displacements from the the total in-service load test are applied. The submodel stress is computed using 
linear elasticity.

4. A two-dimensional crack growth analysis. A 2D fracture mesh is analyzed using the traction and displacements from the 3D structural submodel of Test 2. A crack is grown along a predetermined path from the weld toe through the thickness of the baseplate. As in the SEC test of Section 3.3 the stress intensity factors are computed using the J-integral, obtained from the material force vector.

Figure 4.2(a) shows a closer view of the total three-dimensional weld model while Figure 4.2(b) shows the three-dimensional submodel slice. The two-dimensional submodel, shown in Figures 4.3 and 4.4, is the same as the three-dimensional slice except it is not extruded. The crack initiation life is computed in MATLAB using the separate residual and in-service stresses from Tests 1 and 2. The Smith-Watson-Topper variation of the strain-life method of Section 2.2 is used to account for the influence of the welding residual stress on the mean stress. Neuber's rule is used to convert the linear elastic stresses from the analyses to non-linear Ramberg-Osgood stresses. The FALIN crack initiation software is used to validate the calculations. A FALIN calculation using the equivalent strain energy density (ESED) method is also performed to examine the difference in predicted initiation lives.

\subsection{Results}

The weld toe residual and in-service stresses are presented in Table 4.2. The significant difference between the residual stress from the total model analysis of Test 1, $441 \mathrm{MPa}$, and that of the submodel, $372 \mathrm{MPa}$, comes from the mapping of the displacements and stresses from the total model to the submodel. The residual stress from the three-dimensional weld analysis incorporates plasticity while the submodel stress is 


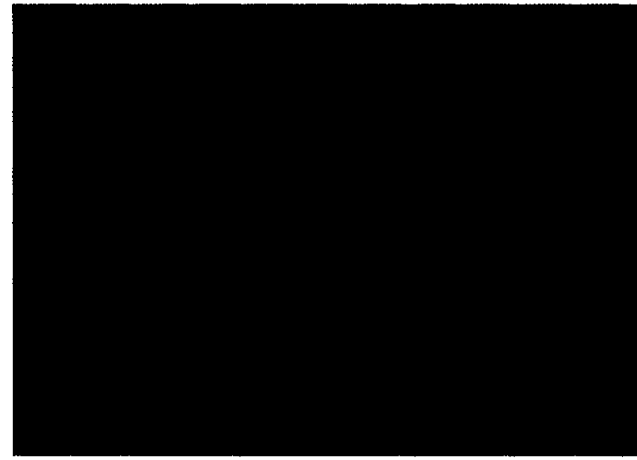

(a)

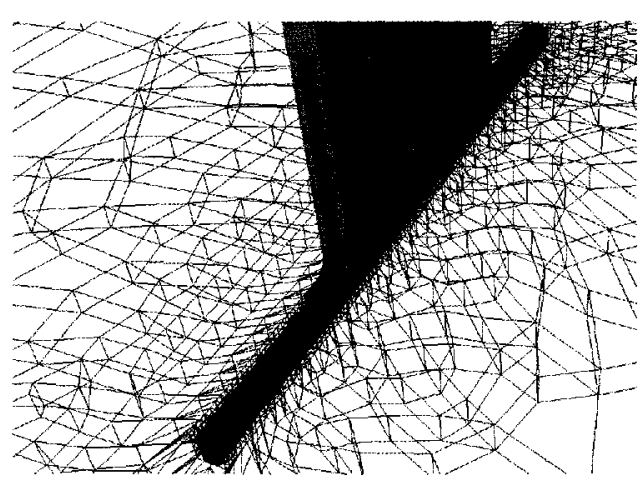

(b)

Figure 4.2: (a) Gusset joint three-dimensional total weld model and (b) three-dimensional slice submodel.

re-solved using linear elasticity. The purpose of re-solving the submodel stress using linear elasticity was to verify mapping and data flows in Test 3 and will be discussed further.

In Test 2 the in-service peak stress was calculated using the hot spot method at the weld toe of the total model and directly at the weld toes of the three-dimensional and two-dimensional submodels. The two-dimensional submodel stress is shown in Figure 4.3 and a close-up view of the weld toe stress distribution is shown in Figure 4.4. The hot spot peak stress from the total model shows good agreement with the peak stresses from both the $2 \mathrm{D}$ and $3 \mathrm{D}$ submodels. The use of either of the three methods for determining the peak local stress at the weld toe is feasible.

In Test 3 the welding residual stress from the total weld model of Test 1 is mapped to the submodel as an initial state and the in-service load from the total in-service model of Test 2 is applied. The stresses from these two projects are re-solved in the submodel using linear elasticity. Since the welding residual stress is considered to be an initial stress state, solving the problem using linear elasticity is a good 


\begin{tabular}{|l||c|}
\hline Method & $\sigma(\mathbf{M P a})$ \\
\hline Test 1: residual, total model & 441.45 \\
Test 1: residual, submodel & 371.71 \\
Test 2: in-service membrane, total model & 6.44 \\
Test 2: in-service bending, total model & 97.62 \\
Test 2: in-service peak, total model & 205.98 \\
Test 2: in-service peak, 3D submodel slice & 191.12 \\
Test 2: in-service peak, 2D submodel & 186.18 \\
Test 1 + 2: residual and in-service peak, total model & 647.43 \\
Test 1 + 2: residual and in-service peak, submodel & 562.83 \\
Test 3: residual and in-service submodel & 556.04 \\
\hline
\end{tabular}

Table 4.2: Gusset joint peak stresses.

method for determining data flows from the parent analyses to the submodel analysis. The separately-computed linear elastic residual stress and in-service stress from the submodel slice analyses of Tests 1 and 2 should add to give the total stress computed in Test 3. Table 4.2 shows that the sum of the submodel stresses from Test 1 and Test 2, $563 \mathrm{MPa}$, and the total stress computed directly in the submodel slice analysis of Test 3, $556 \mathrm{MPa}$, are nearly identical. While there is not much practical sense in recomputing the residual stress using linear elasticity, the exercise demonstrates that the total stress due to welding and in-service loading can be obtained by mapping the final stress state of a weld analysis to a submodel slice and then applying the boundary conditions from in-service loading.

Since the total model analyses of Tests 1 and 2 gave higher stress results than the submodel analyses so these are used in the crack initiation calculations for more conservative estimates. The non-linear stresses and strains obtained using MATLAB and FALIN with the Neuber rule and FALIN with the ESED method are presented 

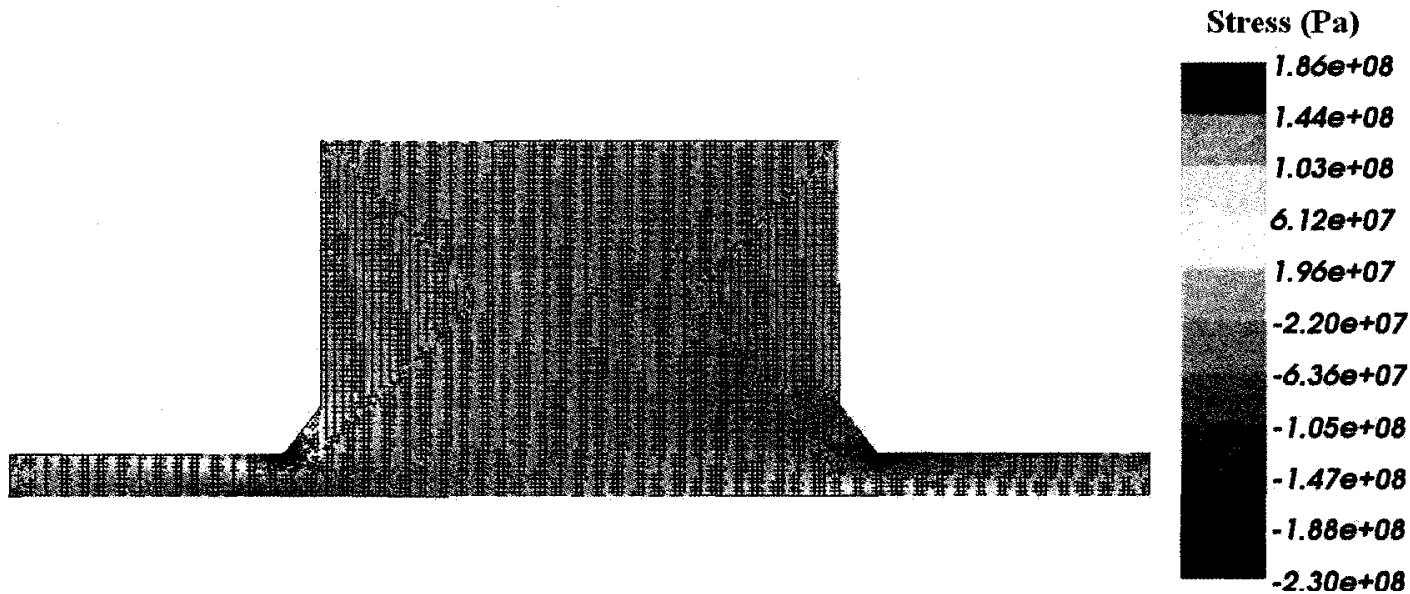

Figure 4.3: Gusset joint 2D submodel mesh and in-service stress.

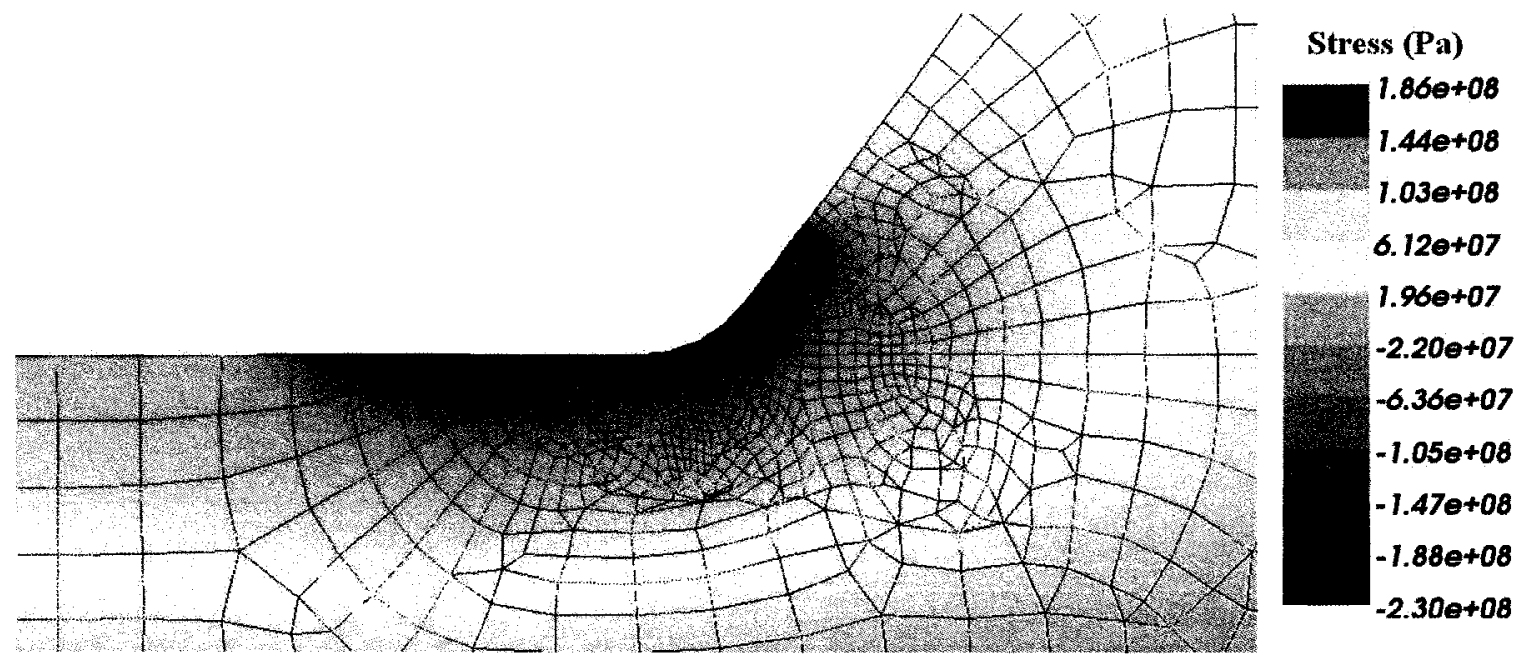

Figure 4.4: Gusset joint 2D submodel mesh and in-service stress (close).

\begin{tabular}{|c|c|c|c|}
\hline Method & MATLAB, Neuber & FALIN, Neuber & FALIN, ESED \\
\hline \hline Peak Stress (MPa) & 493.2 & 496.5 & 494.7 \\
Peak Strain & $9.6 \times 10^{-3}$ & $9.9 \times 10^{-3}$ & $9.8 \times 10^{-3}$ \\
Stress Amplitude (MPa) & 102.8 & 102.0 & 101.89 \\
Strain Amplitude & $5.0 \times 10^{-4}$ & $5.0 \times 10^{-4}$ & $5.0 \times 10^{-4}$ \\
Initiation Life (No. Cycles) & $2.3 \times 10^{6}$ & $2.2 \times 10^{6}$ & $2.2 \times 10^{6}$ \\
\hline
\end{tabular}

Table 4.3: Gusset joint non-linear stresses and strains. 


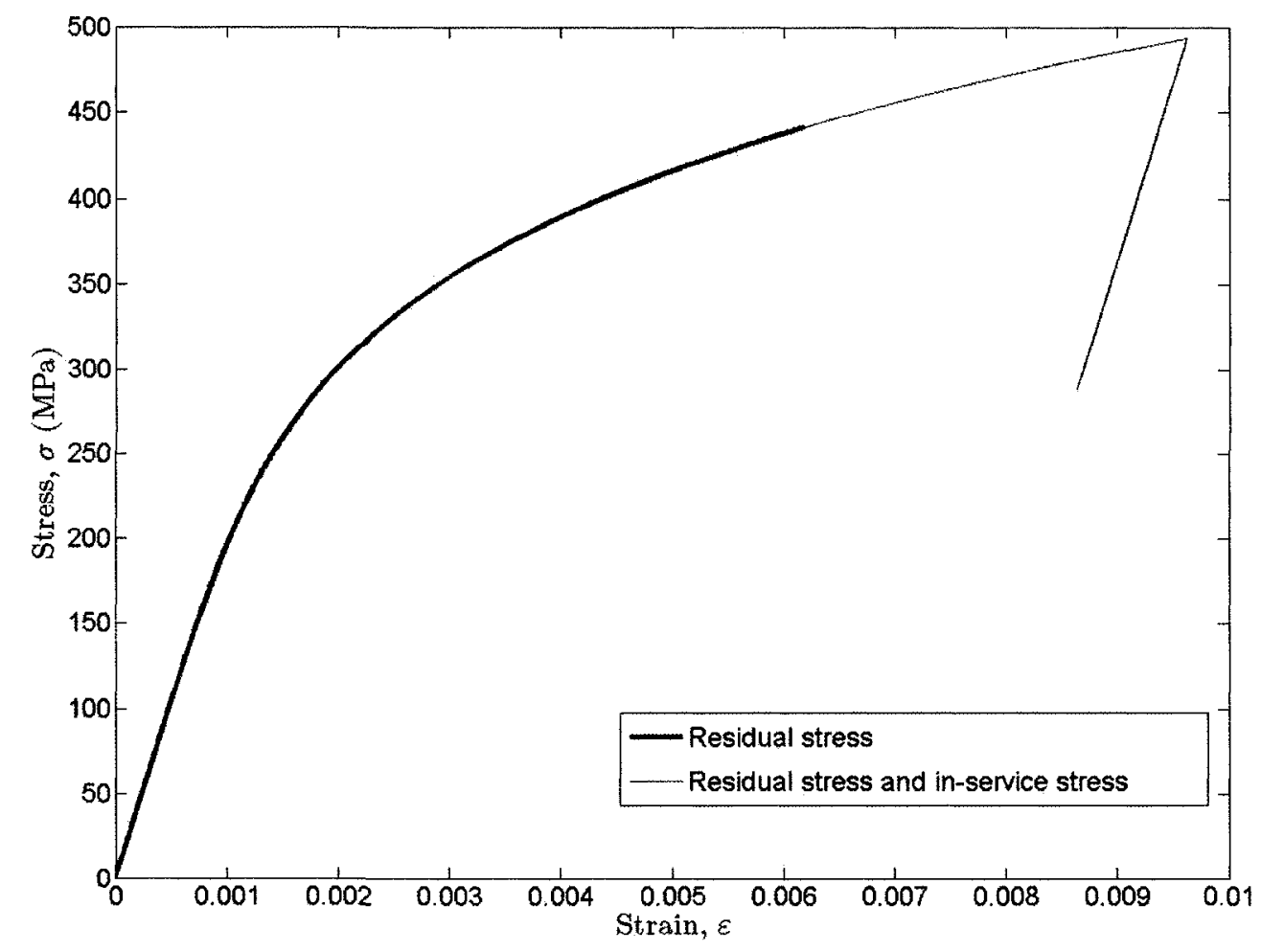

Figure 4.5: Gusset joint stress-strain curve and hysteresis loop with welding residual stress and in-service stress.

in Table 4.3. The MATLAB-calculated stress strain curve and hysteresis loop for the Gusset plate is shown in Figure 4.5. The MATLAB and FALIN calculations using the Neuber rule show good agreement, especially in the computation of the stress and strain amplitudes. The slight differences are most likely due to different numerical strategies for solving the Ramberg-Osgood equation. The local non-linear stresses and strains calculated using the ESED method do not differ much from those calculated using the Neuber rule for this analysis. This is most likely due to the fact that the in-service stress has much less influence than the welding residual stress, which is applied as a non-linear prestress. The crack initiation life predictions using the Smith-Watson-Topper variation of the strain-life equation are also given in Table 
4.3. The relatively long initiation life calculations, of the order of $2.2 \times 10^{6}$ cycles, are due to the small cyclic strain amplitudes.

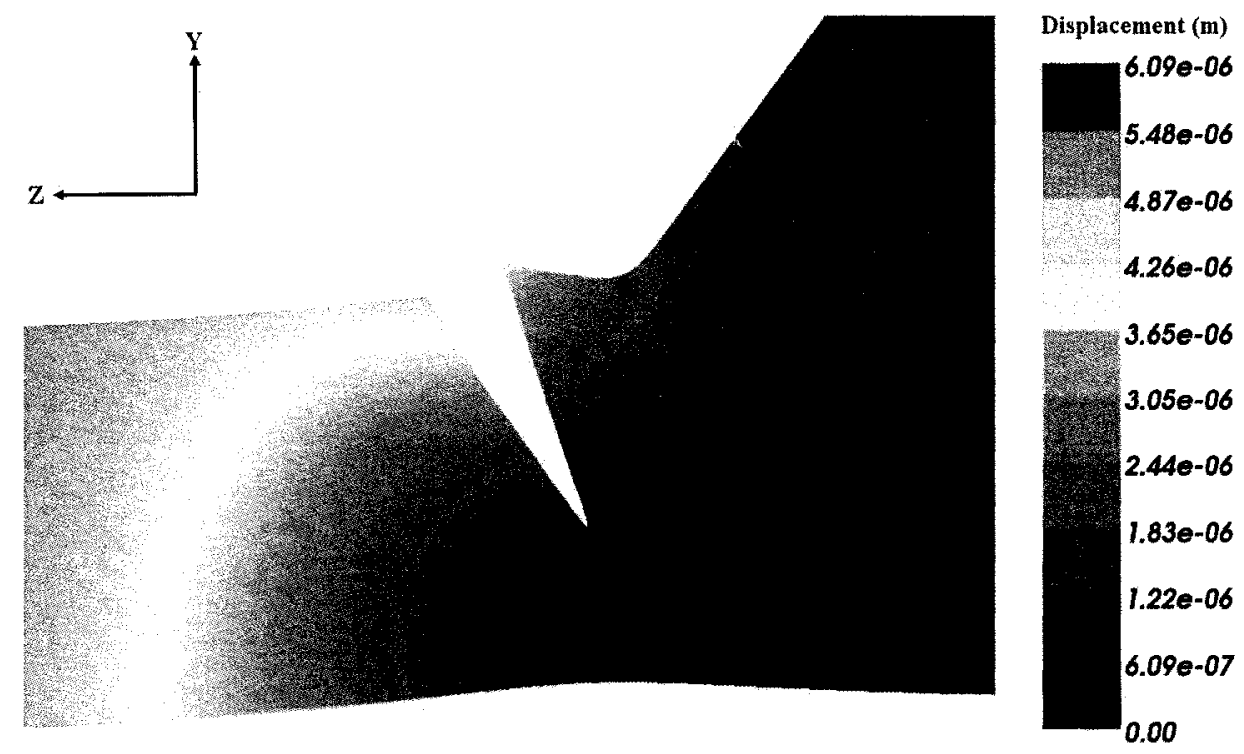

Figure 4.6: Gusset joint crack path and displacement.

The crack was grown slightly ahead of the weld toe with a pre-determined crack path, as shown in Figure 4.6. The crack path was chosen to be approximately normal to the maximum principal tensile stress. The initial crack length was specified to be $1 \mathrm{~mm}$ and the final crack length was specified to be $4 \mathrm{~mm}$. Two crack growth analyses were performed. The first analysis used stress data from the 3D submodel slice stress analysis under in-service loading only with zero initial stress. The second analysis used stress data from the $3 \mathrm{D}$ submodel slice analysis with in-service loading but with the the residual stress from the weld analysis as an initial stress. Both yielded similar results, however. This is because all of the side faces of the $3 \mathrm{D}$ slice submodel are constrained to equal the displacements from the total 3D analysis. In the $2 \mathrm{D}$ fracture analysis, prescribed displacements are only applied to the far edges of the submodel, in this case to the baseplate. Figure 4.7 shows the through-thickness stress distribution ahead of the weld toe for the $3 \mathrm{D}$ total, 3D slice and $2 \mathrm{D}$ analyses incorporating in-service loading only. Figure 4.8 show the through-thickness stress 
distribution for the three same models incorporating in-service loading and welding residual stress as the initial stress.

Since the in-service loading is applied along the same plane as the submodel, the stress components in this plane are the most significant and the $3 \mathrm{D}$ total, $3 \mathrm{D}$ slice and $2 \mathrm{D}$ tests with in-service loading and with zero initial stress only show good agreement. The in-service stress is predominantly a bending stress. The 3D total project has the lowest maximum stress and shallowest slope because of its coarser mesh and the 3D nature of the stress. The 3D slice submodel has the highest stress because it is more constrained, and the 2D submodel falls in between because it is less constrained.

The stress distributions of the 3D total, 3D slice and 2D models incorporating both in-service stress and weld residual stress as initial stress do not show good agreement. The residual stress is a complex three-dimensional stress state. Because so much constraint on the side faces is removed in the two-dimensional analysis, the equilibrium stress state with initial stress mapped from the 3D weld residual stresses are very different from the residual stresses in the $2 \mathrm{D}$ model. Residual stresses are by definition self-equilibrating. The software forces the initial stress in all models including the $2 \mathrm{D}$ models to be self-equilibrating. In this case, the self-equilibration process removes a large portion of the $3 \mathrm{D}$ residual stress. Figures $4.9,4.10$ and 4.11 show the three principal stresses from the 3D submodel slice analysis incorporating both the in-service stress and the residual stress as an initial stress. If the surfaces of the $2 \mathrm{D}$ fracture analysis are not constrained, the $2 \mathrm{D}$ stress distribution will clearly be very different. As seen in Figure 4.8 the $3 \mathrm{D}$ submodel slice again shows the highest stress and greatest slope because it is so highly constrained. The $2 \mathrm{D}$ submodel has a stress distribution closer that of the in-service only analysis because the residual stresses are allowed to relax. This indicates that a 2D crack growth submodel would 
not be accurate when the 2D stress state is not a sufficiently accurate approximation of the $3 \mathrm{D}$ stress state. In such cases the most obvious alternative is use $3 \mathrm{D}$ crack growth models.

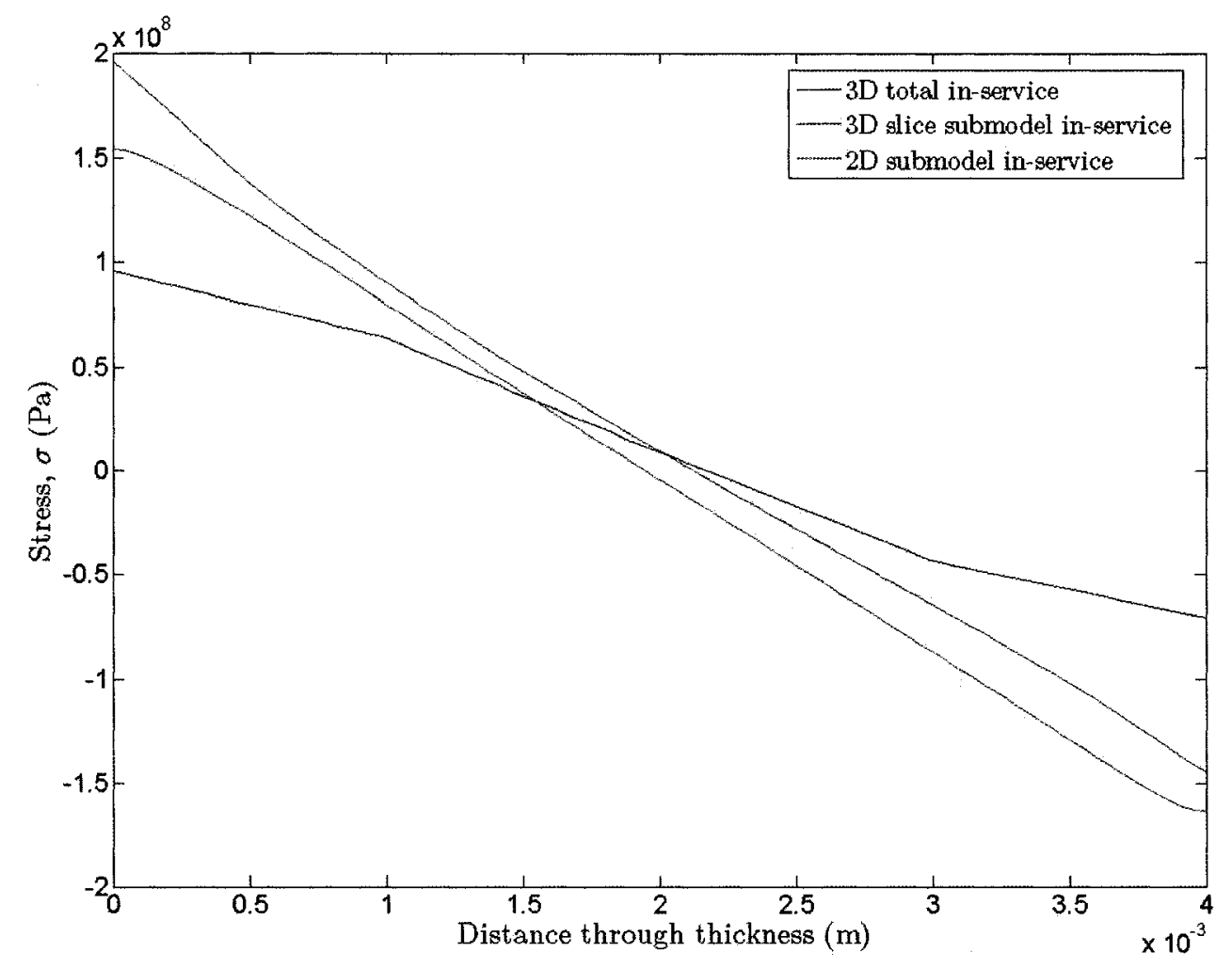

Figure 4.7: Gusset joint through-thickness (zz-) stress distributions ahead of the weld toe for in-service loading only.

Figure 4.12 shows the through-thickness (zz-) stress distribution along the crack path for the crack growth analysis incorporating in-service loading only (see Figure 4.6). The initial through-thickness stress distribution is shown along with recomputed stress distributions as the crack is grown. Figure 4.13 also shows the initial uncracked through-thickness stress distribution. As the crack grows the stress behind the crack goes to zero and as expected there is a large stress concentration at the crack tip. This is seen at crack lengths of $1.1 \mathrm{~mm}$ and $2.5 \mathrm{~mm}$ and in Figure 4.14. 


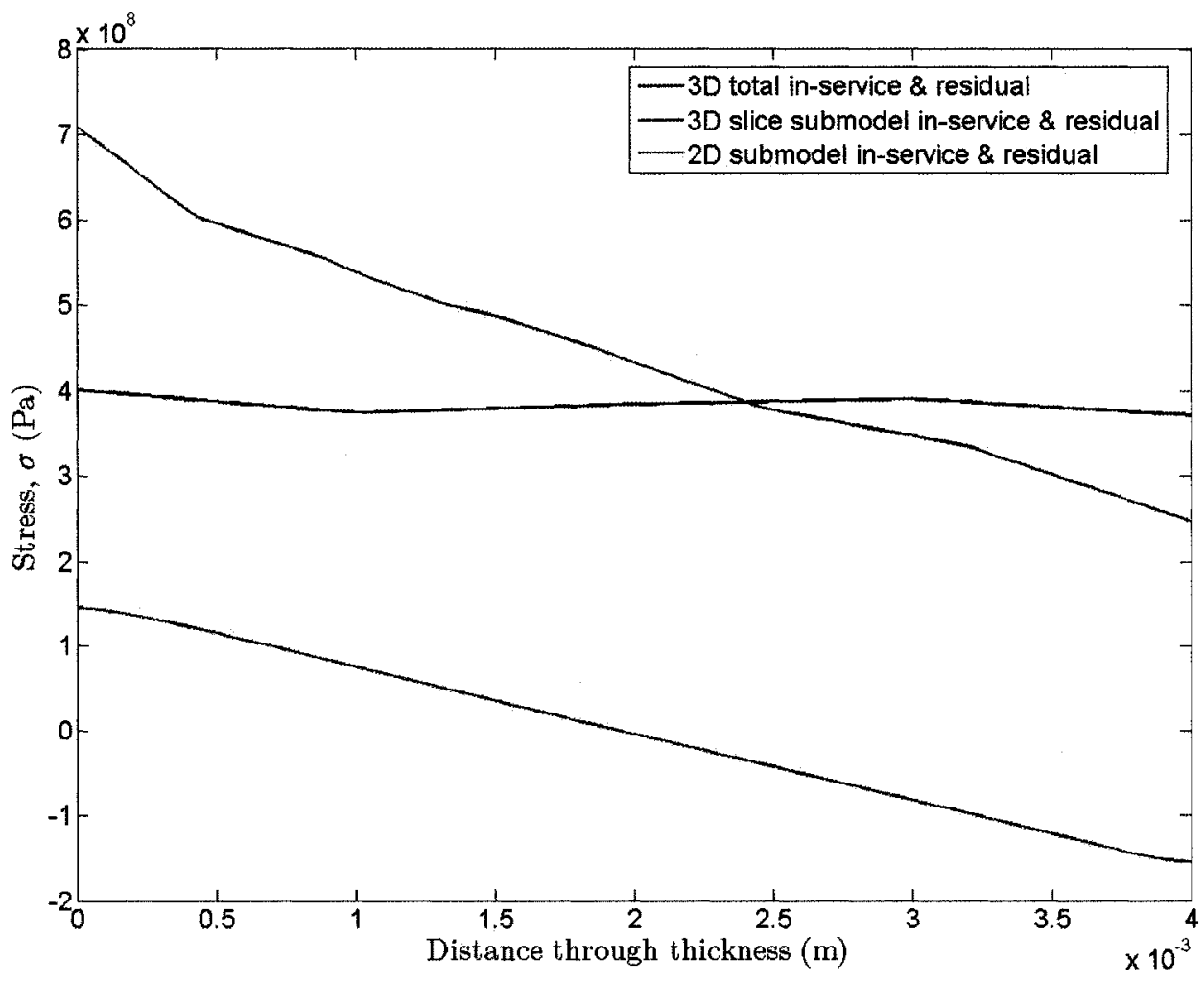

Figure 4.8: Gusset joint through-thickness stress distributions ahead of the weld toe for in-service loading and initial stress.

The zz-stress is mostly bending at the beginning of crack growth, as seen by the initial un-cracked through-thickness stress. The bending stress remains as the crack grows to lengths of $1.1 \mathrm{~mm}$ and $2.5 \mathrm{~mm}$ but the membrane component becomes larger at longer crack lengths. At crack lengths of $3.5 \mathrm{~mm}$ and $4.0 \mathrm{~mm}$ the membrane component is compressive and this increases with crack length, as seen in Figure 4.15.

Figure 4.16 shows the number of cycles for crack growth from $1 \mathrm{~mm}$ to $4 \mathrm{~mm}$ in the test with zero initial stress. Crack growth takes $6 \times 10^{6}$ cycles. The stress intensity factor ranges from $3.28 \mathrm{MPa} \sqrt{\mathrm{m}}$ at $a_{0}=1 \mathrm{~mm}$ to $7.25 \mathrm{MPa} \sqrt{\mathrm{m}}$ at $a_{f}=4.0 \mathrm{~mm}$. Values of $K_{I C}$ for steels range between 45 to $200+\mathrm{MPa} \sqrt{\mathrm{m}}$ [35]. This implies that for this geometry, stress state and maximum $2 \mathrm{D}$ crack length, the gusset joint would 


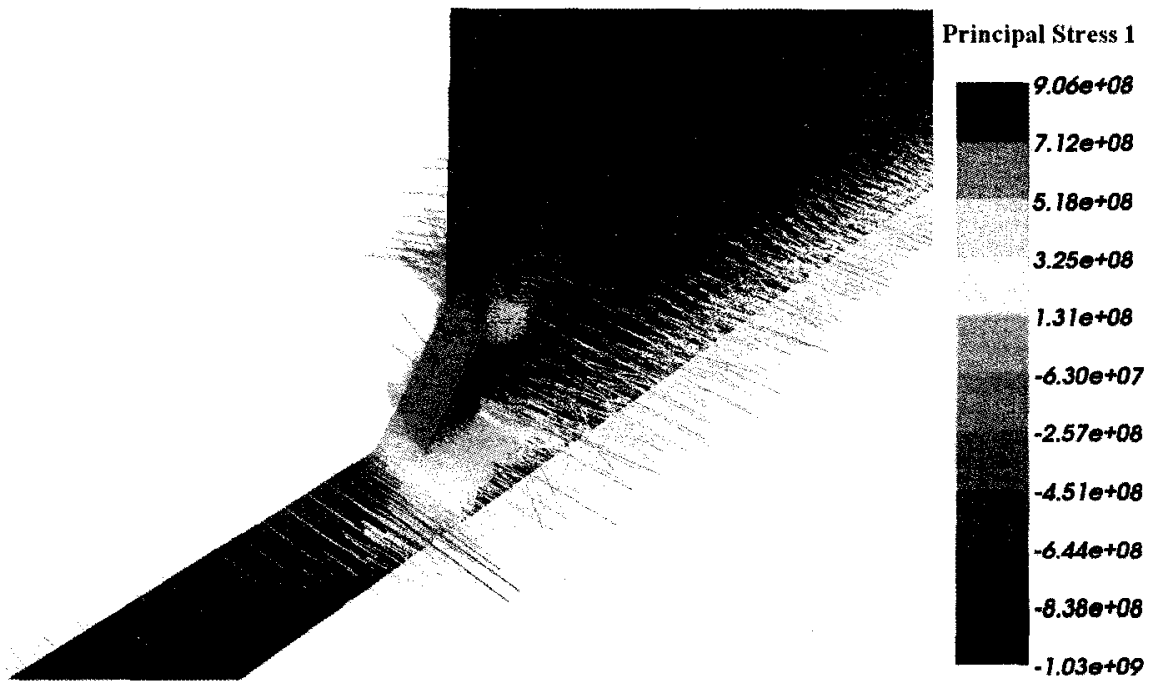

Figure 4.9: Gusset joint 3D slice submodel first principal stress.

not fracture. 


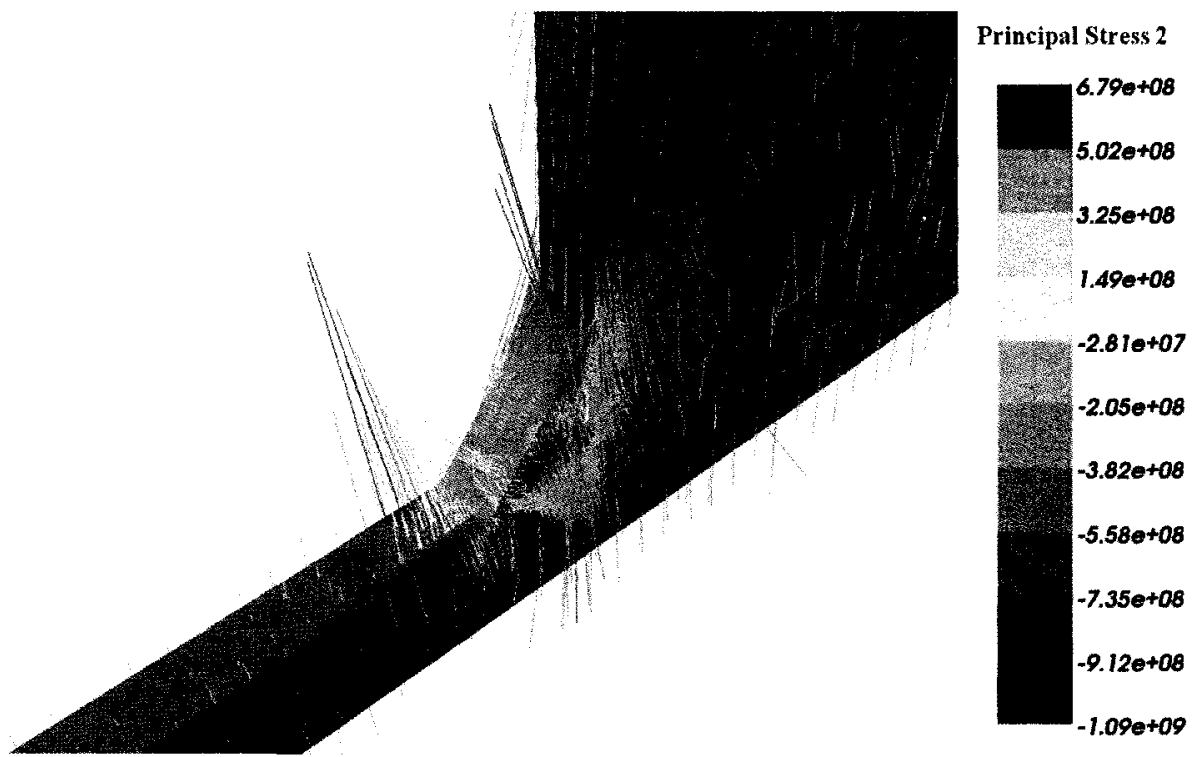

Figure 4.10: Gusset joint 3D slice submodel second principal stress.

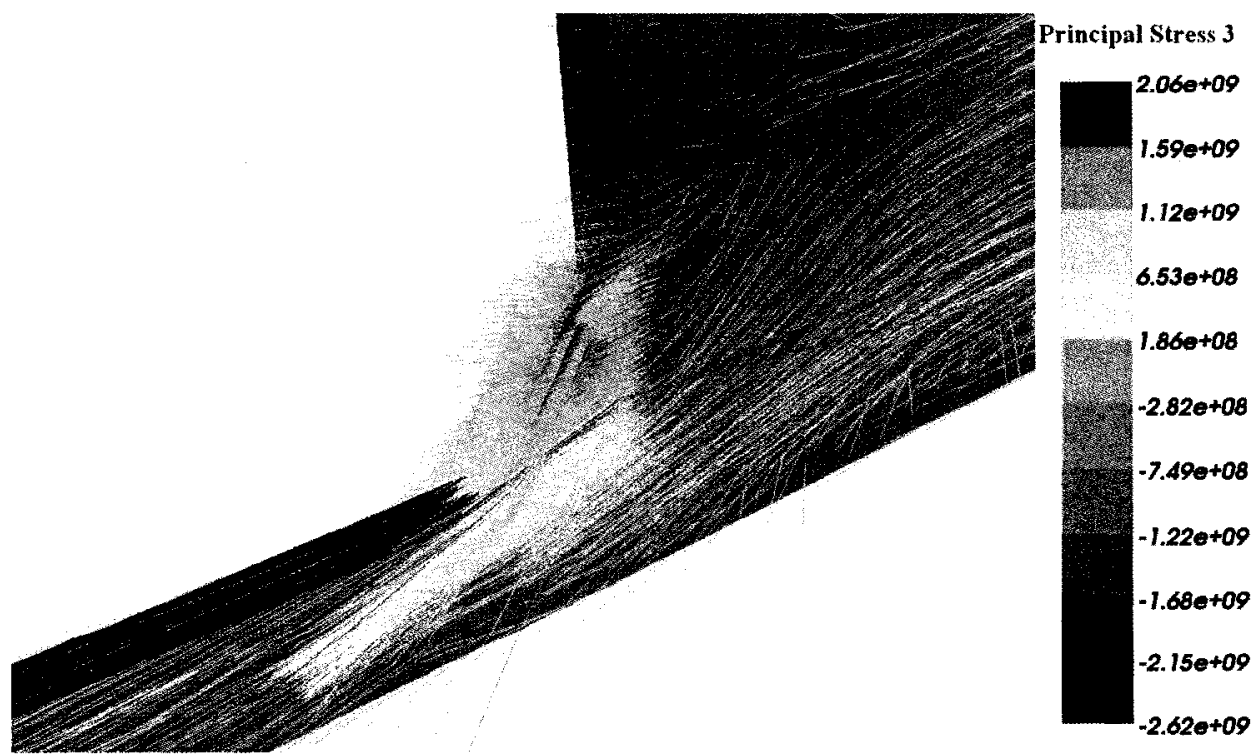

Figure 4.11: Gusset joint 3D slice submodel third principal stress. 


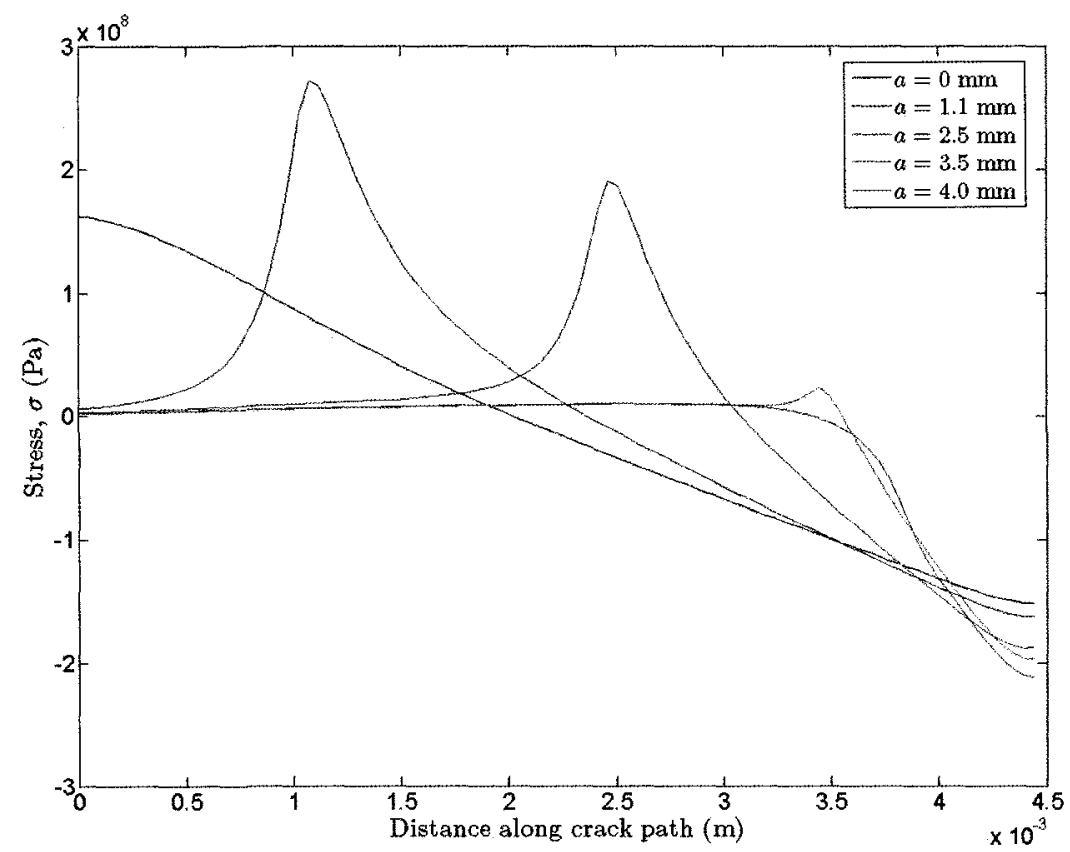

Figure 4.12: Gusset joint through thickness (zz-) stress distributions at different crack lengths.

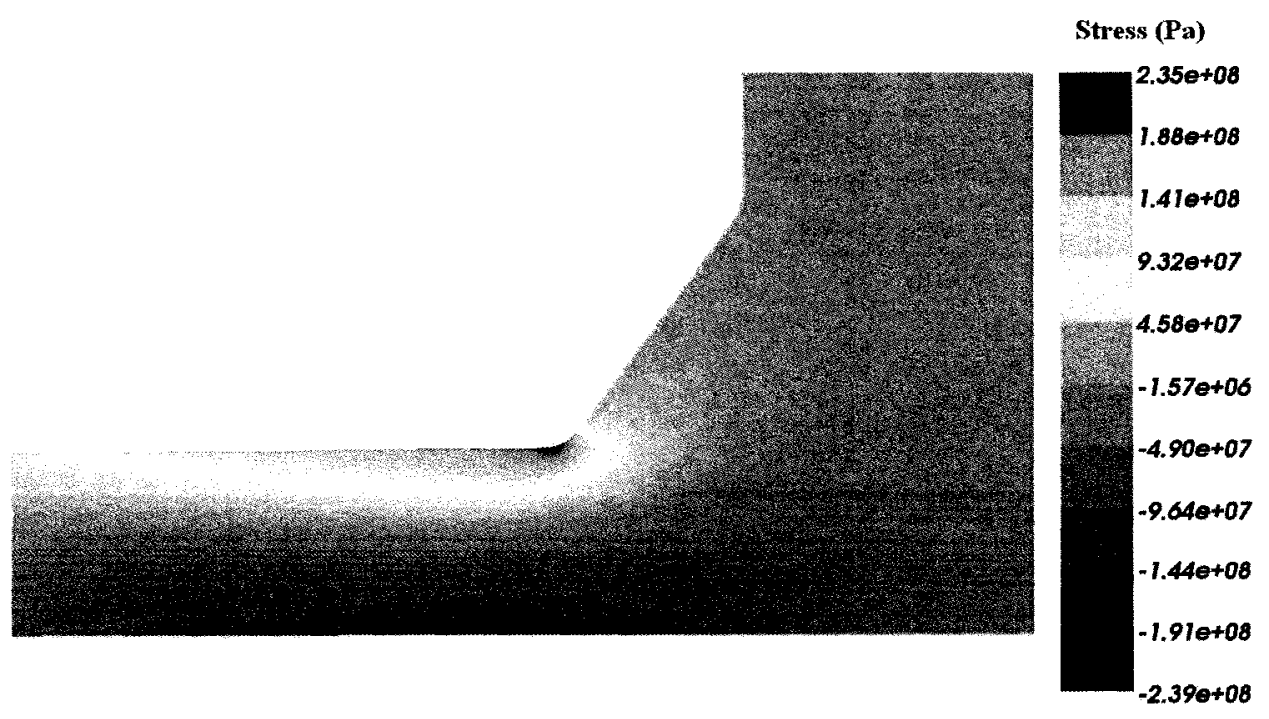

Figure 4.13: Gusset joint initial through-thickness stress. 


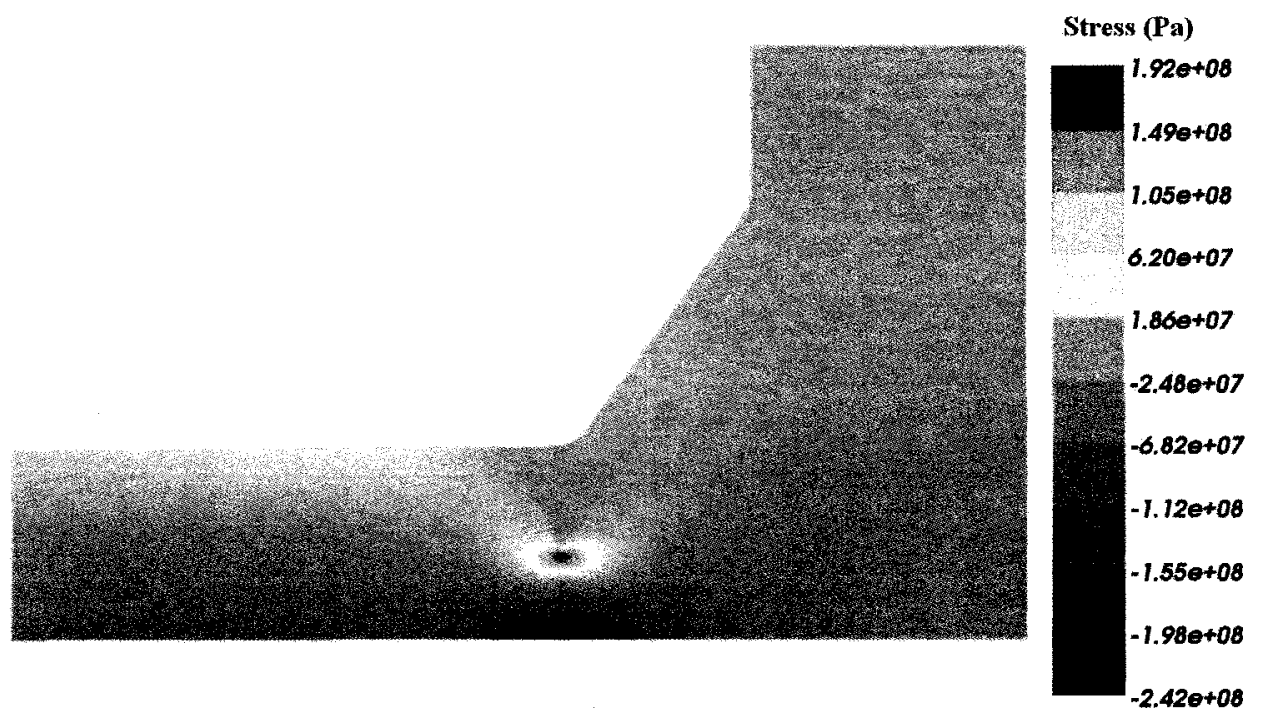

Figure 4.14: Gusset joint through-thickness stress at $a=2.5 \mathrm{~mm}$.

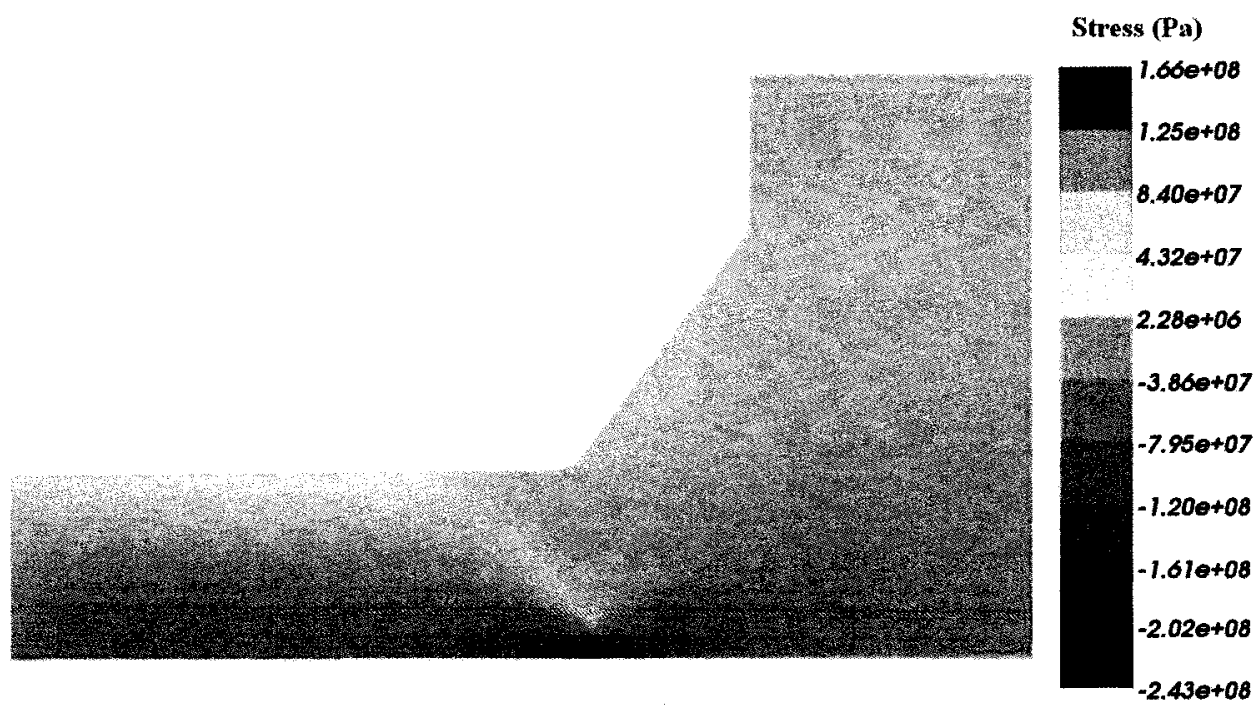

Figure 4.15: Gusset joint through-thickness stress at $a=4.0 \mathrm{~mm}$. 


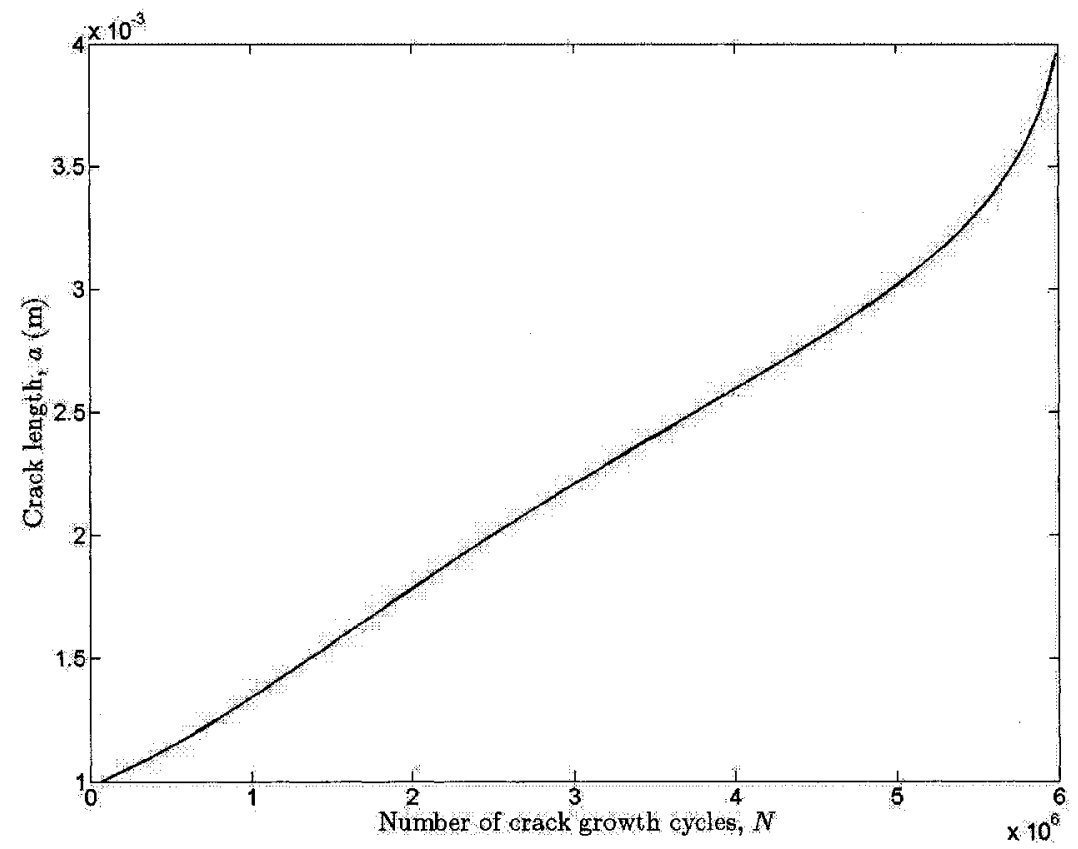

Figure 4.16: Gusset joint crack length, $a$, vs. number of cycles, $N$. 


\section{Chapter 5}

\section{Conclusions}

The foundation for predicting the fatigue life of welded joints using the VrSuite welding simulation software has been established. The prediction of welding residual stresses using VrWeld and other finite element analysis software has been performed previously and several of the studies are listed in Section 1.2. The objectives of the thesis were to predict local linear elastic stress concentrations at weld toes due to in-service loading and, together with residual stresses, to predict crack initiation and propagation at the stress concentrations. The strain-life method was used for crack initiation and linear elastic fracture mechanics was used for crack propagation.

\subsection{Stress Concentrations}

A three-dimensional welding residual stress analysis can be computationally expensive because of the thermal and microstructure data flow. As a result, time stepping and mesh size must be carefully balanced to obtain an accurate analysis in a reasonable period of time and significant detail in geometry is not as important as other factors. For fatigue analyses of specific stress raisers, such as weld toes, detail and fine mesh size become much more important when one tries to resolve the local peak stress directly. In Sections 3.1 and 3.2 analyses were performed on a plate with a hole 
in tension, a blunt notch, and the toe of a double-fillet t-joint weld, a sharp notch. The objective was to accurately compute stress concentrations using two-dimensional plane-strain submodels. In the hole test, the peak stress at the hole and the nominal stress at the edge of the plate were compared to a known analytic solution and showed good agreement with the analytic results. In the t-joint test, more approximate methods were used for validation, although they have been shown to be fairly accurate. The hot spot method detailed in Section 2.1.1 was used to determine the throughthickness bending and membrane stresses at the weld toe. Two different theoretical stress concentration factor formulations were used to predict the peak linear elastic stress at the weld toe. There is still very close agreement between the two-dimensional submodel results and the hot spot results. The hole and t-joint tests demonstrated that the peak stress at a stress concentration can be directly and accurately resolved. This was further validated with the three-dimensional and two-dimensional submodels of the gusset joint in Section 4. The use of the hot spot method with theoretical stress concentration factors on a coarse mesh or a three-dimensional or two-dimensional submodel with a fine mesh and weld geometry detail are valid methods for predicting local peak stresses at weld toes.

\subsection{Local Non-Linear Stress and Strain}

The Ramberg-Osgood non-linear elastic constitutive equation was used to formulate the local weld toe stresses and strains used in the crack initiation predictions. The local uniaxial linear elastic peak stresses obtained at the weld toes were related to the Ramberg-Osgood stresses and strains using the Neuber rule and the Equivalent Strain Energy Density Method. These methods are useful when analytic or purely linear elastic solutions are available, but could be avoided by using the Ramberg-Osgood model directly in the finite element analysis. At this point, a three-dimensional 
generalization of the Ramberg-Osgood law (see [23] and [24]) has been implemented in VrDesigner but not yet fully tested. An actual plastic constitutive model could also be used.

\subsection{Crack Initiation}

The strain-life equation and its variants were used to predict crack initiation based on damage due to plastic strain. As with the local non-linear Ramberg-Osgood stress and strain conversions, crack initiation predictions were performed externally using MATLAB and checked using the FALIN crack initiation software. The strain-life equation has also been implemented in VrDesigner but has not yet been fully tested. For an extension from uniaxial to multiaxial analyses, the strain-life approach can be formulated in terms of the maximum principal strain [23]. The crack initiation formulae presented are applied only to constant amplitude loading conditions. For variable amplitude loading a damage accumulation model such as Rainflow counting [49] could be implemented. The current work also consisted of deterministic analyses. For practical applications a probabilistic approach should be used because of the significant scatter that exists in fatigue test data [50].

\subsection{Stress Intensity Factors}

In order to predict crack growth, the stress intensity factor is used to characterize the stress state at the crack tip. In Section 3.3 a crack was grown in a two-dimensional submodel of a single edge crack specimen under three separate remote loads using stress intensity factors determined from the material force, detailed in Section 2.4.2. The material force was restricted to linear elastic fracture mechanics assumptions and was related to the stress intensity factor, or energy release rate, using the plane-strain 
assumption. The computed stress intensity values were compared against analytic SEC solutions for the corresponding crack lengths. While there was some discrepancy between the computed and analytic stress intensity factors, they showed reasonable agreement, with a maximum difference of less than 10 percent. As mentioned in the analysis, a different meshing strategy, such as a radially-graded mesh, could possibly reduce the error, but would be more computationally expensive as the crack would need to be re-meshed with every crack increment. Another possibility would be the use of quarter-point crack tip elements. If an adaptive mesh strategy is employed, the material force vector can also be used to determine the crack path. The material force method is capable of predicting crack curvature. As applied in this thesis, crack growth followed a pre-determined path. In this thesis, the crack growth analysis was restricted to linear elasticity. For significant plasticity surrounding the crack-tip, elastic-plastic fracture mechanics could be used with the material force or J-integral.

\subsection{Crack Propagation}

The standard form of the Paris-Erdogan equation was used to predict fatigue crack propagation based on the stress intensity factor range. The standard form does not account for residual stress effects or crack closure and applies only to Region II of crack growth. This form is often used, however a stochastic approach would often be preferred in practical situations. Barenblatt cautions against using Paris coefficients as material properties. Barenblatt notes in [5] that the coefficients depend on specimen size. He shows that the coefficients are a function of the dimensionless

parameter, $Z=\frac{\sigma_{y} \sqrt{h}}{K_{I C}}$, where $h$ is the characteristic length scale of the specimen, such as the thickness, $K_{I C}$ is the fracture toughness of the material and $\sigma_{y}$ is the yield stress. Figure 5.1 shows a plot of the Paris exponent, $m$, against the dimensionless parameter, Z. 


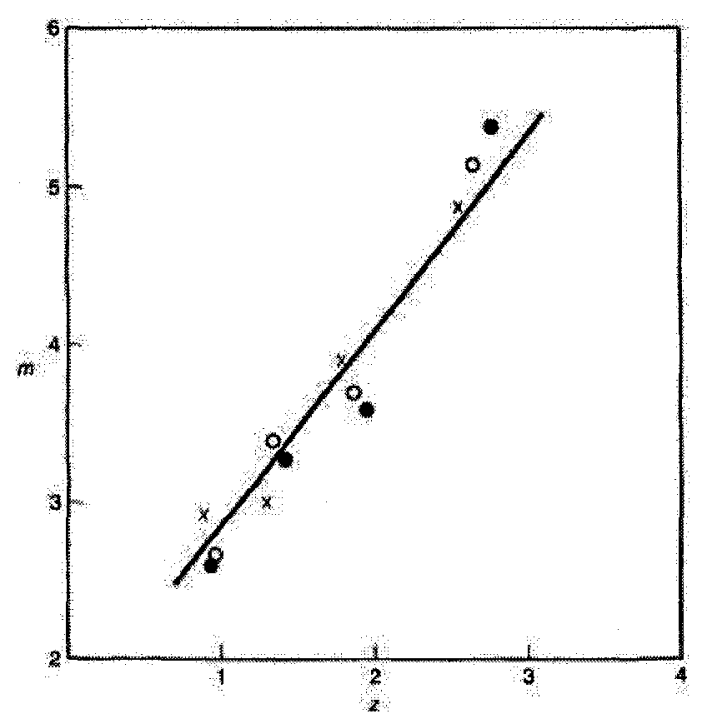

Figure 5.1: The Paris exponent, m, vs. the dimensionless parameter, Z, for 4340 steel [5].

In the gusset joint crack growth analysis the crack was grown from a specified initial crack length of $1 \mathrm{~mm}$ to a specified final crack length of $4 \mathrm{~mm}$. For each increment of crack length, the stress intensity was only computed for the maximum in-service load in each load cycle. Thus the increment in the stress intensity was set equal to the stress intensity. This is correct if the residual stress is zero. The stress intensity at the crack tip should have been computed with zero in-service load but with the residual stress. Then the difference or increment in the stress intensity should have been used to compute the crack growth rate. This was not possible because this option is not currently supported by the code.

If residual stress is incorporated in a crack growth analysis, a three-dimensional crack growth submodel should be used as discussed on page 50. The two-dimensional crack growth submodel is not well-suited for a crack growth analysis incorporating residual stresses in this case because the $2 \mathrm{D}$ model is not a good approximation of the $3 \mathrm{D}$ stress state because the model allows the stresses to relax. 


\section{List of References}

[1] C. Bayley, G. Glinka, and J. Porter, "Fatigue crack initiation and growth in a517 submerged arc welds under variable amplitude loading," International Journal of Fatigue, vol. 22, pp. 799-808, 2000.

[2] B. Farahmand, Fracture Mechanics of Metals, Composites, Welds, and Bolted Joints - Application of LEFM, EPFM, and FMDM Theory, ch. 1.3, pp. 19-24. No. 978-0-7923-7239-4, Springer - Verlag, 2001.

[3] A. Ingraffea, Engineering Fracture Mechanics notes for CEE 770. Cornell University Fracture Group, Fall 2007.

[4] R. Mueller, D. Gross, and G. Maugin, "Use of material forces in adaptive finite element methods," Computational Mechanics, vol. 33, pp. 421-434, 2004.

[5] G. I. Barenblatt, "Scaling phenomena in fatigue and fracture," International Journal of Fracture, vol. 138, pp. 19-35, 2006.

[6] P. R. Bell, "Mech 5602 failure prevention: Fatigue \& fracture analysis," course notes, 2006.

[7] J. Martinsson, "Fatigue assessment of complex welded steel structures," tech. rep., Division of Lightweight Structures, Department of Aeronautical and Vehicle Engineering, Royal Institute of Technology, Stockholm, Sweden, 2005.

[8] X. Chen, Z. Yang, and F. Brust, Processes and mechanisms of welding residual stress and distortion, ch. 7: Modeling Distortion and Residual Stress During Welding: Practical Applications, pp. 225-262. Cambridge, England: Woodhead Publishing Limited, 2005.

[9] Goldak Technologies Inc., "Vr software suite." www.goldaktec.com.

[10] J. Goldak, "Modeling thermal stresses and distortions in welds," in Proceedings of the 2nd International Conference in Welding Research, ASM International, 1989. 
[11] P. Khoral, "Coupling microstructure to heat transfer computation in weld analysis," master of engineering, Carleton University, Ottawa, Canada, October 1989.

[12] S. Wang, Simulation $f$ the Welding Process of Low-Alloy Steel by Finite Element Method. Doctor of philosophy in mechanical engineering, Carleton University, Ottawa, Canada, September 2005.

[13] D. Radaj, Welding Residual stresses and Distortion: Calculation and Measurement. Dusseldorf, Germany: DVS-Verlag GmbH, 2003.

[14] L.-E. Lindgren, "Finite element modeling and simulation of welding. part 2: Improved material modeling," Journal of Thermal Stresses, vol. 24, pp. 195$231,2001$.

[15] J. Goldak and M. Akhlaghi, Computational Welding Mechanics. Springer, 2005.

[16] K. A. Runesson, A. Skyttebol, and L.-E. Lindgren, Comprehensive Structural Integrity, vol. 3, ch. 6: Nonlinear Finite Element Analysis and Applications to Welded Structures, Comprehensive Structural Integrity, pp. 253-318. Elsevier Science Ltd., 2003.

[17] SaFFD Inc., "Stress and fatigue and fracture design." www.saffd.com.

[18] A. Hobbacher, Recommendations for Fatigue Design of Welded Joints and Components. International Institute of Welding, May 2007. IIW document XIII2151-07 / XV-1254-07.

[19] G. Glinka, "Fatigue life prediction from the gy2 shell finite element stress data," tech. rep., March 2006.

[20] H. Pang, "Analysis of weld toe radius effects on fatigue weld toe cracks," International Journal of Pressure Vessels and Piping, vol. 58, pp. 171-177, 1994.

[21] H. Neuber, "Theory of stress concentration for shear-strained prismatical bodies with arbitrary nonlinear stress-strain law," Journal of Applied Mechanics, vol. 28, pp. 544-550, 1961.

[22] G. Glinka, "Energy density approach to calculation of inelastic strain-stress near notches and cracks," Engineering Fracture Mechanics, vol. 22, no. 3, pp. 485-508, 1985.

[23] S. Suresh, Fatigue of Materials. Cambridge University Press, 1991. 
[24] R. Denzer, F. J. Barth, and P. Steinmann, "Studies in elastic fracture mechanics based on the material forces method," International Journal for Numerical Methods in Engineering, vol. 58, pp. 1817-1835, 2002.

[25] R. W. Hertzberg, Deformation and Fracture Mechanics of Engineering Materials. John Wiley \& Sons, 3 ed., 1989.

[26] ETBX, "Strain-life fatigue analysis," tech. rep., Engrasp, 2005.

[27] T. Topper, R. Wetzel, and J. Morrow, "Neuber's rule applied to fatigue of notched specimens," Journal of Materials, vol. 4, pp. 200-209, March 1969.

[28] N. E. Dowling, "Combined use of strain-based fatigue methodology and notched member test data," in 2005 USAF Structural Integrity Program (ASIP) Conference.

[29] G. Glinka, "Fatigue and fracture of materials and structures (a practical approach)," SaFFD Inc., 2004.

[30] D. Givoli and R. Zusman, "An adaptive finite element framework for fatigue crack propagation," International Journal for Numerical Methods in Engineering, vol. 54, pp. 111-135, 2002.

[31] D. Broek, Elementary Engineering Fracture Mechanics, ch. 10, pp. 260-298. Dordrecht, Netherlands: Matinus Nijhoff Publishers, 1986.

[32] R. Davenport and R. Brook, "The threshold stress intensity range in fatigue," Fatigue of Engineering Materials and Structures, vol. 1, pp. 151-158, 1979.

[33] S. T. Rolfe and J. M. Barsom, Fracture and Fatigue Control in Structures: Applications of Fracture Mechanics. Prentice-Hall, 1977.

[34] D. Rooke and D. Cartwright, Compendium of Stress Intensity Factors. Uxbridge: Hillington Press, 1976.

[35] M. F. Kanninen and C. H. Popelar, Advanced Fracture Mechanics. Oxford Engineering Science Series 15, New York, USA: Oxford University Press, Inc., 1985.

[36] A. Moftakhar and G. Glinka, "Calculation of stress intensity factors by efficient integration of weight functions," Engineering Fracture Mechanics, vol. 43, no. 5, pp. 749-756, 1992. 
[37] X. Wang, Stress Intensity Factors And Weight Function For Surface Cracked Plates And Welded Joints. Phd in mechanical engineering, University of Waterloo, Waterloo, Ontario, Canada, 1997.

[38] G. Maugin, Material Inhomogineities in Elasticity. Chapman \& Hall, 1993.

[39] R. Mueller and G. Maugin, "On material forces and finite element discretizations," Computational Mechanics 29, 2002.

[40] P. Steinmann, D. Ackermann, and F. Barth, "Application of material forces to hyperelastic fracture mechanics. ii. computational setting," International Journal of Solids and Structures, vol. 38, pp. 5509-5526, 2001.

[41] J. Eshelby, "The elastic energy-momentum tensor," Journal of Elasticity Vol. 5, pp. 325-335, 1975.

[42] G. Maugin, "Pseudo-plasticity and pseudo-inhomogineity effects in materials mechanics," Journal of Elasticity, vol. 71, pp. 81-103, 2003.

[43] J. Bonet and R. D. Wood, Nonlinear Continuum Mechanics for Finite Element Analysis. Cambridge University Press, 1997.

[44] W. C. Young and R. G. Budynas, Roark's Formulas for Stress and Strain, ch. 17, pp. 773, 785. McGraw-Hill Companies, Inc., 7 ed., 2002.

[45] K. Iida and T. Uemura, "Stress concentration factor formulae widely used in Japan," Fatigue $\&$ Fracture of Engineering Materials $\mathcal{6}$ Structures, vol. 19, no. 6, pp. 779-786, 1996.

[46] F. Brennana, P. Peleties, and A. Hellier, "Predicting weld toe stress concentration factors for $\mathrm{t}$ and skewed t-joint plate connections," International Journal of Fatigue, vol. 22, pp. 573-584, 2000.

[47] R. Barsoum, "Triangular quarter-point elements as elastic and perfectly-plastic crack tip elements," International Journal for Numerical Methods in Engineering, vol. 11, pp. 85-98, 1977.

[48] P. Dusicka, A. M. Itani, and I. G. Buckle, "Cyclic response of plate steels under large inelastic strains," Journal of Constructional Steel Research, vol. 63, pp. 156-164, 2007.

[49] S. Manson and G. Halford, Fatigue and Durability of Structural Materials. Materials Park, Ohio, USA: ASM International, 2006. 
[50] J. Schijve, "Statistical distribution functions and fatigue of structures," International Journal of Fatigue, vol. 27, pp. 1031-1039, 2005. 


\section{Appendix A}

\section{Crack Initiation Calculation}

This example, using MATLAB, determines the crack initiation life for a point that is cyclically loaded at a constant amplitude from zero to a maximum linear elastic stress, $\sigma_{h s}$, using the Neuber rule, the Ramberg-Osgood non-linear elastic constitutive equation and the strain-life equation.

\section{A.1 Part 1: Cyclic Ramberg-Osgood Curve}

The Neuber rule is used to relate the hypothetical local linear elastic stress and strain according to Hooke's Law from any given elastic problem to the corresponding local nonlinear stress and strain according to the Ramberg-Osgood equation. Note that while the monotonic and cyclic versions of the Ramberg-Osgood equation take the same form, the coefficients in monotonic loading are associated with an experimentally measured tensile test. The coefficients of the Ramberg-Osgood equation for cyclic loading are associated with experimentally measured cyclic plasticity or the strainlife coefficients.

According to Neuber's rule, the linear elastic strain energy density, W, in terms of the 
stress concentration factor and the total hot spot stress is related to the RambergOsgood strain energy density for the maximum load.

$$
W=\frac{\left(K_{t, h s} \sigma_{h s_{m a x}}\right)^{2}}{2}=\frac{\sigma_{r o_{1}}^{2}}{E}+\sigma_{r o_{1}}\left(\frac{\sigma_{r o_{1}}}{k^{\prime}}\right)^{\frac{1}{n^{\prime}}}
$$

Once the peak Ramberg-Osgood stress has been determined from the peak linear elastic stress, the Ramberg-Osgood stress-strain curve is generated by incrementally increasing the load from $\sigma_{r o(0)}=0$ to $\sigma_{r o(1)}$. The corresponding Ramberg-Osgood strains are calculated according to

$$
\varepsilon_{r o}=\frac{W}{\sigma_{r o}}
$$

An example of a Ramberg-Osgood stress-strain curve is shown in Figure A.1.

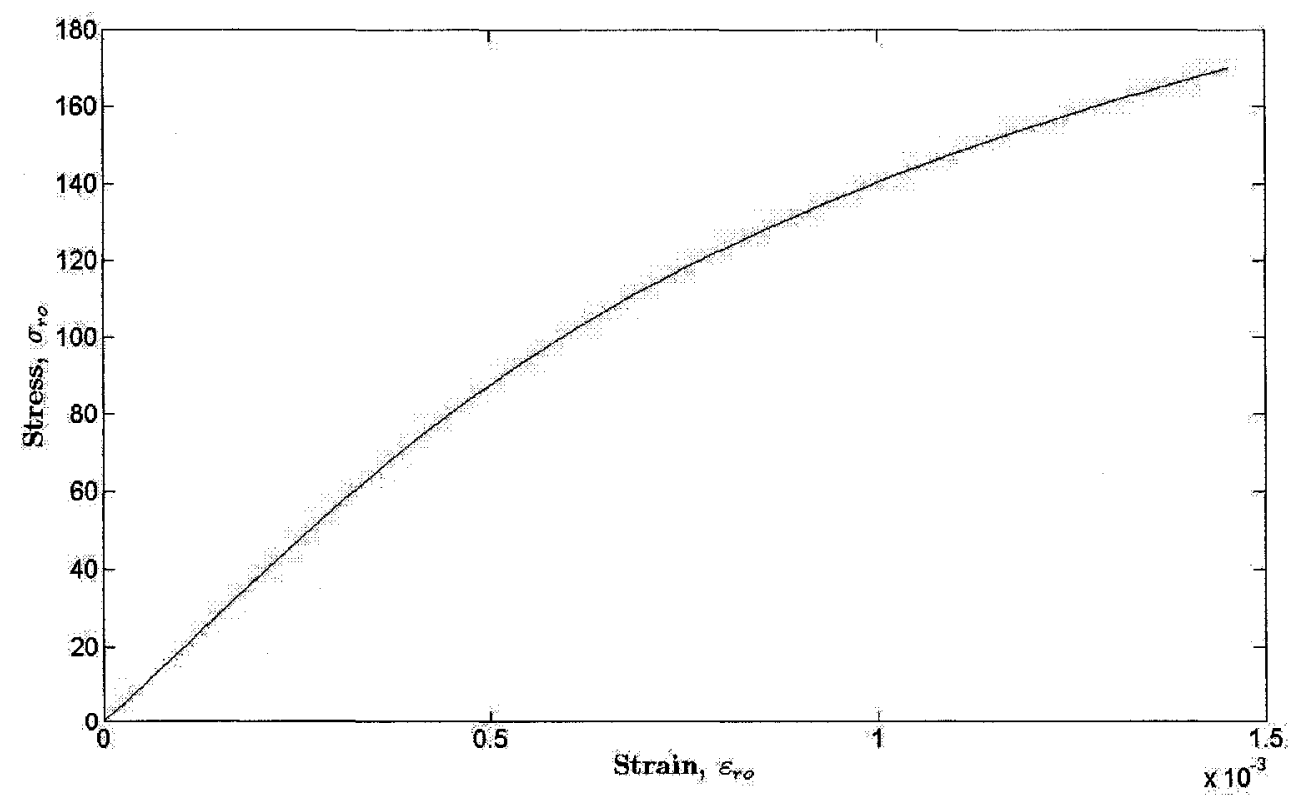

Figure A.1: Cyclic Ramberg-Osgood stress-strain curve 


\section{A.2 Part 2: Ramberg-Osgood Hysteresis Curve}

Since the Ramberg-Osgood equation is nonlinear elastic and not plastic, once the load is released the stress-strain curve will return to the origin by the same path and will not follow a linear-elastic unloading path. The cyclic behaviour of ductile materials can be approximated, however, by using four distinct equations. The first equation uses the cyclic Ramberg-Osgood stress-strain relationship for loading from the origin to the maximum stress, $\sigma_{r o 1}$. The second equation uses the cyclic Ramberg-Osgood relationship to determine the cyclic stress and strain amplitude and the corresponding minimum stress and strain, $\sigma_{r o_{2}}$ and $\varepsilon_{r o_{2}}$. The third equation again uses the cyclic Ramberg-Osgood relationship to increment the stress from the maximum to the minimum stress by defining an incremental stress amplitude, $\Delta \sigma_{r o_{1 \rightarrow 2}}$. This incremental amplitude is defined in such a way as to produce the decreasing section of the hysteresis curve. Finally, a fourth equation is used for the second incremental stress amplitude, $\Delta \sigma_{r_{2 \rightarrow 1} \rightarrow 1}$, which is defined such that one can build the increasing section of the hysteresis loop. The four equations are
1. $\frac{\left(K_{t, h s} \sigma_{h s_{\max }}\right)^{2}}{E}=\frac{\sigma_{r o_{1}}^{2}}{E}+\sigma_{r o_{1}}\left(\frac{\sigma_{r o_{1}}}{k^{\prime}}\right)^{\frac{1}{n^{\prime}}}$
2. $\frac{\left[K_{t}\left(\sigma_{h s}-\sigma_{0}\right)\right]^{2}}{E}=\frac{\Delta \sigma_{r o}^{2}}{E}+2 \Delta \sigma_{r o}\left(\frac{\Delta \sigma_{r o}}{2 k^{\prime}}\right)^{\frac{1}{n^{\prime}}}$
3. $\frac{\varepsilon_{r o_{1}}-\varepsilon_{r o_{1} \rightarrow 2}}{2}=\frac{\sigma_{r o_{1}}-\sigma_{r o_{1 \rightarrow 2}}}{2 E}+\left(\frac{\sigma_{r o_{1}}-\sigma_{r o_{1} \rightarrow 2}}{2 k^{\prime}}\right)^{\frac{1}{n^{\prime}}}$
4. $\frac{\varepsilon_{r o_{2 \rightarrow 1}}-\varepsilon_{r o_{2}}}{2}=\frac{\sigma_{r o_{2 \rightarrow 1}}-\sigma_{r o_{2}}}{2 E}+\left(\frac{\sigma_{r o_{2 \rightarrow 1}}-\sigma_{r o_{2}}}{2 k^{\prime}}\right)^{\frac{1}{n^{\prime}}}$

Once the cyclic Ramberg-Osgood curve has been determined, as in Section A.1, the next step in approximating a hysteresis curve is to determine the stress and strain amplitudes according to the cyclic hysteresis version of the Ramberg-Osgood equation, which is only applicable to materials that exhibit the same behaviour in tension 
and compression. This is done by using Neuber's rule to relate the cyclic linear elastic stress amplitude to the cyclic Ramberg-Osgood stress amplitude according to

$$
\frac{\left[K_{t}\left(\sigma_{h s}-\sigma_{0}\right)\right]^{2}}{E}=\frac{\Delta \sigma_{r o}^{2}}{E}+2 \Delta \sigma_{r o}\left(\frac{\Delta \sigma_{r o}}{2 k^{\prime}}\right)^{\frac{1}{n^{\prime}}}
$$

Once the Ramberg-Osgood stress amplitude has been determined, the strain amplitude can be determined in the same way as for the initial loading case. When the structure has been unloaded the minimum Ramberg-Osgood stress and strain, $\sigma_{r o_{2}}$ and $\varepsilon_{r_{2}}$, are determined according to

$$
\begin{aligned}
& \sigma_{r o_{2}}=\sigma_{r o_{1}}-\Delta \sigma_{r o} \\
& \varepsilon_{r o_{2}}=\varepsilon_{r o_{1}}-\Delta \varepsilon_{r o}
\end{aligned}
$$

\section{A.2.1 Building the Hysteresis: From $\sigma_{r o_{1}}, \varepsilon_{r o_{1}} \rightarrow \sigma_{r o_{2}}, \varepsilon_{r o_{2}}$}

The decreasing part of the hysteresis loop is generated by incrementing the stress from $\sigma_{r o_{1}} \rightarrow \sigma_{r o_{2}}$ and defining an incremental stress amplitude according to

$$
\Delta \sigma_{r o_{1 \rightarrow 2}}=\sigma_{r o_{1}}-\sigma_{r o_{1 \rightarrow 2}}
$$

Then the incremental strain, $\varepsilon_{r o_{1 \rightarrow 2}}$, is computed from

$$
\frac{\varepsilon_{r o_{1}}-\varepsilon_{r o_{1 \rightarrow 2}}}{2}=\frac{\sigma_{r o_{1}}-\sigma_{r o_{1 \rightarrow 2}}}{2 E}+\left(\frac{\sigma_{r o_{1}}-\sigma_{r o_{1 \rightarrow 2}}}{2 k^{\prime}}\right)^{\frac{1}{n^{\prime}}}
$$




\section{A.2.2 Building the Hysteresis: From $\sigma_{r o_{2}}, \varepsilon_{r o_{2}} \rightarrow \sigma_{r o_{1}}, \varepsilon_{r o_{1}}$}

The increasing part of the hysteresis is generated by incrementing the stress from $\sigma_{r o_{2}} \rightarrow \sigma_{r o_{1}}$ and defining an incremental stress amplitude according to

$$
\Delta \sigma_{r 0_{2 \rightarrow 1}}=\sigma_{r o_{2 \rightarrow 1}}-\sigma_{r o_{2}}
$$

Then the incremental strain, $\varepsilon_{r o_{2} \rightarrow 1}$ is computed from

$$
\frac{\varepsilon_{r O_{2 \rightarrow 1}}-\varepsilon_{r o_{2}}}{2}=\frac{\sigma_{r o_{2 \rightarrow 1}}-\sigma_{r o_{2}}}{2 E}+\left(\frac{\sigma_{r o_{2 \rightarrow 1}}-\sigma_{r o_{2}}}{2 k^{\prime}}\right)^{\frac{1}{n^{\prime}}}
$$

The complete hysteresis loop is shown in Figure A.2.

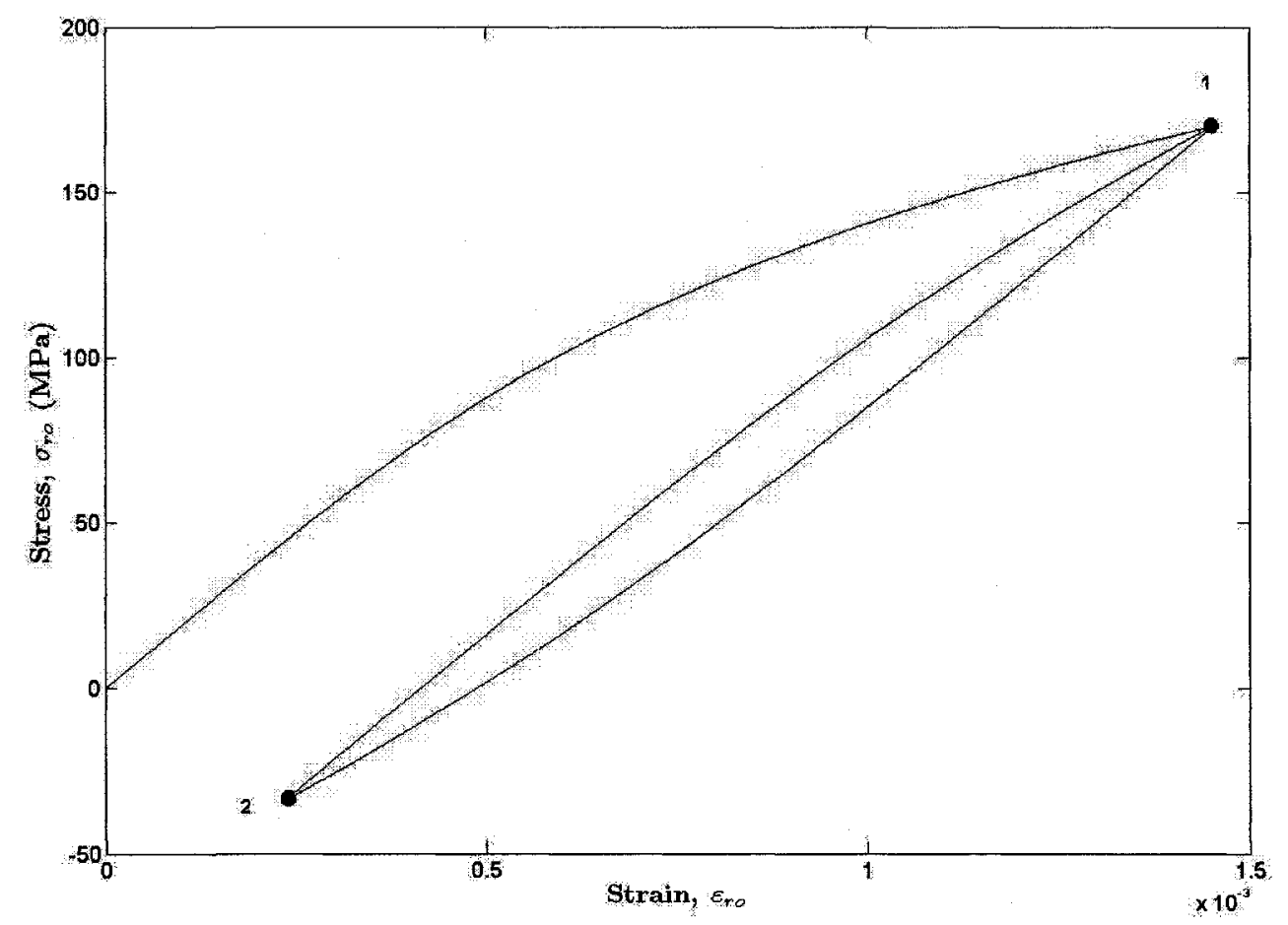

Figure A.2: Ramberg-Osgood constant amplitude hysteresis curve 


\section{A.3 Strain-Life Equation for Crack Initiation}

The strain life equation is used to calculate the initiation life of the the point on the structure using the Ramberg-Osgood strain amplitude determined from equation A.3. The number of cycles to initation is determined according to

$$
\frac{\Delta \varepsilon_{r o}}{2}=\frac{\sigma_{f}^{\prime}}{E}\left(2 N_{I}\right)^{b}+\varepsilon_{f}^{\prime}\left(2 N_{I}\right)^{c}
$$

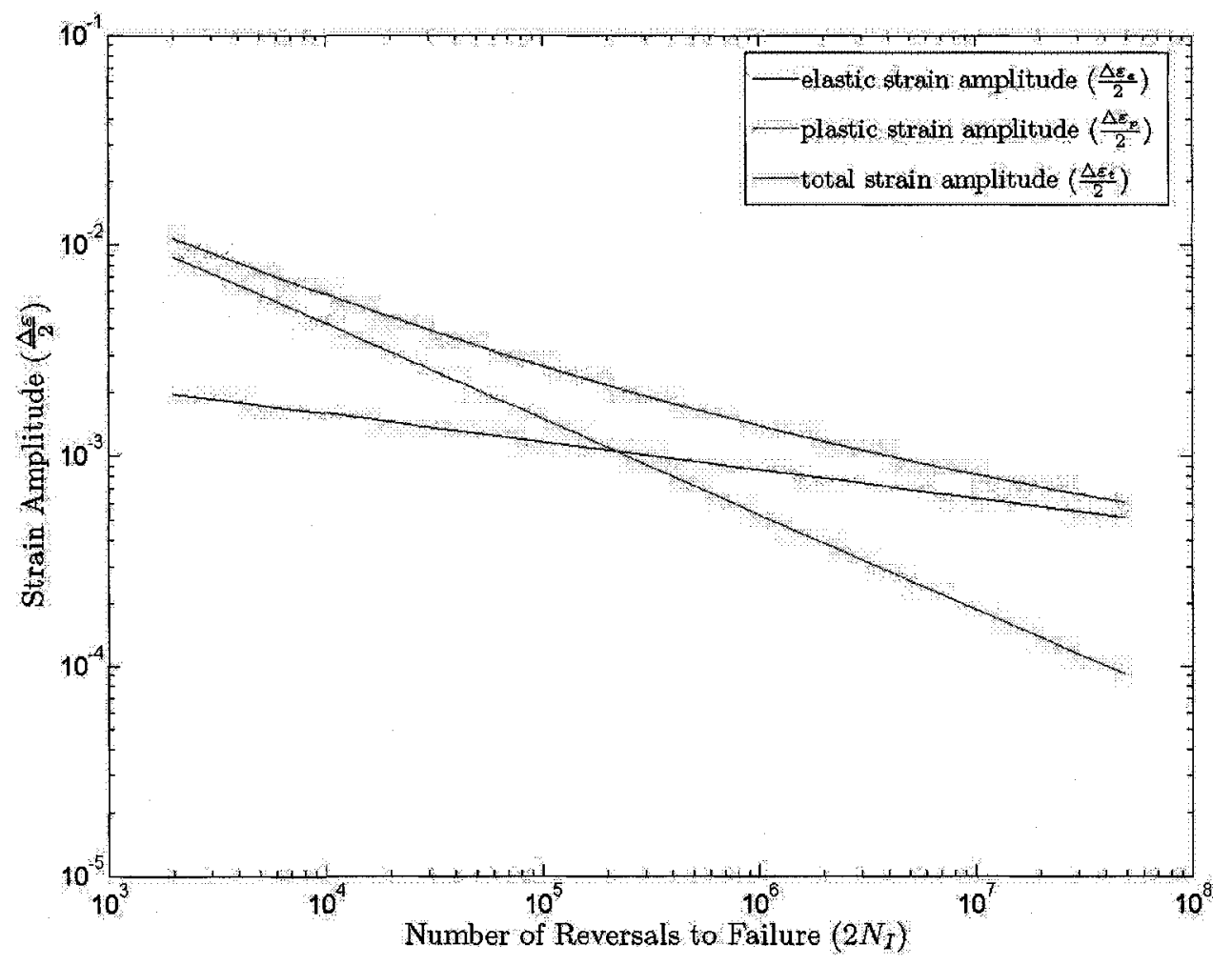

Figure A.3: Number of cycles to failure according to the strain-life crack initiation approach 


\section{A.4 MATLAB code}

$K t=1.87 ; \quad E=190000 ;$

Kprime=1097;

nprime $=0.249$;

$\operatorname{Smax}=116$;

sigmafprime $=1014$;

epsilonfprime $=0.271$;

$b=-0.132$;

$c=-0.451$;

\%Cyclic Ramberg-0sgood

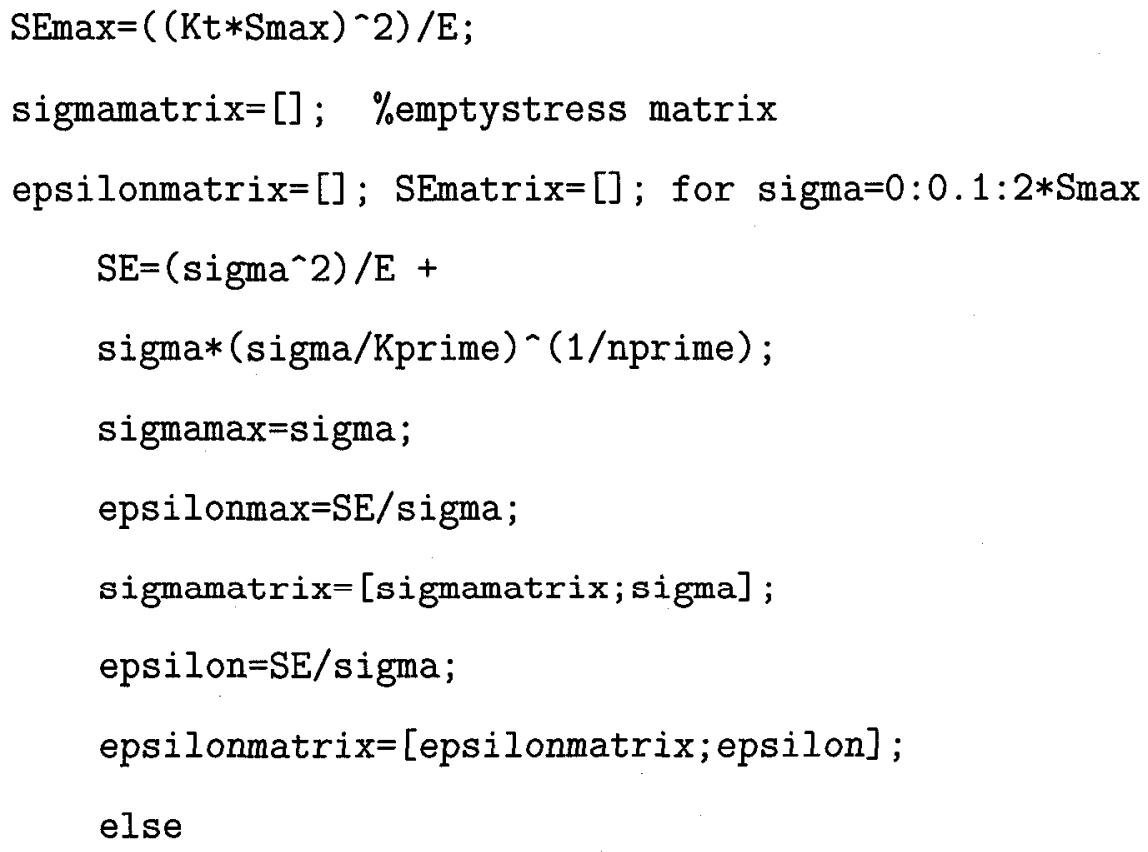


end

end figure(1); plot (epsilonmatrix, sigmamatrix)

\%Ramberg-0sgood stress and strain amplitude

deltaSEmax=SEmax;

for deltasigma $=0: 0.1: 2 *$ sigmamax

$\operatorname{deltaSE}=\left(\operatorname{deltasigma}{ }^{\wedge} 2\right) /(E)+$

$(2 *$ deltasigma $) *(\text { deltasigma/ }(2 * \text { Kprime }))^{\wedge}(1 /$ nprime $)$;

if (deltase<deltasEmax)

sigmamin=sigmamax - deltasigma;

deltaepsilon=deltaSE/deltasigma;

epsilonmin=epsilonmax-deltaepsilon;

end

end

$\%$ to generate hysteresis loop

for sigmahyst=sigmamax: -0.1 : sigmamin

deltasigmahyst=sigmamax-sigmahyst;

deltaSEhyst $=\left(\right.$ deltasigmahyst $\left.{ }^{` 2}\right) /(E)+$

( $2 *$ deltasigmahyst $) *($ deltasigmahyst $/(2 *$ Kprime $))$ ^ $(1 /$ nprime $)$;

deltaepsilonhyst=deltaSEhyst/deltasigmahyst;

epsilonhyst=epsilonmax-deltaepsilonhyst;

sigmamatrix $=[$ sigmamatrix;sigmahyst $]$;

epsilonmatrix=[epsilonmatrix; epsilonhyst] ; 
end for sigmahyst=sigmamin:0.1:sigmamax

deltasigmahyst=sigmahyst-sigmamin;

deltaSEhyst $=($ deltasigmahyst`2) $/(E)+$

(2*deltasigmahyst)*(deltasigmahyst/(2*Kprime) $) \wedge(1 /$ nprime $)$;

deltaepsilonhyst=deltaSEhyst/deltasigmahyst;

epsilonhyst=epsilonmin+deltaepsilonhyst;

sigmamatrix $=[$ sigmamatrix ; sigmahyst $]$;

epsilonmatrix=[epsilonmatrix;epsilonhyst ] ;

end figure(2); title('Stress-Strain Hysteresis');

xlabel('\epsilon'); ylabel('\sigma (MPa)'); plot(epsilonmatrix, sigmamatrix)

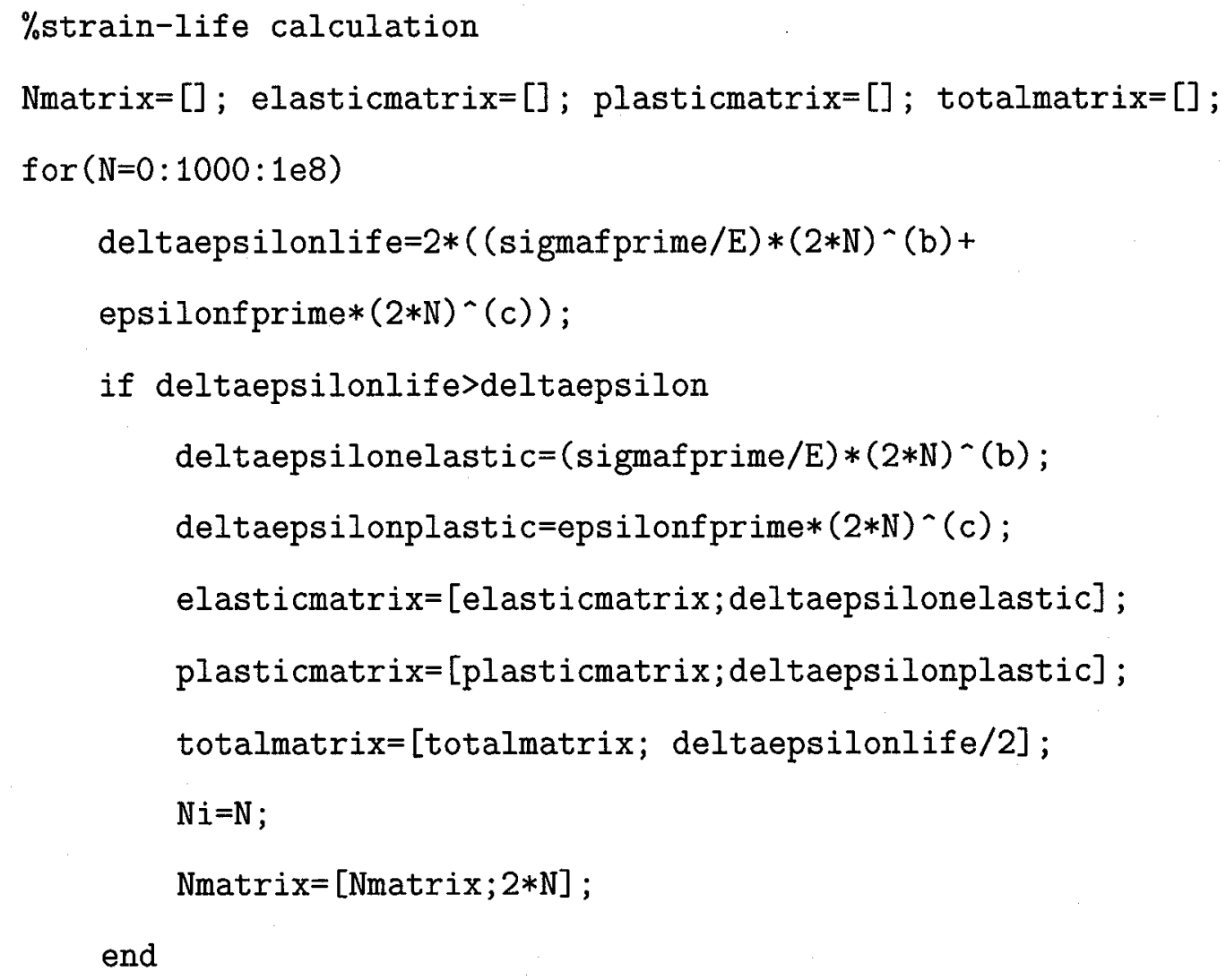


figure(3); $\log \log$ (Nmatrix, elasticmatrix, Nmatrix, plasticmatrix, Nmatrix, totalmatrix)

InitiationLife =

24512000 